NBER WORKING PAPER SERIES

A MULTIVARIATE MODEL OF STRATEGIC ASSET ALLOCATION

John Y. Campbell

Yeung Lewis Chan

Luis M. Viceira

Working Paper 8566

http://www.nber.org/papers/w8566

\author{
NATIONAL BUREAU OF ECONOMIC RESEARCH \\ 1050 Massachusetts Avenue \\ Cambridge, MA 02138
}

October 2001

Campbell acknowledges the financial support of the National Science Foundation, and Viceira the financial support of the Division of Research of the Harvard Business School. We are grateful for helpful comments and suggestions by Ludger Hentschel, Anthony Lynch, an anonymous referee, and seminar participants at Harvard, the 1999 Intertemporal Asset Pricing Conference hosted by the Centre Interuniversitaire de Recherche en Analyse des Organizations (CIRANO) of Montreal and the 2000 WFA Meetings. Josh White provided invaluable research assistance. The views expressed herein are those of the authors and not necessarily those of the National Bureau of Economic Research.

(C) 2001 by John Y. Campbell, Yeung Lewis Chan and Luis M. Viceira. All rights reserved. Short sections of text, not to exceed two paragraphs, may be quoted without explicit permission provided that full credit, including (C) notice, is given to the source. 
A Multivariate Model of Strategic Asset Allocation

John Y. Campbell, Yeung Lewis Chan and Luis M. Viceira

NBER Working Paper No. 8566

October 2001

JEL No. G12

$\underline{\text { ABSTRACT }}$

Much recent work has documented evidence for predictability of asset returns. We show how such predictability can affect the portfolio choices of long-lived investors who value wealth not for its own sake but for the consumption their wealth can support. We develop an approximate solution method for the optimal consumption and portfolio choice problem of an infinitely-lived investor with Epstein-Zin utility who faces a set of asset returns described by a vector autoregression in returns and state variables. Empirical estimates in long-run annual and postwar quarterly US data suggest that the predictability of stock returns greatly increases the optimal demand for stocks. The role of nominal bonds in long-term portfolios depends on the importance of real interest rate risk relative to other sources of risk. We extend the analysis to consider long-term inflation-indexed bonds and find that these bonds greatly increase the utility of conservative investors, who should hold large positions when they are available.

John Y. Campbell

Department of Economics

Littauer Center 213

Harvard University

Cambridge, MA 02138

and NBER

Email: john_campbell@harvard.edu

Website: http://post.economics.harvard.edu/faculty/jcampbell/campbell.html

Yeung Lewis Chan

Department of Finance

School of Business and Management

Hong Kong University of Science and Technology

Clear Water Bay

Kowloon, Hong Kong

Email: ylchan@ust.hk

Luis M. Viceira

Graduate School of Business Administration

Morgan Hall 367

Harvard University

Boston, MA 02163,

CEPR and NBER

Email: lviceira@hbs.edu

Website: http://www.people.hbs.edu/lviceira 


\section{Introduction}

Academic finance has had a remarkable impact on many participants in the financial services industry, from mutual fund managers to corporate risk managers. Curiously, however, financial planners offering portfolio advice to long-term investors have received little guidance from academic financial economists.

The mean-variance analysis of Markowitz (1952) has provided a basic paradigm, and has usefully emphasized the ability of diversification to reduce risk, but this model ignores several critically important factors. Most notably, the analysis is static; it assumes that investors care only about risks to wealth one period ahead. In reality, however, many investors - both individuals and institutions such as charitable foundations or universities - seek to finance a stream of consumption over a long lifetime.

Financial economists have understood at least since the work of Samuelson (1969) and Merton $(1969,1971,1973)$ that the solution to a multi-period portfolio choice problem can be very different from the solution to a static portfolio choice problem. In particular, if investment opportunities are varying over time, then long-term investors care about shocks to investment opportunities - the productivity of wealth - as well as shocks to wealth itself. They may seek to hedge their exposures to wealth productivity shocks, and this gives rise to intertemporal hedging demands for financial assets. Brennan, Schwartz, and Lagnado (1997) have coined the phrase "strategic asset allocation" to describe this far-sighted response to time-varying investment opportunities.

Unfortunately Merton's intertemporal model is hard to solve in closed form. For many years solutions to the model were only available in those trivial cases where it reduces to the static model. Therefore the Merton model has not become a usable empirical paradigm, has not displaced the Markowitz model, and has had little influence on financial planners and their clients.

Recently this situation has begun to change as a result of several related developments. First, computing power and numerical methods have advanced to the point at which realistic multi-period portfolio choice problems can be solved numerically using discrete-state approximations. Balduzzi and Lynch (1999), Barberis (1999), Brennan, Schwartz, and Lagnado (1997, 1999), Cocco, Gomes, and Maenhout (1998), and Lynch (2001) are important examples of this style of work. Second, financial the- 
orists have discovered some new closed-form solutions to the Merton model. In a continuous-time model with a constant riskless interest rate and a single risky asset whose expected return follows a mean-reverting (Ornstein-Uhlenbeck) process, for example, the model can be solved if long-lived investors have power utility defined over terminal wealth (Kim and Omberg 1996), or if investors have power utility defined over consumption and the innovation to the expected asset return is perfectly correlated with the innovation to the unexpected return, making the asset market effectively complete (Wachter 2002), or if the investor has Epstein-Zin utility with intertemporal elasticity of substitution equal to one (Campbell and Viceira 1999, Schroder and Skiadas 1999). Similar results are available in affine models of the term structure (Brennan and Xia 2001, Campbell and Viceira 2001, Liu 1998, Wachter 2000). Third, approximate analytical solutions to the Merton model have been developed (Campbell and Viceira 1999, 2001). These solutions are based on perturbations of the known exact solutions for intertemporal elasticity of substitution equal to one, so they are accurate provided that the intertemporal elasticity is not too far from one. They offer analytical insights into investor behavior in models that fall outside the still limited class that can be solved exactly.

Despite this encouraging progress, it remains extremely hard to solve realistically complex cases of the Merton model. Discrete-state numerical algorithms become slow and unreliable in the presence of many assets and state variables, and approximate analytical methods seem to require a daunting quantity of algebra. Neither approach has been developed to the point at which one can specify a general vector autoregression (VAR) for asset returns and hope to solve the associated portfolio choice problem.

The purpose of this paper is to remedy this situation by extending the approximate analytical approach of Campbell and Viceira $(1999,2001)$. Specifically, we show that if asset returns are described by a VAR, if the investor is infinitely lived with EpsteinZin utility, and if there are no borrowing or short-sales constraints on asset allocations, then the Campbell-Viceira approach implies a system of linear-quadratic equations for portfolio weights and consumption as functions of state variables. These equations are generally too cumbersome to solve analytically, but can be solved very rapidly by simple numerical methods. As the time interval of the model shrinks, the solutions become exact if the elasticity of intertemporal substitution equals one. They are accurate approximations for short time intervals and elasticities close to one.

We apply our method to a VAR for short-term real interest rates, excess stock 
returns, and excess bond returns. We also include variables that have been identified as return predictors by past empirical research: the short-term interest rate (Fama and Schwert 1977, Campbell 1987, Glosten, Jagannathan, and Runkle 1993); the dividendprice ratio (Campbell and Shiller 1988, Fama and French 1988a); and the yield spread between long-term and short-term bonds (Shiller, Campbell, and Schoenholtz 1983, Fama 1984, Fama and French 1989, Campbell and Shiller 1991). In a variant of the basic approach we construct data on hypothetical inflation-indexed bond returns, following the approach of Campbell and Shiller (1996), and study the allocation to stocks, inflation-indexed bonds, nominal bonds, and bills.

Two closely related papers are by Brennan, Schwartz, and Lagnado (1999) and Lynch (2001). Brennan, Schwartz, and Lagnado consider asset allocation among stocks, nominal bonds, bills, and interest-rate futures, using short- and long-term nominal interest rates and the dividend-price ratio as state variables. The investor is assumed to have power utility defined over wealth at a given horizon, and the stochastic optimization problem is solved using numerical dynamic programming imposing borrowing and short-sales constraints. Lynch considers asset allocation among portfolios of stocks sorted by size and book-to-market ratios, using the long-short yield spread and the dividend-price ratio as state variables, and assuming power utility defined over consumption. He solves the optimization problem with and without short-sales constraints, again using numerical dynamic programming. Our paper, by contrast, assumes recursive Epstein-Zin utility defined over an infinite stream of consumption and does not impose any portfolio constraints. The simplicity of our solution method allows us to consider an unrestricted VAR in which lagged returns are state variables along with the short-term nominal interest rate, dividend-price ratio, and yield spread. Our method also allows us to break intertemporal hedging demands into components associated with individual state variables.

The organization of the paper is as follows. Section 2 explains our basic setup, and Section 3 describes our approximate solution method. Section 4 presents empirical results for the case where stocks, nominal bonds, and bills are available. Section 5 considers portfolio allocation in the presence of inflation-indexed bonds. Section 6 concludes. 


\section{The Model}

Our model is set in discrete time. We assume an infinitely-lived investor with EpsteinZin $(1989,1991)$ recursive preferences defined over a stream of consumption. This contrasts with papers such as Brennan, Schwartz and Lagnado (1997, 1999), Kim and Omberg (1996), and Barberis (2000) that consider finite-horizon models with power utility defined over terminal wealth. We allow an arbitrary set of traded assets and state variables. Thus we do not make the assumption of Wachter $(2000,2002)$ that markets are complete, and we substantially extend the work of Campbell and Viceira (1999) in which there is a single risky asset with a single state variable.

\section{$2.1 \quad$ Securities}

There are $n$ assets available for investment. The investor allocates her after-consumption wealth among these assets. The real return on her portfolio $R_{p, t+1}$ is given by

$$
R_{p, t+1}=\sum_{i=2}^{n} \alpha_{i, t}\left(R_{i, t+1}-R_{1, t+1}\right)+R_{1, t+1},
$$

where $\alpha_{i, t}$ is the portfolio weight on asset $i$. The first asset is a short-term instrument whose real return is $R_{1, t+1}$. Although we use the short-term return as a benchmark and measure other returns relative to it, we do not assume that this return is riskless. In practice we use a nominal bill as the short-term asset; the nominal return on a nominal bill is riskless, but the real return is not because it is subject to short-term inflation risk. In most of our empirical analysis we consider two other assets: stocks and long-term nominal bonds. In Section 5 we also consider long-term inflationindexed bonds.

\subsection{Dynamics of state variables}

We postulate that the dynamics of the relevant state variables are well captured by a first-order vector autoregressive process or VAR(1). This type of dynamic specification has been used by Kandel and Stambaugh (1987), Campbell (1991, 1996), Hodrick (1992), and Barberis (2000), among others. In principle the use of a VAR(1) is not restrictive since any vector autoregression can be rewritten as a VAR(1) through 
an expansion of the vector of state variables. For parsimony, however, in our empirical work we avoid additional lags that would require an expanded state vector with additional parameters to estimate. Specifically, we define

$$
\mathbf{x}_{t+1} \equiv\left[\begin{array}{c}
r_{2, t+1}-r_{1, t+1} \\
r_{3, t+1}-r_{1, t+1} \\
\vdots \\
r_{n, t+1}-r_{1, t+1}
\end{array}\right],
$$

where $r_{i, t+1} \equiv \log \left(R_{i, t+1}\right)$ for all $i$, and $\mathbf{x}_{t+1}$ is the vector of $\log$ excess returns. In our empirical application, $r_{1, t+1}$ is the real short rate, $r_{2, t+1}$ refers to the real stock return and $r_{3, t+1}$ to the real return on nominal bonds.

We allow the system to include other state variables $\mathbf{s}_{t+1}$, such as the dividendprice ratio. Stacking $r_{1, t+1}, \mathbf{x}_{t+1}, \mathbf{s}_{t+1}$ into an $m \times 1$ vector $\mathbf{z}_{t+1}$, we have

$$
\mathbf{z}_{t+1} \equiv\left[\begin{array}{c}
r_{1, t+1} \\
\mathbf{x}_{t+1} \\
\mathbf{s}_{t+1}
\end{array}\right] .
$$

We will call $\mathbf{z}_{t+1}$ the state vector and we assume a first order vector autoregression for $\mathbf{z}_{t+1}$ :

$$
\mathbf{z}_{t+1}=\Phi_{0}+\Phi_{1} \mathbf{z}_{t}+\mathbf{v}_{t+1}
$$

where $\boldsymbol{\Phi}_{0}$ is the $m \times 1$ vector of intercepts, $\boldsymbol{\Phi}_{1}$ is the $m \times m$ matrix of slope coefficients, and $\mathbf{v}_{t+1}$ are the shocks to the state variables satisfying the following distributional assumptions:

$$
\begin{gathered}
\mathbf{v}_{t+1} \stackrel{i . i . d .}{\sim} \mathcal{N}\left(0, \boldsymbol{\Sigma}_{v}\right) \\
\boldsymbol{\Sigma}_{v} \equiv \operatorname{Var}_{t}\left(\mathbf{v}_{t+1}\right)=\left[\begin{array}{ccc}
\sigma_{1}^{2} & \boldsymbol{\sigma}_{1 x}^{\prime} & \boldsymbol{\sigma}_{1 s}^{\prime} \\
\boldsymbol{\sigma}_{1 x} & \boldsymbol{\Sigma}_{x x} & \boldsymbol{\Sigma}_{x s}^{\prime} \\
\boldsymbol{\sigma}_{1 s} & \boldsymbol{\Sigma}_{x s} & \boldsymbol{\Sigma}_{s s}
\end{array}\right] .
\end{gathered}
$$

Thus, we allow the shocks to be cross-sectionally correlated, but assume that they are homoskedastic and independently distributed over time. The VAR framework conveniently captures the dependence of expected returns of various assets on their past histories as well as on other predictive variables. The stochastic evolution of these other state variables $\mathbf{s}_{t+1}$ is also determined by the system.

The assumption of homoskedasticity is of course restrictive. It rules out the possibility that the state variables predict changes in risk; they can affect portfolio 
choice only by predicting changes in expected returns. Authors such as Campbell (1987), Harvey (1989, 1991), and Glosten, Jagannathan, and Runkle (1993) have explored the ability of the state variables used here to predict risk and have found only modest effects that seem to be dominated by the effects of the state variables on expected returns. Chacko and Viceira (1999) show how to include changing risk in a long-term portfolio choice problem, using a continuous-time extension of the methodology of Campbell and Viceira (1999); they find that changes in equity risk are not persistent enough to have large effects on the intertemporal hedging demand for equities. Aït-Sahalia and Brandt (2001) adopt a semiparametric methodology that accommodates both changing expected returns and changing risk.

Given our homoskedastic VAR formulation, the unconditional distribution of $\mathbf{z}_{t}$ is easily derived. The state vector $\mathbf{z}_{t}$ inherits the normality of the shocks $\mathbf{v}_{t+1}$. Appendix A gives expressions for the unconditional mean and variance-covariance matrix of $\mathbf{z}_{t}$.

\subsection{Preferences and optimality conditions}

We assume that the investor has Epstein-Zin $(1989,1991)$ recursive preferences. This preference specification has the desirable property that the notion of risk aversion is separated from that of the elasticity of intertemporal substitution. Following EpsteinZin, we let

$$
U\left(C_{t}, \mathrm{E}_{t}\left(U_{t+1}\right)\right)=\left[(1-\delta) C_{t}^{\frac{1-\gamma}{\theta}}+\delta\left(\mathrm{E}_{t}\left(U_{t+1}^{1-\gamma}\right)\right)^{\frac{1}{\theta}}\right]^{\frac{\theta}{1-\gamma}}
$$

where $C_{t}$ is consumption at time $t, \gamma>0$ is the relative risk aversion coefficient, $\psi>0$ is the elasticity of intertemporal substitution, $0<\delta<1$ is the time discount factor, $\theta \equiv(1-\gamma) /\left(1-\psi^{-1}\right)$, and $\mathrm{E}_{t}(\cdot)$ is the conditional expectation operator.

Epstein-Zin recursive utility nests as a special case the standard, time-separable power utility specification. Figure 1 shows graphically the relation between EpsteinZin utility and power utility. The horizontal axis in the figure shows the intertemporal elasticity of substitution $\psi$, while the vertical axis shows the coefficient of relative risk aversion $\gamma$. The set of points with unit elasticity of intertemporal substitution is drawn as a vertical line, while the set of points with unit relative risk aversion is drawn as a horizontal line. For time-separable power utility, $\gamma=\psi^{-1}$ and hence $\theta=1$. This corresponds to the hyperbola $\gamma=\psi^{-1}$ plotted in the figure. Log utility obtains when 
we impose the additional restriction $\gamma=\psi^{-1}=1$. This is the point in the figure where all three lines cross.

At time $t$, the investor uses all relevant information to make optimal consumption and portfolio decisions. She faces the intertemporal budget constraint

$$
W_{t+1}=\left(W_{t}-C_{t}\right) R_{p, t+1}
$$

where $C_{t}$ is consumption and $W_{t}$ is wealth at time $t$.

Epstein and Zin $(1989,1991)$ have shown that with this budget constraint, the Euler equation for consumption is

$$
\mathrm{E}_{t}\left[\left\{\delta\left(\frac{C_{t+1}}{C_{t}}\right)^{-\frac{1}{\psi}}\right\}^{\theta} R_{p, t+1}^{-(1-\theta)} R_{i, t+1}\right]=1,
$$

for any asset $i$, including the portfolio $p$ itself. This first-order condition reduces to the standard one in the power utility case where $\gamma=\psi^{-1}$ and $\theta=1$.

The investor's optimal consumption and portfolio policies must satisfy the Euler equation (8). When investment opportunities are constant, the optimal policies imply a constant consumption-wealth ratio and a myopic portfolio rule - that is, the investor chooses her portfolio as if her investment horizon was only one period. However, when investment opportunities are time-varying, there are no known exact analytical solutions to this equation except for some specific values of $\gamma$ and $\psi$. Giovannini and Weil (1989) have shown that with $\gamma=1$, it is optimal for the investor to follow a myopic portfolio rule. This case corresponds to the horizontal line plotted in Figure 1. They also show that with $\psi=1$, the investor optimally chooses a constant consumption-wealth ratio equal to $(1-\delta)$. This corresponds to the vertical line in Figure 1. However, with $\gamma=1$, the optimal consumption-wealth ratio is not constant unless $\psi=1$ and, conversely, with $\psi=1$ the optimal portfolio rule is not myopic unless $\gamma=1$. This corresponds to the point where the vertical and horizontal lines in Figure 1 cross - i.e., the log utility case. To solve for the optimal rules in all other cases, we extend the approximate analytical solution method in Campbell and Viceira $(1999,2001)$ to a multivariate framework.

Epstein and Zin $(1989,1991)$ have derived one other useful result. They show that the value function - the maximized utility function (6) - per unit of wealth can 
be written as a power function of the optimal consumption-wealth ratio:

$$
V_{t} \equiv \frac{U_{t}}{W_{t}}=(1-\delta)^{-\frac{\psi}{1-\psi}}\left(\frac{C_{t}}{W_{t}}\right)^{\frac{1}{1-\psi}}
$$

We have already noted that the ratio $C_{t} / W_{t}$ approaches $(1-\delta)$ as $\psi$ approaches one. This allows the value function (9) to have a finite limit as $\psi$ approaches one.

\section{Solution Methodology}

\subsection{An approximate framework}

The return on the portfolio in (1) is expressed in terms of the simple returns on the assets. Since it is more convenient to work with log returns in our framework, we first derive an expression for the log return on the portfolio. Following Campbell and Viceira $(1999,2001)$, we approximate the log return on the portfolio as

$$
r_{p, t+1}=r_{1, t+1}+\boldsymbol{\alpha}_{t}^{\prime} \mathbf{x}_{t+1}+\frac{1}{2} \boldsymbol{\alpha}_{t}^{\prime}\left(\boldsymbol{\sigma}_{x}^{2}-\boldsymbol{\Sigma}_{x x} \boldsymbol{\alpha}_{t}\right)
$$

where $\boldsymbol{\sigma}_{x}^{2} \equiv \operatorname{diag}\left(\boldsymbol{\Sigma}_{x x}\right)$ is the vector consisting of the diagonal elements of $\boldsymbol{\Sigma}_{x x}$, the variances of excess returns. This approximation holds exactly in continuous time and is highly accurate for short time intervals. Just as in a continuous-time model, (10) prevents bankruptcy even when asset positions are leveraged; Campbell and Viceira (2001) discuss the relation of this approach with continuous-time modelling. When there is only one risky asset, (10) collapses to the approximation derived in Campbell and Viceira (1999). Detailed derivations for this and other results in this section are provided in Appendix A.

The budget constraint in (7) is nonlinear. Following Campbell (1993, 1996), we log-linearize around the unconditional mean of the log consumption-wealth ratio to obtain

$$
\Delta w_{t+1} \approx r_{p, t+1}+\left(1-\frac{1}{\rho}\right)\left(c_{t}-w_{t}\right)+k
$$

where $\Delta$ is the difference operator, $\rho \equiv 1-\exp \left(\mathrm{E}\left[c_{t}-w_{t}\right]\right)$ and $k \equiv \log (\rho)+$ $(1-\rho) \log (1-\rho) / \rho$. When consumption is chosen optimally by the investor, $\rho$ depends on the optimal level of $c_{t}$ relative to $w_{t}$ and in this sense is endogenous. This 
form of the budget constraint is exact if the elasticity of intertemporal substitution $\psi=1$, in which case $c_{t}-w_{t}$ is constant and $\rho=\delta$.

Next, we apply a second-order Taylor expansion to the Euler equation (8) around the conditional means of $\Delta c_{t+1}, r_{p, t+1}, r_{i, t+1}$ to obtain

$$
\begin{aligned}
0= & \theta \log \delta-\frac{\theta}{\psi} \mathrm{E}_{t} \Delta c_{t+1}-(1-\theta) \mathrm{E}_{t} r_{p, t+1}+\mathrm{E}_{t} r_{i, t+1} \\
+ & \frac{1}{2} \operatorname{Var}_{t}\left[-\frac{\theta}{\psi} \Delta c_{t+1}-(1-\theta) r_{p, t+1}+r_{i, t+1}\right]
\end{aligned}
$$

This loglinearized Euler equation is exact if consumption and asset returns are jointly lognormally distributed, which is the case when the elasticity of intertemporal substitution $\psi=1$. It can be usefully transformed as follows. Setting $i=1$ in (12), subtracting from the general form of (12), and noting that $\Delta c_{t+1}=\Delta\left(c_{t+1}-w_{t+1}\right)+$ $\Delta w_{t+1}$, we obtain, for asset $i=2, \ldots, n$,

$$
\begin{aligned}
\mathrm{E}_{t}\left(r_{i, t+1}-r_{1, t+1}\right)+\frac{1}{2} \operatorname{Var}_{t}\left(r_{i, t+1}-r_{1, t+1}\right)= & \frac{\theta}{\psi}\left(\sigma_{i, c-w, t}-\sigma_{1, c-w, t}\right) \\
& +\gamma\left(\sigma_{i, p, t}-\sigma_{1, p, t}\right)-\left(\sigma_{i, 1, t}-\sigma_{1,1, t}\right),
\end{aligned}
$$

where $\sigma_{i, c-w, t}=\operatorname{Cov}_{t}\left(r_{i, t+1}, c_{t+1}-w_{t+1}\right), \sigma_{1, c-w, t}=\operatorname{Cov}_{t}\left(r_{1, t+1}, c_{t+1}-w_{t+1}\right), \sigma_{i, p, t}=$ $\operatorname{Cov}_{t}\left(r_{i, t+1}, r_{p, t+1}\right), \sigma_{1, p, t}=\operatorname{Cov}_{t}\left(r_{1, t+1}, r_{p, t+1}\right), \sigma_{i, 1, t}=\operatorname{Cov}_{t}\left(r_{i, t+1}, r_{1, t+1}\right)$, and $\sigma_{1,1, t}=$ $\operatorname{Var}_{t}\left(r_{1, t+1}\right)$. The left hand side of this equation is the risk premium on asset $i$ over asset 1 , adjusted for Jensen's Inequality by adding one-half the variance of the excess return. The equation relates asset $i$ 's risk premium to its excess covariance with consumption growth, its excess covariance with the portfolio return, and the covariance of its excess return with the return on asset 1 . (The last term drops out when asset 1 is riskless.) Of course, consumption growth and the portfolio return are endogenous so this is a first-order condition describing the optimal solution rather than a statement of the solution itself. 


\subsection{Solving the approximate model}

To solve the model, we now guess that the optimal portfolio and consumption rules take the form

$$
\begin{aligned}
\boldsymbol{\alpha}_{t} & =\mathbf{A}_{0}+\mathbf{A}_{1} \mathbf{z}_{t}, \\
c_{t}-w_{t} & =b_{0}+\mathbf{B}_{1}^{\prime} \mathbf{z}_{t}+\mathbf{z}_{t}^{\prime} \mathbf{B}_{2} \mathbf{z}_{t}
\end{aligned}
$$

That is, the optimal portfolio rule is linear in the VAR state vector but the optimal consumption rule is quadratic. $\mathbf{A}_{0}, \mathbf{A}_{1}, b_{0}, \mathbf{B}_{1}$, and $\mathbf{B}_{2}$ are constant coefficient matrices to be determined, with dimensions $(n-1) \times 1,(n-1) \times m, 1 \times 1, m \times 1$, and $m \times m$, respectively. This is a multivariate generalization of the solution obtained by Campbell and Viceira (1999). ${ }^{2}$

To verify this guess and solve for the parameters of the solution, we write the conditional moments that appear in (13) as functions of the VAR parameters and the unknown parameters of (14) and (15). We then solve for the parameters that satisfy (13). Recalling that the vector of excess returns is written as $\mathbf{x}_{t}$, the conditional expectation on the left hand side of (13) is

$$
\mathrm{E}_{t}\left(\mathbf{x}_{t+1}\right)+\frac{1}{2} \operatorname{Var}_{t}\left(\mathbf{x}_{t+1}\right)=\mathbf{H}_{x} \boldsymbol{\Phi}_{0}+\mathbf{H}_{x} \boldsymbol{\Phi}_{1} \mathbf{z}_{t}+\frac{1}{2} \boldsymbol{\sigma}_{x}^{2},
$$

where $\mathbf{H}_{x}$ is a selection matrix that selects the vector of excess returns from the full state vector.

Appendix A shows that the three conditional covariances on the right hand side of (13) can all be written as linear functions of the state variables. In matrix notation,

$$
\begin{aligned}
\boldsymbol{\sigma}_{c-w, t}-\sigma_{1, c-w, t} \boldsymbol{\iota} & \equiv\left[\sigma_{i, c-w, t}-\sigma_{1, c-w, t}\right]_{i=2, \ldots n}=\boldsymbol{\Lambda}_{0}+\boldsymbol{\Lambda}_{1} \mathbf{z}_{t} \\
\boldsymbol{\sigma}_{p, t}-\sigma_{1, p, t} \boldsymbol{\iota} & \equiv\left[\sigma_{i, p, t}-\sigma_{1, p, t}\right]_{i=2, \ldots n}=\boldsymbol{\Sigma}_{x x} \boldsymbol{\alpha}_{t}+\boldsymbol{\sigma}_{1 x} \\
\boldsymbol{\sigma}_{1, t}-\sigma_{1,1, t} \boldsymbol{\iota} & \equiv\left[\sigma_{i, 1, t}-\sigma_{1,1, t}\right]_{i=2, \ldots n}=\boldsymbol{\sigma}_{1 x}
\end{aligned}
$$

\footnotetext{
${ }^{2}$ It is important to note that only $m+\left(m^{2}-m\right) / 2$ elements of $\mathbf{B}_{2}$ are determined. The diagonal elements of $\mathbf{B}_{2}$ are unique, but the consumption-wealth ratio is determined by the sums of offdiagonal elements $b_{2, i j}+b_{2, j i}$ because $z_{i, t} z_{j, t}=z_{j, t} z_{i, t}$. Thus we can impose arbitrary normalizations on $\mathbf{B}_{2}$ provided that we leave each sum $b_{2, i j}+b_{2, j i}$ unrestricted. For example, we could restrict $\mathbf{B}_{2}$ to be symmetric, upper triangular, or lower triangular.
} 
where $\iota$ is a vector of ones.

\subsection{Optimal portfolio choice}

Solving the Euler equation (13) for the portfolio rule we have

$$
\begin{aligned}
\boldsymbol{\alpha}_{t}= & \frac{1}{\gamma} \boldsymbol{\Sigma}_{x x}^{-1}\left[\mathrm{E}_{t}\left(\mathbf{x}_{t+1}\right)+\frac{1}{2} \operatorname{Var}_{t}\left(\mathbf{x}_{t+1}\right)+(1-\gamma) \boldsymbol{\sigma}_{1 x}\right] \\
& +\frac{1}{\gamma} \boldsymbol{\Sigma}_{x x}^{-1}\left[-\frac{\theta}{\psi}\left(\boldsymbol{\sigma}_{c-w, t}-\sigma_{1, c-w, t} \boldsymbol{\iota}\right)\right]
\end{aligned}
$$

where $\mathrm{E}_{t}\left(\mathbf{x}_{t+1}\right)+\operatorname{Var}_{t}\left(\mathbf{x}_{t+1}\right) / 2$ and $\boldsymbol{\sigma}_{c-w, t}-\sigma_{1, c-w, t} \boldsymbol{\iota}$ are the linear functions of $\mathbf{z}_{t}$ given in (16) and (17), respectively. This equation is a multiple-asset generalization of Restoy (1992) and Campbell and Viceira (1999). It expresses the optimal portfolio choice as the sum of two components.

The first term on the right hand side of (20) is the myopic component of asset demand. When the benchmark asset 1 is riskless $\left(\boldsymbol{\sigma}_{1 x}=0\right)$, then the myopic allocation is the vector of Sharpe ratios on risky assets, scaled by the inverse of the variance-covariance matrix of risky asset returns and the reciprocal of the coefficient of relative risk aversion. Investors with $\gamma \neq 1$ adjust this allocation slightly by a term $(1-\gamma) \boldsymbol{\sigma}_{1 x}$ when asset 1 is risky. Because of its myopic nature, this component does not depend on $\psi$, the elasticity of intertemporal substitution.

The second term on the right hand side of (20) is the intertemporal hedging demand. In our model, the investment opportunity set is time varying since expected returns on various assets are state-dependent. Merton (1969, 1971) shows that a rational investor who is more risk averse than a logarithmic investor will hedge against adverse changes in investment opportunities. For a logarithmic investor, the optimal portfolio rule is purely myopic and hence the hedging demand is identically equal to zero. This can be easily seen from (20) since when $\gamma=1, \theta=0$ and the hedging component vanishes. Also, when investment opportunities are constant over time, hedging demand is zero for any level of risk aversion. This case corresponds

to having only the intercept term in our VAR specification. It is straightforward to verify that the coefficient matrices $\Lambda_{0}$ and $\Lambda_{1}$ in the hedging component are zero matrices in this case and thus there is no hedging component of asset demand. 
Substituting (16) and (17) in (20) and rearranging the terms yields

$$
\boldsymbol{\alpha}_{t} \equiv \mathbf{A}_{0}+\mathbf{A}_{1} \mathbf{z}_{t}
$$

where

$$
\begin{aligned}
& \mathbf{A}_{0}=\left(\frac{1}{\gamma}\right) \boldsymbol{\Sigma}_{x x}^{-1}\left(\mathbf{H}_{x} \Phi_{0}+\frac{1}{2} \boldsymbol{\sigma}_{x}^{2}+(1-\gamma) \boldsymbol{\sigma}_{1 x}\right)+\left(1-\frac{1}{\gamma}\right) \boldsymbol{\Sigma}_{x x}^{-1}\left(\frac{-\boldsymbol{\Lambda}_{0}}{1-\psi}\right), \\
& \mathbf{A}_{1}=\left(\frac{1}{\gamma}\right) \boldsymbol{\Sigma}_{x x}^{-1} \mathbf{H}_{x} \Phi_{1}+\left(1-\frac{1}{\gamma}\right) \boldsymbol{\Sigma}_{x x}^{-1}\left(\frac{-\boldsymbol{\Lambda}_{1}}{1-\psi}\right) .
\end{aligned}
$$

Equation (21) verifies our initial guess for the form of the optimal portfolio rule and expresses the coefficient matrices $\mathbf{A}_{0}, \mathbf{A}_{1}$ as functions of the underlying parameters describing preferences and the dynamics of the state variables. $\mathbf{A}_{0}$ and $\mathbf{A}_{1}$ also depend on the parameters in the consumption-wealth ratio equation, $\mathbf{B}_{1}$ and $\mathbf{B}_{2}$, through the coefficient matrices $\Lambda_{0}$ and $\Lambda_{1}$. It is important to note that the terms in $(1-1 / \gamma)$ in equations (22) and (23) reflect the effect of intertemporal hedging on optimal portfolio choice. Thus intertemporal hedging considerations affect both the mean optimal portfolio allocation to risky assets - through $\mathbf{A}_{0}$ and $\mathbf{A}_{1}$ - and the sensitivity of the optimal portfolio allocation to changes in the state variables - through $\mathbf{A}_{1}$.

Appendix A shows that, given the loglinearization parameter $\rho$, the coefficient matrices $-\Lambda_{0} /(1-\psi)$ and $-\Lambda_{1} /(1-\psi)$ are independent of the intertemporal elasticity of substitution $\psi$. This implies that the optimal portfolio rule is independent of $\psi$ given $\rho$. $\psi$ only affects portfolio choice to the extent that it enters into the determination of $\rho$. This property is a generalization to a model with multiple assets and state variables of a similar result shown by Campbell and Viceira (1999) in the context of a univariate model.

\subsection{Optimal consumption}

Next, we solve for the optimal consumption-wealth ratio. Setting $i=p$ in (12) and rearranging,

$$
\mathrm{E}_{t}\left(\Delta c_{t+1}\right)=\psi \log \delta+\chi_{p, t}+\psi \mathrm{E}_{t}\left(r_{p, t+1}\right),
$$

where

$$
\chi_{p, t}=\frac{1}{2}\left(\frac{\theta}{\psi}\right) \operatorname{Var}_{t}\left(\Delta c_{t+1}-\psi r_{p, t+1}\right) .
$$


This equation relates expected consumption growth to preferences and investment opportunities. A patient investor with high $\delta$ plans more rapid consumption growth. Similarly, when the return on the portfolio is expected to be higher, the investor increases planned consumption growth to take advantage of good investment opportunities. The sensitivity of planned consumption growth to both patience and returns is measured by the elasticity of intertemporal substitution $\psi$.

The term $\chi_{p, t}$ arises from the precautionary savings motive. Randomness in future consumption growth, relative to portfolio returns, increases precautionary savings and lowers current consumption if $\theta>0$ (a condition satisfied by power utility for which $\theta=1$ ), but reduces precautionary savings and increases current consumption if $\theta<0$.

We show in Appendix A that combining equation (24) and the log-linearized budget constraint (11), we obtain a difference equation in $c_{t}-w_{t}$ :

$$
c_{t}-w_{t}=-\rho \psi \log \delta-\rho \chi_{p, t}+\rho(1-\psi) \mathrm{E}_{t}\left(r_{p, t+1}\right)+\rho k+\rho \mathrm{E}_{t}\left(c_{t+1}-w_{t+1}\right),
$$

where both $\mathrm{E}_{t}\left(r_{p, t+1}\right)$ and $\chi_{p, t}$ are quadratic functions of the VAR state variables. Given our conjectured quadratic form for the optimal consumption-wealth ratio, both sides of this equation are quadratic in the VAR state variables. This confirms our initial conjecture on the form of the consumption-wealth ratio and gives us a set of equations that solve for the coefficients of the optimal consumption policy, $b_{0}, \mathbf{B}_{1}$ and $\mathbf{B}_{2}$.

In a model with a single state variable, as in Campbell and Viceira $(1999,2001)$, it is feasible to solve these equations to obtain approximate closed-form solutions for consumption and portfolio choice given the parameter of loglinearization $\rho$. A simple numerical recursion then obtains the value of $\rho$ that is consistent with the derived consumption rule. In the current model, with multiple state variables, we use a numerical procedure to solve for consumption and portfolio choice given $\rho$. This procedure, which is described in detail in Appendix B, converges much more rapidly than the usual numerical procedures which approximate the model on a discrete grid. In our empirical results we emphasize the case $\psi=1$, for which the value of $\rho$ is known to equal the time discount factor $\delta$; however it is straightforward to add a numerical recursion for $\rho$ when this is needed. 


\subsection{Value function}

Substitution of the optimal log consumption-wealth ratio into the expression for the value function (9) gives

$$
\begin{aligned}
V_{t} & =(1-\delta)^{-\frac{\psi}{1-\psi}}\left(\frac{C_{t}}{W_{t}}\right)^{\frac{1}{1-\psi}} \\
& =\exp \left\{-\frac{\psi}{1-\psi} \log (1-\delta)+\frac{b_{0}}{1-\psi}+\frac{\mathbf{B}_{1}^{\prime}}{1-\psi} \mathbf{z}_{t}+\mathbf{z}_{t}^{\prime} \frac{\mathbf{B}_{2}}{1-\psi} \mathbf{z}_{t}\right\} \\
& =\exp \left\{\mathcal{B}_{0}+\mathcal{B}_{1}^{\prime} \mathbf{z}_{t}+\mathbf{z}_{t}^{\prime} \mathcal{B}_{2} \mathbf{z}_{t}\right\}
\end{aligned}
$$

where the definitions of $\mathcal{B}_{0}, \mathcal{B}_{1}$ and $\mathcal{B}_{2}$ are obvious from the second equality.

Appendix $\mathrm{A}$ shows that $\mathcal{B}_{1}$, and $\mathcal{B}_{2}$ are independent of $\psi$ given $\rho$. However, $\mathcal{B}_{0}$ does depend on $\psi$. Appendix $\mathrm{A}$ also derives an expression for $\mathcal{B}_{0}$ when $\psi=1$. This derivation uses the fact that $C_{t} / W_{t}=1-\delta$ when $\psi=1$, which implies that $\rho=\delta$. Therefore, the value function (27) has a well defined finite limit in the case $\psi=1$, that obtains by setting $\rho=\delta$ in the expressions for $\mathcal{B}_{0}, \mathcal{B}_{1}$ and $\mathcal{B}_{2}$. Finally, Appendix A derives an expression for the unconditional mean of the value function, $\mathrm{E}\left[V_{t}\right]$. We can use these results to calculate the utility of long-term investors who are offered alternative menus of assets.

\section{An Empirical Application: Stocks, Bonds, and Bills}

Section 3 provides a general theoretical framework for strategic asset allocation. In this section, we use the framework to investigate how investors who differ in their consumption preferences and risk aversion allocate their portfolios among three assets: stocks, nominal bonds, and nominal Treasury bills. Investment opportunities are described by a VAR system that includes short-term ex-post real interest rates, excess stock returns, excess bond returns and variables that have been identified as return predictors by empirical research: the short-term nominal interest rate, the dividendprice ratio, and the yield spread between long-term bonds and Treasury bills.

The short-term nominal interest rate has been used to predict stock and bond returns by authors such as Fama and Schwert (1977), Campbell (1987), and Glosten, 
Jagannathan, and Runkle (1993). An alternative approach, suggested by Campbell (1991) and Hodrick (1992), is to stochastically detrend the short-term rate by subtracting a backwards moving average (usually measured over one year). For two reasons we do not adopt this alternative here. First, one of our data sets is annual and does not allow us to measure a one-year moving average of short rates. Second, we want our model to capture inflation dynamics. If we include both the ex-post real interest rate and the nominal interest rate in the VAR system, we can easily calculate inflation by subtracting one from the other. This allows us to separate nominal from real variables, so that we can extend our model to include a hypothetical inflationindexed bond in the menu of assets. We consider this extension in section 5 .

We compute optimal portfolio rules for different values of $\gamma$, assuming $\psi=1$ and $\delta=0.92$ in annual terms. This case gives the exact solution of Giovannini and Weil (1989), where the consumption-wealth ratio is constant and equal to $1-\delta$. This implies that the loglinearization parameter $\rho \equiv 1-\exp \left(\mathrm{E}\left[c_{t}-w_{t}\right]\right)$ is equal to $\delta^{3}$

Section 4.1 describes the quarterly and annual data used in this exercise, and section 4.2 reports the estimates of the VAR system. The numerical procedure used to calculate optimal asset allocations is described in detail in Appendix B. Section 4.3 discusses our findings on asset allocation.

\subsection{Data description}

Our calibration exercise is based on postwar quarterly and long-term annual data for the US stock market. The quarterly data begin in 1952:2, shortly after the FedTreasury Accord that fundamentally changed the stochastic process for nominal interest rates, and end in 1999:4. We obtain our quarterly data from the Center for Research in Security Prices (CRSP). We construct the ex post real Treasury bill rate as the difference of the log return (or yield) on a 90-day bill and log inflation, and the excess log stock return as the difference between the log return on a stock index and the log return on the 90-day bill. We use the value-weighted return, including dividends, on the NYSE, NASDAQ and AMEX markets. We construct the excess log bond return in a similar way, using the 5-year bond return from the US Treasury and

\footnotetext{
${ }^{3}$ The choice of $\psi=1$ is convenient but not necessary for our results. We have also calculated optimal portfolios for the case $\psi=0.5$ and $\delta=0.92$, and find very similar results to those reported in the paper.
} 
Inflation Series (CTI) file in CRSP. The source of the 90-day bill rate is the CRSP Fama Risk-Free Rate file.

The nominal yield on Treasury bills is the log yield on a 90-day bill. To calculate the dividend-price ratio, we first construct the dividend payout series using the valueweighted return including dividends, and the price index series associated with the value-weighted return excluding dividends. Following the standard convention in the literature, we take the dividend series to be the sum of dividend payments over the past year. The dividend-price ratio is then the log dividend less the log price index. The yield spread is the difference between the 5-year zero-coupon bond yield from the CRSP Fama-Bliss data file (the longest yield available in the file) and the bill rate.

The annual dataset covers over a century from 1890 to 1998. Its source is the data used in Grossman and Shiller (1981), updated for the recent period by Campbell (1999). ${ }^{4}$ This dataset contains data on prices and dividends on S\&P 500 stocks as well as data on inflation and short-term interest rates. The equity price index is the endof-December S\&P 500 Index, and the price index is the Producer Price Index. The short rate is the return on 6-month commercial paper bought in January and rolled over July. We use this dataset to construct time series of short-term, nominal and ex-post real interest rates, excess returns on equities, and dividend-yields. Finally, we obtain data on long-term nominal bonds from the long yield series in Shiller (1989), which we have updated using the Moody's AAA corporate bond yield average. We construct the long bond return from this series using the loglinear approximation technique described in Chapter 10 of Campbell, Lo and MacKinlay (1997):

$$
r_{n, t+1} \approx D_{n, t} y_{n, t}-\left(D_{n, t}-1\right) y_{n-1, t+1},
$$

where $n$ is bond maturity, the bond yield is written $Y_{n t}$, the $\log$ bond yield $y_{n, t}=$ $\log \left(1+Y_{n, t}\right)$, and $D_{n, t}$ is bond duration. We calculate duration at time $t$ as

$$
D_{n, t} \approx \frac{1-\left(1+Y_{n, t}\right)^{-n}}{1-\left(1+Y_{n, t}\right)^{-1}}
$$

and we set $n$ to 20 years. We also approximate $y_{n-1, t+1}$ by $y_{n, t+1}$.

\footnotetext{
${ }^{4}$ See the Data Appendix to Campbell (1999), available on the author's website.
} 


\subsection{VAR estimation}

Table 1 gives the first and second sample moments of the data. Except for the dividend-price ratio, the sample statistics are in annualized, percentage units. Mean excess log returns are adjusted by one-half their variance to account for Jensen's Inequality. For the postwar quarterly dataset, Treasury bills offer a low average real return (a mere $1.53 \%$ per year) along with low variability. Stocks have an excess return of $7.72 \%$ per year compared to $1.08 \%$ for the 5 -year bond. Although volatility is much higher for stocks than for bonds ( $16.23 \%$ vs. $5.63 \%)$, the Sharpe ratio is almost three and a half times as high for stocks as for bonds. The average Treasury bill rate and yield spread are $5.50 \%$ and $0.95 \%$, respectively. Figure 2 plots the history of the variables included in the quarterly VAR.

Covering a century of data, the annual dataset gives a different description of the relative performance of each asset. The real return on short-term nominal debt is quite volatile, due to greater volatility in both real interest rates and inflation before World War II. Stocks offer a slightly lower excess return, and yet a higher standard deviation, than the postwar quarterly data. The Depression period is largely responsible for this result. The long-term bond also performs rather poorly, giving a Sharpe ratio of only 0.10 versus a Sharpe ratio of 0.37 for stocks. The bill rate has a lower mean in the annual dataset, but the yield spread has a higher mean. Both bill rates and yield spreads have higher standard deviations in the annual dataset.

Table 2 reports the estimation results for the VAR system in the quarterly dataset (Panel A) and the annual dataset (Panel B). The top section of each panel reports coefficient estimates (with $t$-statistics in parentheses) and the $R^{2}$ statistic (with the p-value of the $F$ test of joint significance in parentheses) for each equation in the system. ${ }^{5}$ The bottom section of each panel shows the covariance structure of the innovations in VAR system. The entries above the main diagonal are correlation statistics, and the entries on the main diagonal are standard deviations multiplied by 100. All variables in the VAR are measured in natural units, so standard deviations are per quarter in panel $\mathrm{A}$ and per year in panel $\mathrm{B}$.

The first row of each panel corresponds to the real bill rate equation. The lagged

\footnotetext{
${ }^{5}$ We estimate the VAR imposing the restriction that the unconditional means of the variables implied by the VAR coefficient estimates equal their full-sample arithmetic counterparts. Standard, unconstrained least-squares fits exactly the mean of the variables in the VAR excluding the first observation. We use constrained least-squares to ensure that we fit the full-sample means.
} 
real bill rate and the lagged nominal bill rate have positive coefficients and $t$-statistics above 2 in both sample periods. The yield spread also has a positive coefficient and a $t$-statistic above 2 in the quarterly data. The rest of the variables are not significant in predicting real bill rates one period ahead.

The second row corresponds to the equation for the excess stock return. Predicting excess stock returns is difficult: This equation has the lowest $R^{2}$ in both the quarterly and the annual sample $-8.6 \%$ and $5.0 \%$, respectively. The dividend-price ratio, with a positive coefficient, is the only variable with a $t$-statistic above 2 in both samples. The coefficient on the lagged nominal short-term interest rate is also significant in the quarterly sample, and it has a negative sign in both samples. The yield spread has positive coefficients in both samples, but they are not statistically significant.

The third row is the equation for the excess bond return. In the quarterly postwar data, excess stock returns and yield spreads help predict future excess bond returns. In the long annual dataset, real Treasury bill rates also help predict future excess bond returns. The fit of the equation in the annual sample, with an $R^{2}$ of $39 \%$, is four times as large as the fit in the quarterly sample, where the $R^{2}$ is only $9.6 \%$. In part, this difference in results may reflect approximation error in our procedure for constructing annual bond returns; the possibility of such error should be kept in mind when interpreting our annual results.

The last three rows report the estimation results for the remaining state variables, each of which are fairly well described by a univariate AR(1) process. The nominal bill rate in the fourth row is predicted by the lagged nominal yield, whose coefficient is above 0.9 in both samples, implying extremely persistent dynamics. The log dividendprice ratio in the fifth row also has persistent dynamics; the lagged dividend-price ratio has a coefficient of 0.96 in the quarterly data and 0.84 in the annual data. The yield spread in the sixth row also seems to follow an $\mathrm{AR}(1)$ process, but is considerably less persistent than the other variables, especially in the quarterly sample.

The bottom section of each panel describes the covariance structure of the innovations in the VAR system. Unexpected log excess stock returns are highly negatively correlated with shocks to the log dividend-price ratio in both samples. This result is consistent with previous empirical results in Campbell (1991), Campbell and Viceira (1999), Stambaugh (1999) and others. Unexpected log excess bond returns are negatively correlated with shocks to the nominal bill rate, but positively correlated with the yield spread. This positive correlation is about $20 \%$ in the quarterly sample, and $26 \%$ in the annual sample. 
The signs of these correlations help to explain the contrasting results of recent studies that apply Monte Carlo analysis to judge the statistical evidence for predictability in excess stock and bond returns. Stock-market studies typically find that asymptotic tests overstate the evidence for predictability of excess stock returns (Hodrick 1992, Goetzmann and Jorion 1993, Nelson and Kim 1993). Bond-market studies, on the other hand, find that asymptotic procedures are actually conservative and understate the evidence for predictability of excess bond returns (Bekaert, Hodrick, and Marshall 1997). The reason for the discrepancy is that the evidence for stock market predictability comes from positive regression coefficients of stock returns on the dividend-price ratio, while the evidence for bond market predictability comes from positive regression coefficients of bond returns on the yield spread. Stambaugh (1999) shows that the small-sample bias in such regressions has the opposite sign to the sign of the correlation between innovations in returns and innovations in the predictive variable. In the stock market the log dividend-price ratio is negatively correlated with returns, leading to a positive small-sample bias which helps to explain some apparent predictability; in the bond market, on the other hand, the yield spread is positively correlated with returns, leading to a negative small-sample bias which cannot explain the positive regression coefficient found in the data.

Although finite-sample bias may well have some effect on the coefficients reported in Table 2, bias corrections are complex in multivariate systems and we do not attempt any corrections here. Instead we take the estimated VAR coefficients as given, and known by investors, and explore their implications for optimal long-term portfolios.

\subsection{Strategic allocations to stocks, bonds, and bills}

We have shown in section 3.3 that the optimal portfolio rule is linear in the vector of state variables. Thus the optimal portfolio allocation to stocks, bonds and bills changes over time. One way to characterize this rule is to examine its mean and volatility. To analyze level effects we compute the mean allocation to each asset as well as the mean hedging portfolio demand for different specifications of the vector of state variables. Specifically, we estimate a series of restricted VAR systems, in which the number of explanatory variables increases sequentially, and use them to calculate mean optimal portfolios for $\psi=1, \delta=0.92$ at an annual frequency, and $\gamma=1,2,5$ or 20 .

The first VAR system only has a constant term in each regression, corresponding to 
the case in which risk premia are constant and realized returns on all assets, including the short-term real interest rate, are i.i.d. The second system includes an intercept term, the ex-post real bill rate and log excess returns on stocks and bonds. We then add sequentially the nominal bill rate, the dividend yield and the yield spread. Thus we estimate five VAR systems in total.

Table 3 reports the results of this experiment for values of the coefficient of relative risk aversion $\gamma$ equal to 1, 2, 5 and 20, with the intertemporal elasticity of substitution $\psi=1$. Panel A considers the quarterly dataset, while Panel B considers the annual dataset. The entries in each column are mean portfolio demands in percentage points when the explanatory variables in the VAR system include the state variable in the column heading and those to the left of it. For instance, the "constant" column reports mean portfolio allocations when the explanatory variables include only a constant term, that is, when investment opportunities are constant. The right-hand "spread" column gives the case where all state variables are included in the VAR.

Table 3 reports results only for selected values of risk aversion, but we have also computed portfolio allocations for a continuum of values of risk aversion; Figure 3 plots these allocations and their myopic component using the quarterly VAR with all state variables included. In this figure the horizontal axis shows risk tolerance $1 / \gamma$ rather than risk aversion $\gamma$, both in order to display the behavior of highly conservative investors more compactly, and because myopic portfolio demands are linear in risk tolerance. Infinitely conservative investors with $1 / \gamma=0$ are plotted at the right edge of the figure, so that as the eye moves from left to right we see the effects of increasing risk aversion on asset allocation.

Table 3 enables us to analyze two effects on the level of portfolio demands. By comparing numbers within any column, we can study how total asset allocation and intertemporal hedging demand vary with risk aversion. By comparing numbers within any row, we can examine the incremental effects of the state variables on asset allocation. Here we explore the first topic and leave the second for the next section. To simplify the discussion we focus only on the allocations implied by the full VAR, shown in the right-hand column of the table.

The first set of numbers in Table 3 reports the mean portfolio allocation to stocks, bonds and bills of a logarithmic investor. For this investor, the optimal portfolio rule is purely myopic. Equation (20) evaluated at $\gamma=1$ shows that asset allocation depends only on the inverse of the variance-covariance matrix of unexpected excess returns and the mean excess return on stocks and bonds. This myopic allocation 
is long in stocks and bonds in both the quarterly dataset and the annual dataset. However, the ratio of stocks to bonds is about 1.8 in the quarterly dataset, and close to one in the annual dataset. The preference for stocks in the quarterly dataset is primarily due to the estimated large positive correlation between unexpected excess returns on stocks and bonds in the quarterly dataset. This shifts the optimal myopic allocation towards stocks - the asset with the largest Sharpe ratio. In the annual dataset the correlation between excess bond and stock returns is very low, implying that the optimal portfolio allocation to one asset is essentially independent of the optimal allocation to the other.

Conservative investors, with risk aversion $\gamma>1$, have an intertemporal hedging demand for stocks. This demand is most easily understood by looking at Figure 3, which is based on the quarterly dataset. In Figure 3, the total demand for stocks is a concave function of risk tolerance $1 / \gamma$, while the myopic portfolio demand is a linear function of $1 / \gamma^{6}{ }^{6}$ Moreover, total stock demand is always larger than myopic portfolio demand for all $1 / \gamma<1$. This implies that intertemporal hedging demand is a positive, hump-shaped function of $1 / \gamma$. We can verify this by looking at the hedging demands reported in Table 3. In both datasets, the hedging demand for stocks is always positive and exhibits a hump-shaped pattern as a function of $1 / \gamma$.

These patterns reflect the time-variation in expected stock returns, which is captured in our VAR model by the predictability of stock returns from the dividend-price ratio. Because stocks have a large positive Sharpe ratio, investors are normally long in the stock market. Hence an increase in expected stock returns represents an improvement in the investment opportunity set. Our VAR model implies that expected stock returns increase when the dividend-price ratio increases; since stocks are strongly negatively correlated with the dividend-price ratio, this means that poor stock returns are correlated with an improvement in future investment opportunities. Thus stocks can be used to hedge the variation in their own future returns, and this increases the demand for stocks by conservative investors. The effect is strongest at intermediate levels of risk aversion, because investors with $\gamma=1$ do not wish to hedge intertemporally, and extremely conservative investors have little interest in the risky investment opportunities available in the stock market.

\footnotetext{
${ }^{6}$ We can see this formally by looking at equation (20). This equation implies that myopic demand is a linear function of $1 / \gamma$ with intercept given by $-\boldsymbol{\Sigma}_{x x}^{-1} \boldsymbol{\sigma}_{1 x}$. The intercept is zero only when shocks to the real interest rate on nominal Treasury bills are uncorrelated with excess returns on all other assets, that is, when $\boldsymbol{\sigma}_{1 x}$ is zero.
} 
These results are comparable to those reported by Campbell and Viceira (2000) for a model with a single risky asset (stocks) and a single state variable (the dividendprice ratio) over a slightly shorter postwar sample period. ${ }^{7}$ Although there is slightly weaker predictability of stock returns in our longer postwar sample, which tends to reduce intertemporal hedging demand, there is also more persistence in the dividendprice ratio, which tends to increase intertemporal hedging demand. These two effects roughly cancel.

Intertemporal hedging demands are just as striking for nominal bonds. Figure 3 and Table 3 show that the intertemporal hedging demand for nominal bonds is $\mathrm{U}$ shaped in risk aversion in the quarterly dataset. It is strongly negative at intermediate coefficients of risk aversion, but turns positive for extremely conservative investors. This effect is large enough to make the total demand for nominal bonds negative for investors with intermediate risk aversion.

This pattern results from several features of bond returns in our quarterly VAR model. First, there is a positive correlation between unexpected excess stock returns and nominal bond returns in the quarterly dataset. Thus investors can offset the short-term risk implied by their large positive intertemporal hedging demand for stocks by taking short positions in long-term nominal bonds. This negative effect on bond demand is largest at intermediate levels of risk aversion because the positive intertemporal hedging demand for stocks is largest at these levels of risk aversion.

Second, the short-term nominal interest rate forecasts real interest rates positively, but excess stock returns negatively in the quarterly dataset. A high real interest rate is a good investment opportunity, but a low excess stock return is a poor investment opportunity. Thus there are opposing effects of short-term interest rates on the investment opportunity set. An investor with intermediate risk aversion is most interested in the opportunities available in the stock market, and will consider an increase in the short rate to be a deterioration in investment opportunities, but an extremely conservative investor is most interested in real interest rates and will consider an increase in the short nominal rate to be an improvement in investment opportunities. Since nominal bond returns are highly negatively correlated with movements in the short nominal interest rate, this generates negative intertemporal hedging demand by investors with intermediate risk aversion but positive intertemporal hedging demand

\footnotetext{
${ }^{7}$ Campbell and Viceira (2000) correct an estimation error in Campbell and Viceira (1999) that understated the predictability of postwar quarterly stock returns and the absolute value of the correlation between innovations to stock returns and dividend yields.
} 
by extremely conservative investors.

Third, the yield spread forecasts real interest rates and excess bond returns positively in the quarterly dataset; thus an increase in the yield spread represents an improvement in investment opportunities. Since innovations in the yield spread are positively correlated with unexpected bond returns, this reduces the intertemporal hedging demand for long-term bonds. We can see the importance of this effect in Table 3 by noting the negative shift in average bond demand that occurs when the yield spread is included in the VAR system.

Panel B of Table 3 shows that the intertemporal hedging demand for long-term nominal bonds is always positive in the annual dataset. There are several reasons for this difference in results. Bond and stock returns are uncorrelated rather than positively correlated in the annual data, so the positive intertemporal hedging demand for stocks does not reduce the demand for bonds. The nominal interest rate still predicts the real interest rate positively but does not predict excess stock returns negatively in the annual data, so an increase in the interest rate unambiguously represents an improvement in investment opportunities that can be hedged by holding bonds. Finally, the yield spread forecasts low rather than high real interest rates in the annual data. ${ }^{8}$

The contrast in results between the postwar quarterly and long-term annual data can also be understood by noting that real interest rate variation is more important in the annual dataset. Row 2 of Table 1 shows that the standard deviation of ex post real interest rates is almost six times higher in the annual dataset, while Table 2 shows that the predictability of real interest rates is only modestly lower, implying that ex ante real interest rates are much more variable in the long-term annual data. This implies that a strategy of rolling over Treasury bills is highly risky at long horizons because bills must be reinvested at unknown future real interest rates. This risk can be hedged using long-term bonds, as emphasized by Campbell and Viceira (2001). In the postwar data real interest rate variation is less important relative to other sources of risk.

\footnotetext{
${ }^{8}$ The yield spread still predicts excess bond returns positively in the annual data. By itself this would generate negative intertemporal hedging demand for bonds. A univariate model, not shown here to save space, where short-term real interest rates are constant and yield spreads forecast only excess bond returns, shows a negative intertemporal hedging demand for bonds. This negative demand is a direct result of the positive regression coefficient of future bond excess returns on yield spreads, and the positive correlation between shocks to yield spreads and unexpected bond excess returns.
} 
We turn now to the analysis of the variability of asset demands. From equation (20), we can express the optimal portfolio rule as

$$
\alpha_{i, t}=\alpha_{i, t}^{m}+\alpha_{i, t}^{h}
$$

where $i$ denotes stocks or bonds, $m$ denotes myopic and $h$ denotes hedging. Thus,

$$
\operatorname{Var}\left(\alpha_{i, t}\right)=\operatorname{Var}\left(\alpha_{i, t}^{m}\right)+\operatorname{Var}\left(\alpha_{i, t}^{h}\right)+2 \operatorname{Cov}\left(\alpha_{i, t}^{m}, \alpha_{i, t}^{h}\right)
$$

Table 4 reports this variance decomposition for the case $\gamma=5$ and $\psi=1$. Panel A refers to the quarterly sample, and panel B to the annual sample. The top rows in each panel report the contribution of $\operatorname{Var}\left(\alpha_{i, t}^{m}\right), \operatorname{Var}\left(\alpha_{i, t}^{h}\right)$ and $\operatorname{Cov}\left(\alpha_{i, t}^{m}, \alpha_{i, t}^{h}\right)$ to the total variance of the demand for each asset. The variance of the hedging component explains at most $22 \%$ of the total variation in stock and bond demand in the quarterly dataset, and $14 \%$ in the annual dataset. Thus hedging portfolio demand is much more stable than total portfolio demand. Kim and Omberg (1996) and Campbell and Viceira (1999) give an intuitive explanation for this result, showing that hedging demand can change sign only in extreme circumstances where investors have replaced their normal long positions with short positions in risky assets. To a first approximation, intertemporal hedging shifts the intercept of risky asset demand rather than the slope with respect to state variables; put another way, long-term investors should "time the market" just as aggressively as short-term investors.

Figure 4 illustrates the result graphically. The figure plots time series of total portfolio allocations based on the quarterly dataset for $\gamma=5$, along with the myopic and hedging components of total portfolio demand. For all three assets, hedging demands are considerably less volatile than myopic demands. The allocation to long-term nominal bonds has the greatest short-term volatility, despite the low predictability in bond excess returns. This can be understood by noting that the variability of myopic allocations depends positively on the predictability of returns, but negatively on their unpredictable volatility, which is relatively low for bonds. ${ }^{9}$

\footnotetext{
${ }^{9}$ In the case with only a single risky asset, the variability of the optimal myopic allocation is proportional to $R^{2} /\left(\sigma^{2}\left(1-R^{2}\right)\right)$, where $R^{2}$ is the R-squared of the predictive regression for the excess return on the asset and $\sigma^{2}$ is the variance of the unexpected excess return. Thus we should expect variable asset demand when this variance is low, even if there is only a modest degree of predictability.
} 


\subsection{Which state variables matter?}

The analysis so far has focused on the shape of asset demands and their hedging components. It is equally important to understand the effects of various state variables on the level and variability of asset demands. To analyze the level effects of state variables, we can compare average portfolio demands across rows in Table 3.

Panel A shows that there are important changes in the magnitude of hedging demands as we consider new state variables in the investor information set. In the case of stocks, hedging demand is very small when only lagged Treasury bill rates (either real or nominal) and excess returns on bonds and stocks are included in the VAR. It increases dramatically when the dividend-price ratio is introduced into the VAR as a regressor. The inclusion of the yield spread has a negligible effect on the hedging demand for stocks.

The correlation structure shown in Table 2 helps explain these results. In the full annual VAR system, there is a strong negative correlation between unexpected excess returns on stocks and shocks to the dividend-price ratio, while the magnitude of all other correlations in the table is much smaller. These correlations are not sensitive to the inclusion or exclusion of state variables in the VAR. The presence of the dividend-price ratio in the investor information set increases the hedging demand for stocks because negative shocks to the dividend-price ratio, which drive down expected returns on stocks, tend to coincide with positive realized excess returns on stocks. This negative correlation is even stronger in the quarterly dataset, which makes the pattern for hedging demands more pronounced in this dataset.

The case of bonds is more complex, particularly in the quarterly dataset. As we have noted in section 4.3, several different factors influence the demand for nominal bonds. The positive correlation of bond and stock returns in the quarterly dataset means that positive hedging demand for stocks tends to produce negative hedging demand for bonds in that dataset. In the annual dataset, by contrast, the correlation of bond and stock returns is very small, so that positive hedging demand for stocks has little effect on the hedging demand for bonds. The VAR system also includes the expost real bill rate, the nominal bill rate and the yield spread; these variables capture the complex dynamics of real interest rates, inflation and excess bond returns. In the quarterly dataset, these variables tend to create a negative intertemporal hedging demand for bonds, while in the annual dataset they create a positive hedging demand for bonds. 
We can analyze the importance of each state variable for the variability of asset demands by looking at Table 4 . The lower section of Table 4 report the contribution of each state variable to total asset demand variation $\operatorname{Var}\left(\alpha_{i, t}\right)$. For each block, the diagonal elements are the own variance components and the lower off-diagonal elements are the covariance components, normalized to sum to $100 \%$. The numbers on the main diagonals indicate that in both samples the variance of the dividend-price ratio is the dominant source of movements in stock demand, explaining about $84 \%$ of the variance of stock demand. The dividend-price ratio explains almost $28 \%$ of the variability of bond demand in the annual dataset, but less than $2 \%$ in the annual dataset. The nominal bill rate and the yield spread are the most important variables driving the variability of bond demand in the quarterly dataset, while the yield spread alone is of dominant importance for bond demand in the annual dataset.

The numbers off the main diagonals in Table 4 indicate that shifts in asset demands caused by innovations of some state variables are not independent of each other. The covariance terms are particularly important in the quarterly dataset, where shifts in stock and bond demands caused by innovations to the nominal bill rate are partially offset by shifts of opposite sign caused by contemporaneous shocks to the dividendprice ratio and the yield spread. These offsets reduce the overall variability of asset demands. In the annual dataset, covariances are much less important.

In summary, our results indicate that the most important state variable determining the mean and volatility of stock demand is the dividend yield, while variables that forecast real interest rates, inflation and excess bond returns determine the mean and volatility of bond demand. Aït-Sahalia and Brandt (2001) also find that these variables are important determinants of optimal portfolio choice. 


\section{$5 \quad$ Strategic Asset Allocation with Inflation-Indexed Bonds}

We have found that the intertemporal hedging demand for long-term bonds is negative for investors with intermediate levels of risk aversion in the quarterly postwar sample. This finding contrasts with conventional investment advice that conservative long-term investors should hold bonds to obtain a stable stream of income, disregarding short-run fluctuations in capital value. There are two possible reasons for the discrepancy between our results and conventional wisdom. First, the conventional wisdom disregards the distinction between nominal and inflation-indexed bonds. In the presence of significant inflation risk, long-term nominal bonds are not suitable assets for conservative long-term investors. Campbell and Viceira (2001) use a term structure model with time-varying real interest rates and inflation rates, but constant risk premia, and find that inflation uncertainty drastically reduces the intertemporal hedging demand for long-term nominal bonds in the postwar period. ${ }^{10}$ Second, our model has a general dynamic structure in which either stocks or bonds might be good hedges for predictable variation in stock and bond returns. Conventional investment advice may be based on the presumption that bonds are the best hedges for predictable variation in returns on all risky assets; the model of Campbell and Viceira (2001) explicitly assumes this.

To determine which of these explanations is correct, we now extend our model to include an inflation-indexed perpetuity in the menu of available assets. This requires us to construct hypothetical real bond returns, because inflation-indexed bonds were first issued by the US Treasury in 1997 and thus very little direct evidence is available about their returns. The VAR framework is well suited for this purpose, provided that we make the assumption that expected real returns on real bonds of all maturities and the expected real return on short-term nominal bills differ only by a constant. This amounts to assuming that the inflation risk premium on nominal bills is constant. We now briefly describe the construction procedure, which is adapted from the work of Campbell and Shiller (1996). Appendix C provides full details.

We first use the estimates of the coefficient matrices in the VAR to construct returns on hypothetical real perpetuities according to the procedure outlined in Ap-

\footnotetext{
${ }^{10}$ Campbell and Viceira also look at recent data since 1983, and find much smaller inflation uncertainty. We do not examine this period here as our VAR system is not sufficiently parsimonious for such a short sample period.
} 
pendix C. The procedure assumes a zero inflation risk premium. As noted in Campbell and Shiller (1996), if the inflation risk premium is not zero but constant, the procedure will miss the average level of the yield curve, but will still capture the dynamics of the curve. This is important, because intertemporal hedging demand depends sensitively on the dynamics of asset returns. With the correct dynamics in hand, we set the mean excess return of the real perpetuity to zero. We deliberately choose this value to be conservative about the appeal of this bond to a myopic investor. ${ }^{11}$ Finally, we include the imputed excess return on real perpetuities in two new VAR systems. In the first VAR we replace the excess return on nominal bonds with the excess return on real perpetuities, while in the second system we include both variables. Appendix D shows the estimation results.

Table 5 reports the resulting mean asset demands for values of $\gamma$ equal to 1,2 , 5, 20 and 2000 and $\psi=1$ in the quarterly dataset. We include the case $\gamma=2000$ because we want to study asset demand for infinitely risk averse investors, which we proxy using this large value of $\gamma$. We also report mean asset allocations under constant investment opportunities. Appendix D shows results for the annual dataset. Figures 5 and 6 plot the allocations implied by the full quarterly VAR for a continuum of values of $\gamma$.

We start by looking at the optimal portfolio of a myopic logarithmic investor in Table 5. This investor should hold long positions in both stocks and the inflationindexed perpetuity, and a short position in long-term nominal bonds when these assets are available. The positive holdings of stocks result from the positive expected excess return on stocks. The positive holdings of the real perpetuity result from a large negative correlation (shown in Appendix D) between excess returns on stocks and on the real perpetuity, which makes this asset good to hedge long positions in stocks. The myopic demand for long-term nominal bonds is negative because there is a large positive correlation between nominal bond returns and stock returns, and between nominal bond returns and real consol returns. The first correlation makes it optimal to use a short position in nominal bonds to offset a long position in stocks.. The second correlation has the effect of strengthening the long and short positions on the

\footnotetext{
${ }^{11}$ In our model with multiple risky assets the assumption of a zero risk premium on the real perpetuity does not necessarily imply a zero mean myopic allocation to this bond. The myopic mean allocation can differ from zero if unexpected excess returns on the real perpetuity are correlated with unexpected excess returns on other assets. We have also considered a positive mean excess return on the perpetuity. In particular, we have considered a mean excess return such that the Sharpe ratio of the real perpetuity is equal to the Sharpe ratio of nominal bonds. This choice increases the myopic demand for the perpetuity but has only modest effects on intertemporal hedging demands.
} 
real perpetuity and nominal bonds determined by the correlations of these assets with stock returns. By contrast, the correlation structure of excess returns in the annual sample (shown in Appendix D) is markedly different: The excess return on stocks is negatively correlated with the excess return on the real perpetuity, and almost uncorrelated with the excess return on nominal bonds, while the excess returns on the real perpetuity and nominal bonds are still positively correlated. This correlation structure results in long positions in stocks and the nominal bond, and a short position in the real perpetuity.

We can learn about the myopic allocations of non-logarithmic investors by looking at the allocations under constant investment opportunities shown in the "constant" column in Table 5. Investors with $\gamma>1$ have a myopic demand for real perpetuities that is larger than $1 / \gamma$ times the optimal allocation of the logarithmic investor. This is driven by the fact that the short-term bill is risky in real terms, so the portfolio with the smallest short-term risk is a combination of the short-term bill and the real perpetuity, with a short position in nominal bonds when they are available. The myopic portfolio approaches this "minimum short-term variance" portfolio as risk aversion $\gamma$ increases. ${ }^{12}$

The "full VAR" column in Table 5 shows total portfolio demands with timevarying investment opportunities. The total portfolio demand for the real perpetuity is increasing in risk aversion, approaching $100 \%$ of the portfolio as the investor becomes infinitely conservative. By contrast, the total portfolio demand for stocks, the nominal bill and the nominal bond are decreasing in $\gamma$, approaching $0 \%$ as the investor becomes infinitely conservative. Thus inflation-indexed bonds drive out cash from the portfolios of conservative investors. In their model with time-varying interest rates but constant risk premia, Campbell and Viceira (2001) show that an infinitely risk-averse long-horizon investor with zero elasticity of intertemporal substitution would choose to be fully invested in a real perpetuity. ${ }^{13}$ Table 5 shows that this result extends to a world in which both interest rates and expected excess returns

\footnotetext{
${ }^{12}$ Equation (20) shows that the myopic demand of non-logarithmic investors is not proportional to $1 / \gamma$; instead it is a linear function of $1 / \gamma$ whose intercept depends on the covariance between shocks to the real interest rate on nominal bills and unexpected excess returns on all other assets $\left(\boldsymbol{\sigma}_{1 x}\right)$. Appendix D shows that the correlation between shocks to the real interest rate on nominal bills and unexpected excess returns on the real consol bond is negative and large (about $-46 \%$ in the quarterly dataset, and $-85 \%$ in the annual dataset), which in turn translates into a substantial, positive intercept for the real perpetuity.

${ }^{13}$ Wachter (2000) has extended this result to more general models with complete markets. See also Brennan and Xia (2001).
} 
are time-varying. ${ }^{14}$

In this model the intertemporal hedging demand for long-term nominal bonds is negative for all levels of risk aversion; it does not turn positive for extremely conservative investors as in the model where only nominal bonds are available. We have noted that the dynamic properties of bond returns imply a multiplicity of hedging roles for these assets. The presence of inflation-indexed bonds in the menu of assets allows investors to use long positions in inflation-indexed bonds to hedge real interest rate risk, and short positions in nominal bonds to hedge their long positions in stocks and the risk of time-variation in expected excess bond returns.

\subsection{The utility benefits of inflation-indexation}

Another way to judge the importance of an asset class is to compare the utility of an investor who has access to that asset class, with the utility of an investor who does not. In Table 6 we carry out this comparison. The table shows the mean value function for values of $\gamma$ equal to $1,2,5,20$ and 2000 and $\psi=1$ in the quarterly dataset. The value function is normalized so that a doubling from one asset menu to another implies that an investor would require twice as much wealth to obtain the same utility with the worse asset menu than with the better one. We report results for a base case in which only nominal bills and stocks are available, and for the three asset menus we have discussed earlier in the paper: nominal bills, long-term nominal bonds, and stocks; nominal bills, real perpetuities, and stocks; and nominal bills, long-term nominal bonds, real perpetuities, and stocks. To make these asset menus fully comparable, we compute value functions for all of them based on the same VAR, which includes the real perpetuity as an additional state variable. Thus the value function numbers for bills, nominal bonds, and stocks do not correspond exactly to the mean asset allocations reported in Table 3 -although the numbers are extremely close. Appendix D shows results for the annual dataset.

A comparison of the top panel of Table 6 , in which no long-term bonds are available, with the lower panels shows that long-term bonds generate large welfare gains

\footnotetext{
${ }^{14}$ Note that the allocation to the real consol bond for an investor with an extremely large coefficient of relative risk aversion does not equal $100 \%$ exactly. This is due primarily to the fact that the investor we consider in Table 5 has unit, not zero, elasticity of intertemporal substitution. There is also a small effect caused by the fact that the VAR system in Table 5 does not exactly capture the information set we used to construct the long-term real bond yield.
} 
for all investors. Aggressive investors gain by having access to risky nominal bonds with positive expected excess returns, and by the ability to use bonds to hedge long positions in stocks. Conservative investors gain by having access to long-term instruments that hedge the risk of variation in real interest rates. A comparison of the second panel of Table 6 with the bottom panel shows that the addition of real perpetuities to an asset menu that already includes nominal bonds also creates large gains for all investors by improving static and intertemporal hedging opportunities. A comparison of the second panel of Table 6 with the third panel shows that extremely conservative investors would prefer to have real perpetuities available instead of nominal bonds; however aggressive and moderately conservative investors prefer to be able to invest in nominal bonds because of the risk premium they offer and their ability to hedge stock positions. In interpreting this result, it is important to recall that we have assumed that real perpetuities offer no risk premium. Also, results are somewhat more favorable for real perpetuities in the annual dataset, where real interest rate risk is more important. In that dataset even moderately conservative investors prefer to have real perpetuities instead of nominal bonds in the asset menu.

\section{Conclusion}

This paper has explored the implications for long-term investors of the empirical evidence on the predictability of asset returns. Dividend yields, interest rates, yield spreads, inflation, and other variables that predict asset returns in previous empirical research have substantial effects on optimal portfolio allocations among bills, stocks, and nominal and inflation-indexed bonds. These effects are strategic, working through intertemporal hedging demands, rather than merely tactical effects on myopic optimal portfolios.

Strategic effects on asset demands arise because shocks to the forecasting variables are correlated with the unexpected returns on stocks and bonds. The correlation is strongest for the dividend-price ratio, and thus we find that this variable is the most important determinant of both the level and the variability of optimal portfolio demands. Predictability of stock returns from the dividend-price ratio tilts the optimal portfolio holdings of moderately conservative investors towards stocks and away from bonds and cash.

We find that the intertemporal hedging demand for long-term nominal bonds is 
negative for intermediate levels of risk aversion in postwar quarterly data, and positive in long-term annual data covering the whole 20th Century. These contrasting results reflect the importance of real interest rate risk in each period. In the annual dataset real interest rates are much more variable than in the quarterly postwar dataset, thus increasing the desire of conservative investors to use bonds to hedge real interest rate risk. Also, nominal bonds have been positively correlated with stocks in the postwar period, encouraging investors to use short bond positions to hedge long stock positions; this correlation is much weaker in the long-term annual dataset. When we add inflation-indexed bonds to the asset menu, we find that conservative investors use these assets to hedge real interest rate risk; extremely conservative investors should hold most of their wealth in inflation-indexed bonds when these assets are available.

Our research has several limitations that should be kept in mind when interpreting the results. First, we consider a long-term investor who has financial wealth but no labor income. We hope to remedy this serious omission in future work by extending the approach of Viceira (2001). Second, we do not impose borrowing or short-sales constraints; to do so would take us outside the tractable linear-quadratic approximate framework and would require a fully numerical solution method of the sort used by Brennan, Schwartz, and Lagnado $(1997,1999)$ and Lynch (2001). Third, our solutions are approximate for investors with elasticity of intertemporal substitution not equal to one. Campbell, Cocco, Gomes, Maenhout, and Viceira (1998) have checked the accuracy of the approximation in the simpler model of Campbell and Viceira (1999) with only one risky asset and one state variable, and have explored the effects of portfolio constraints in that context, but further work is needed within the richer dynamic framework used here. Fourth, we ignore the differential tax treatment of interest or dividend income and capital gains. Dammon, Spatt, and Zhang (2001) have recently argued that tax effects can be particularly important for long-term investors. Fifth, we assume that a VAR system, estimated without corrections for small-sample biases and without the use of Bayesian priors, is a reasonable description of the dynamic behavior of stock and bond returns. Finally, we assume that investors know all the parameters of the model. We have found that these parameters, including not only the means and covariances of asset returns but also the parameters governing the dynamics of asset returns and state variables, can have enormous effects on optimal portfolio demands. Given this, it is not surprising that parameter uncertainty and learning can have a large effect on optimal long-term investment strategies as shown by Barberis (2000), Brennan (1998), Xia (2001), and others. A challenging task for future research will be to integrate all these effects into a single empirically implementable framework. 


\section{References}

Aït-Sahalia, Yacine and Michael Brandt, 2001, "Variable Selection for Portfolio Choice", Journal of Finance 56, 1297-1351.

Balduzzi, Perluigi and Anthony Lynch, 1999, "Transaction Costs and Predictability: Some Utility Cost Calculations", Journal of Financial Economics 52, 47-78.

Barberis, Nicholas C., 2000, "Investing for the Long Run When Returns Are Predictable", Journal of Finance 55, 225-264.

Bekaert, Geert, Robert J. Hodrick, and David A. Marshall, 1997, "On Biases in Tests of the Expectations Hypothesis of the Term Structure of Interest Rates", Journal of Financial Economics 44, 309-348.

Brandt, Michael, 1999, "Estimating Portfolio and Consumption Choice: A Conditional Euler Equations Approach", Journal of Finance 54, 1609-1645.

Brennan, Michael J., 1998, "The Role of Learning in Dynamic Portfolio Decisions", European Finance Review 1, 295-306.

Brennan, Michael J., Eduardo S. Schwartz, and Ronald Lagnado, 1997, "Strategic Asset Allocation", Journal of Economic Dynamics and Control 21, 1377-1403.

Brennan, Michael J., Eduardo S. Schwartz, and Ronald Lagnado, 1999, "The Use of Treasury Bill Futures in Strategic Asset Allocation Programs", in William T. Ziemba and John M. Mulvey eds. World Wide Asset and Liability Modeling, Cambridge University Press, 205-228.

Brennan, Michael J. and Y. Xia, 2001, "Dynamic Asset Allocation Under Inflation", forthcoming Journal of Finance.

Campbell, John Y., 1987, "Stock Returns and the Term Structure", Journal of Financial Economics 18, 373-399.

Campbell, John Y., 1991, "A Variance Decomposition for Stock Returns", Economic Journal 101, 157-179.

Campbell, John Y., 1993, "Intertemporal Asset Pricing without Consumption Data", American Economic Review 83, 487-512. 
Campbell, John Y., 1996, "Understanding Risk and Return", Journal of Political Economy 104, 298-345.

Campbell, John Y., 1999, "Asset Prices, Consumption, and the Business Cycle", in John Taylor and Michael Woodford eds. Handbook of Macroeconomics, NorthHolland, Amsterdam.

Campbell, John Y., Joao Cocco, Francisco Gomes, Pascal Maenhout, and Luis Viceira, 2001, "Stock Market Mean Reversion and the Optimal Equity Allocation of a Long-Lived Investor", forthcoming European Finance Review.

Campbell, John Y., Andrew W. Lo and A. Craig MacKinlay, 1997, The Econometrics of Financial Markets, Princeton University Press, Princeton, NJ.

Campbell, John Y. and Hyeng Keun Koo, 1997, "A Comparison of Numerical and Analytical Approximate Solutions to an Intertemporal Consumption Choice Problem", Journal of Economic Dynamics and Control 21, 273-295.

Campbell, John Y. and Robert J. Shiller, 1988, "The Dividend-Price Ratio and Expectations of Future Dividends and Discount Factors", Review of Financial Studies 1, 195-228.

Campbell, John Y. and Robert J. Shiller, 1991, "Yield Spreads and Interest Rates: A Bird's Eye View", Review of Economic Studies 58, 495-514.

Campbell, John Y. and Robert J. Shiller, 1996, "A Scorecard for Indexed Government Debt", in Ben S. Bernanke and Julio Rotemberg eds. National Bureau of Economic Research Macroeconomics Annual 11:155-197.

Campbell, John Y. and Luis M. Viceira, 1999, "Consumption and Portfolio Decisions when Expected Returns are Time Varying", Quarterly Journal of Economics 114, 433-495.

Campbell, John Y. and Luis M. Viceira, 2000, "Consumption and Portfolio Decisions when Expected Returns are Time Varying: Erratum", unpublished paper, Harvard University, available on the authors' websites.

Campbell, John Y. and Luis M. Viceira, 2001, "Who Should Buy Long-Term Bonds?", American Economic Review 91, 99-127.

Canner, Niko, N. Gregory Mankiw, and David N. Weil, 1997, "An Asset Allocation Puzzle", American Economic Review 87, 181-191. 
Chacko, George and Luis Viceira, 1999, "Dynamic Consumption and Portfolio Choice with Stochastic Volatility in Incomplete Markets", NBER Working Paper 7377, National Bureau of Economic Research, Cambridge, MA.

Cocco, Joao, Francisco Gomes, and Pascal Maenhout, 1998, "Consumption and Portfolio Choice over the Life Cycle", unpublished paper, Harvard University.

Cox, John C. and Chi-fu Huang, "Optimal Consumption and Portfolio Policies when Asset Prices Follow a Diffusion Process", Journal of Economic Theory 39, 3383.

Dammon, Robert M., Chester S. Spatt, and Harold H. Zhang, 2001, "Optimal Consumption and Investment with Capital Gains Taxes", Review of Financial Studies 14, 583-616.

Epstein, Lawrence and Stanley Zin, 1989, "Substitution, Risk Aversion, and the Temporal Behavior of Consumption and Asset Returns: A Theoretical Framework", Econometrica 57, 937-69.

Epstein, Lawrence and Stanley Zin, 1991, "Substitution, Risk Aversion, and the Temporal Behavior of Consumption and Asset Returns: An Empirical Investigation", Journal of Political Economy 99, 263-286.

Fama, Eugene, "The Information in the Term Structure", Journal of Financial Economics 13, 509-528.

Fama, Eugene and Kenneth French, 1988a, "Dividend Yields and Expected Stock Returns", Journal of Financial Economics 22, 3-27.

Fama, Eugene and Kenneth French, 1988b, "Permanent and Temporary Components of Stock Prices", Journal of Political Economy 96, 246-273.

Fama, Eugene and Kenneth French, 1989, "Business Conditions and Expected Returns on Stocks and Bonds", Journal of Financial Economics 25, 23-49.

Fama, Eugene and G. William Schwert, 1977, "Asset Returns and Inflation”, Journal of Financial Economics 5, 115-146.

Giovannini, Alberto and Philippe Weil, 1989, "Risk Aversion and Intertemporal Substitution in the Capital Asset Pricing Model", NBER Working Paper 2824, National Bureau of Economic Research, Cambridge, MA. 
Glosten, Lawrence R., Ravi Jagannathan, and David Runkle, 1993, "On the Relation Between the Expected Value and the Volatility of the Nominal Excess Return on Stocks", Journal of Finance 48, 1779-1801.

Goetzmann, William N. and Philippe Jorion, 1993, "Testing the Predictive Power of Dividend Yields", Journal of Finance 48, 663-679.

Hansen, Lars P. and Ravi Jagannathan, 1991, "Restrictions on Intertemporal Marginal Rates of Substitution Implied by Asset Returns", Journal of Political Economy 99, 225-262.

Harvey, Campbell, 1989, "Time-Varying Conditional Covariances in Tests of Asset Pricing Models", Journal of Financial Economics 22, 305-334.

Harvey, Campbell, 1991, "The World Price of Covariance Risk", Journal of Finance $46,111-157$.

Hodrick, Robert J., 1992, "Dividend Yields and Expected Stock Returns: Alternative Procedures for Inference and Measurement", Review of Financial Studies 5, 357-386.

Kandel, Shmuel, and Robert Stamburgh, 1987, "Long Horizon Returns and Short Horizon Models", CRSP Working Paper No.222, University of Chicago.

Kim, Tong Suk and Edward Omberg, 1996, "Dynamic Nonmyopic Portfolio Behavior", Review of Financial Studies 9, 141-161.

Liu, Jun, 1998, "Portfolio Choice in Stochastic Environments", unpublished paper, Stanford University.

Lynch, Anthony W., 2001, "Portfolio Choice and Equity Characteristics: Characterizing the Hedging Demands Induced by Return Predictability", Journal of Financial Economics 62, 67-130..

Markowitz, Harry, 1952, "Portfolio Selection", Journal of Finance 7, 77-91.

Merton, Robert C., 1969, "Lifetime Portfolio Selection Under Uncertainty: The Continuous Time Case", Review of Economics and Statistics 51, 247-257.

Merton, Robert C., 1971, "Optimum Consumption and Portfolio Rules in a ContinuousTime Model", Journal of Economic Theory 3, 373-413. 
Merton, Robert C., 1973, "An Intertemporal Capital Asset Pricing Model", Econometrica 41, 867-87.

Merton, Robert C., 1990, Continuous Time Finance, Basil Blackwell, Cambridge, MA.

Muirhead, Robb J., 1982, Aspects of Multivariate Statistical Theory, John Wiley \& Sons, Inc., New York.

Nelson, Charles R. and Myung J. Kim, 1993, "Predictable Stock Returns: The Role of Small Sample Bias", Journal of Finance 48, 641-661.

Poterba, James M. and Lawrence H. Summers, 1988, "Mean Reversion in Stock Returns: Evidence and Implications", Journal of Financial Economics 22, 2760.

Restoy, Fernando, 1992, "Optimal Portfolio Policies Under Time-Dependent Returns", Bank of Spain Working Paper 9207, Bank of Spain, Madrid, Spain.

Samuelson, Paul A., 1969, "Lifetime Portfolio Selection by Dynamic Stochastic Programming", Review of Economics and Statistics 51, 239-246.

Schroder, Mark and Costis Skiadas, 1999, "Optimal Consumption and Portfolio Selection with Stochastic Differential Utility", Journal of Economic Theory 89, $68-126$.

Shiller, Robert J., John Y. Campbell, and Kermit L. Schoenholtz, 1983, "Forward Rates and Future Policy: Interpreting the Term Structure of Interest Rates", Brookings Papers on Economic Activity 1, 173-217.

Siegel, Jeremy, 1998, Stocks for the Long Run, 2nd ed., McGraw-Hill.

Stambaugh, Robert F., 1999, "Predictive Regressions", Journal of Financial Economics 54, 375-421.

Viceira, Luis M., 2001, "Optimal Portfolio Choice for Long-Horizon Investors with Nontradable Labor Income", Journal of Finance 56, 433-470.

Wachter, Jessica, 2000, "Risk Aversion and Allocation to Long-Term Bonds", Chapter 2 in Essays in Financial Economics, $\mathrm{PhD}$ dissertation, Harvard University.. 
Wachter, Jessica, 2002, "Portfolio and Consumption Decisions Under Mean-Reverting Returns: An Exact Solution for Complete Markets", forthcoming Journal of Financial and Quantitative Analysis.

Xia, Yihong, 2001, "Learning About Predictability: The Effects of Parameter Uncertainty on Dynamic Asset Allocation", Journal of Finance 56, 205-246. 
TABLE 1

\section{Sample Statistics}

\begin{tabular}{|c|c|c|c|}
\hline & Sample Moment & 1952.Q2 - 1999.Q4 & $1890-1998$ \\
\hline (1) & $E\left[r_{1, t}^{\$}-\pi_{t}\right]+\sigma^{2}\left(r_{1, t}^{\$}-\pi_{t}\right) / 2$ & 1.528 & 2.101 \\
\hline (2) & $\sigma\left(r_{1, t}^{\$}-\pi_{t}\right)$ & 1.354 & 8.806 \\
\hline$(3)$ & $E\left[r_{e, t}^{\$}-r_{1, t}^{\$}\right]+\sigma^{2}\left(r_{e, t}^{\$}-r_{1, t}^{\$}\right) / 2$ & 7.719 & 6.797 \\
\hline (4) & $\sigma\left(r_{e, t}^{\$}-r_{1, t}^{\$}\right)$ & 16.231 & 18.192 \\
\hline$(5)$ & $S R=(3) /(4)$ & 0.476 & 0.374 \\
\hline (6) & $E\left[r_{n, t}^{\$}-r_{1, t}^{\$}\right]+\sigma^{2}\left(r_{n, t}^{\$}-r_{1, t}^{\$}\right) / 2$ & 1.079 & 0.674 \\
\hline (7) & $\sigma\left(r_{n, t}^{\Phi}-r_{1, t}^{\Phi}\right)$ & 5.631 & 6.543 \\
\hline (8) & $S R=(6) /(7)$ & 0.192 & 0.103 \\
\hline (9) & $E\left[y_{t}^{\$}\right]$ & 5.501 & 4.361 \\
\hline (10) & $\sigma\left(y_{t}^{\$}\right)$ & 1.413 & 2.597 \\
\hline (11) & $E\left[d_{t}-p_{t}\right]$ & -3.420 & -3.101 \\
\hline$(12)$ & $\sigma\left(d_{t}-p_{t}\right)$ & 0.305 & 0.304 \\
\hline$(13)$ & $E\left[y_{n, t}^{\$}-y_{1, t}^{\$}\right]$ & 0.951 & 0.902 \\
\hline (14) & $\sigma\left(y_{n, t}^{\$}-y_{1, t}^{\$}\right)$ & 0.507 & 1.450 \\
\hline
\end{tabular}

Note: $r_{1, t}^{\$}=\log$ return on T-bills, $\pi_{t}=\log$ inflation rate, $r_{e, t}^{\$}=\log$ return on equities, $r_{n, t}^{\$}=\log$ return on nominal bond, $(d-p)_{t}=\log$ dividend-price ratio, $r b_{t}=$ relative bill rate, $y_{n, t}^{\$}=\log$ yield on the nominal bond, and $y_{1, t}^{\$}$ is the short yield. The bond is a 5 -year nominal bond in the quarterly dataset and a 20-year for the annual dataset. 
TABLE 2

VAR Estimation Results

\begin{tabular}{|c|c|c|c|c|c|c|c|}
\hline \multicolumn{8}{|c|}{ A: Quarterly Sample (1952.Q2 - 1999.Q4) } \\
\hline $\begin{array}{c}\text { Dependent } \\
\text { Variable }\end{array}$ & $\begin{array}{c}r t b_{t} \\
(t)\end{array}$ & $\begin{array}{l}x r_{t} \\
(t)\end{array}$ & $\begin{array}{l}x b_{t} \\
(t)\end{array}$ & $\begin{array}{l}y_{t} \\
(t)\end{array}$ & $\begin{array}{c}(d-p)_{t} \\
(t)\end{array}$ & $\begin{array}{l}s p r_{t} \\
(t)\end{array}$ & $\begin{array}{l}R^{2} \\
(p)\end{array}$ \\
\hline \multicolumn{8}{|c|}{ VAR Estimation Results } \\
\hline$r t b_{t+1}$ & $\begin{array}{c}0.444 \\
(6.557)\end{array}$ & $\begin{array}{c}0.005 \\
(0.837)\end{array}$ & $\begin{array}{c}-0.012 \\
(-0.630)\end{array}$ & $\begin{array}{c}0.255 \\
(3.374)\end{array}$ & $\begin{array}{c}-0.001 \\
(-0.975)\end{array}$ & $\begin{array}{c}0.455 \\
(2.414)\end{array}$ & $\begin{array}{c}0.340 \\
(0.000)\end{array}$ \\
\hline$x r_{t+1}$ & $\begin{array}{c}0.639 \\
(0.644)\end{array}$ & $\begin{array}{c}0.021 \\
(0.257)\end{array}$ & $\begin{array}{c}0.428 \\
(1.729)\end{array}$ & $\begin{array}{c}-2.108 \\
(-2.357)\end{array}$ & $\begin{array}{c}0.047 \\
(2.213)\end{array}$ & $\begin{array}{c}0.408 \\
(0.160)\end{array}$ & $\begin{array}{c}0.086 \\
(0.006)\end{array}$ \\
\hline$x b_{t+1}$ & $\begin{array}{c}0.047 \\
(0.143)\end{array}$ & $\begin{array}{c}-0.055 \\
(-2.728)\end{array}$ & $\begin{array}{c}-0.088 \\
(-0.779)\end{array}$ & $\begin{array}{c}0.355 \\
(0.816)\end{array}$ & $\begin{array}{c}0.002 \\
(0.320)\end{array}$ & $\begin{array}{c}3.068 \\
(2.768)\end{array}$ & $\begin{array}{c}0.096 \\
(0.003)\end{array}$ \\
\hline$y_{t+1}$ & $\begin{array}{c}-0.008 \\
(-0.200)\end{array}$ & $\begin{array}{c}0.004 \\
(1.808)\end{array}$ & $\begin{array}{c}0.004 \\
(0.341)\end{array}$ & $\begin{array}{c}0.952 \\
(19.467)\end{array}$ & $\begin{array}{c}-0.000 \\
(-0.116)\end{array}$ & $\begin{array}{c}0.115 \\
(1.075)\end{array}$ & $\begin{array}{c}0.868 \\
(0.000)\end{array}$ \\
\hline$(d-p)_{t+1}$ & $\begin{array}{c}-0.848 \\
(-0.820)\end{array}$ & $\begin{array}{c}-0.020 \\
(-0.222)\end{array}$ & $\begin{array}{c}-0.402 \\
(-1.513)\end{array}$ & $\begin{array}{c}1.412 \\
(1.508)\end{array}$ & $\begin{array}{c}0.963 \\
(44.001)\end{array}$ & $\begin{array}{c}-1.114 \\
(-0.425)\end{array}$ & $\begin{array}{c}0.932 \\
(0.000)\end{array}$ \\
\hline$s p r_{t+1}$ & $\begin{array}{c}-0.000 \\
(-0.004)\end{array}$ & $\begin{array}{c}-0.001 \\
(-0.329)\end{array}$ & $\begin{array}{c}0.002 \\
(0.270)\end{array}$ & $\begin{array}{c}0.026 \\
(0.857)\end{array}$ & $\begin{array}{l}-0.000 \\
(-0.254)\end{array}$ & $\begin{array}{c}0.747 \\
(10.897)\end{array}$ & $\begin{array}{c}0.539 \\
(0.000)\end{array}$ \\
\hline
\end{tabular}

Cross-Correlation of Residuals

$\begin{array}{llllccc} & r t b & x r & x b & y & (d-p) & s p r \\ r t b & 0.550 & 0.239 & 0.393 & -0.389 & -0.238 & 0.186 \\ x r & - & 7.752 & 0.229 & -0.171 & -0.981 & 0.026 \\ x b & - & - & 2.674 & -0.765 & -0.246 & 0.198 \\ y & - & - & - & 0.255 & 0.202 & -0.777 \\ (d-p) & - & - & - & - & 7.932 & -0.058 \\ s p r & - & - & - & - & - & 0.172\end{array}$

Note: $r t b_{t}=$ ex post real T-Bill rate, $x r_{t}=$ excess stock return, $x b_{t}=$ excess bond return, $(d-p)_{t}=$ $\log$ dividend-price ratio, $y_{t}=$ nominal T-bill yield, $s p r_{t}=$ yield spread. The bond is a 5 -year nominal bond in the quarterly dataset and a 20-year for the annual dataset. 
TABLE 2 (ctd.)

VAR Estimation Results

\begin{tabular}{cccccccc}
\hline \multicolumn{7}{c}{ B: Annual Sample } & $(\mathbf{1 8 9 0}-\mathbf{1 9 9 8})$ \\
\hline $\begin{array}{c}\text { Dependent } \\
\text { Variable }\end{array}$ & $r t b_{t}$ & $x r_{t}$ & $x b_{t}$ & $y_{t}$ & $(d-p)_{t}$ & $s p r_{t}$ & $R^{2}$ \\
$(t)$ & $(t)$ & $(t)$ & $(t)$ & $(t)$ & $(t)$ & $(p)$ \\
\hline VAR Estimation Results & & & & & \\
$r t b_{t+1}$ & 0.303 & -0.052 & 0.122 & 0.701 & -0.004 & -0.776 & 0.240 \\
& $(2.434)$ & $(-1.314)$ & $(0.902)$ & $(2.365)$ & $(-0.146)$ & $(-1.242)$ & $(0.000)$ \\
$x r_{t+1}$ & 0.116 & 0.075 & -0.091 & -0.074 & 0.131 & 1.291 & 0.050 \\
& $(0.438)$ & $(0.607)$ & $(-0.305)$ & $(-0.105)$ & $(2.320)$ & $(0.957)$ & $(0.399)$ \\
$x b_{t+1}$ & 0.200 & 0.106 & -0.197 & -0.112 & 0.012 & 2.628 & 0.392 \\
& $(3.072)$ & $(2.990)$ & $(-1.502)$ & $(-0.319)$ & $(0.614)$ & $(5.289)$ & $(0.000)$ \\
$y_{t+1}$ & -0.042 & -0.012 & 0.037 & 0.921 & -0.005 & -0.017 & 0.776 \\
& $(-1.922)$ & $(-1.784)$ & $(1.318)$ & $(12.307)$ & $(-1.119)$ & $(-0.136)$ & $(0.000)$ \\
$(d-p)_{t+1}$ & -0.567 & -0.124 & 0.357 & -0.597 & 0.842 & -1.662 & 0.721 \\
& $(-2.272)$ & $(-1.146)$ & $(1.115)$ & $(-0.941)$ & $(13.362)$ & $(-1.194)$ & $(0.000)$ \\
$s p r_{t+1}$ & 0.020 & 0.002 & -0.013 & 0.085 & 0.004 & 0.820 & 0.540 \\
& $(1.118)$ & $(0.409)$ & $(-0.667)$ & $(1.625)$ & $(1.153)$ & $(8.900)$ & $(0.000)$
\end{tabular}

\section{Cross-Correlation of Residuals}

\begin{tabular}{llllrrr} 
& $r t b$ & $x r$ & $x b$ & $y$ & $(d-p)$ & \multicolumn{1}{c}{$s p r$} \\
$r t b$ & 7.592 & -0.167 & -0.020 & 0.114 & 0.100 & -0.155 \\
$x r$ & - & 17.498 & -0.020 & -0.135 & -0.725 & 0.186 \\
$x b$ & - & - & 5.102 & -0.650 & -0.055 & 0.264 \\
$y$ & - & - & - & 1.228 & 0.179 & -0.894 \\
$(d-p)$ & - & - & - & - & 16.067 & -0.170 \\
$s p r$ & - & - & - & - & - & 0.978
\end{tabular}

Note: $r t b_{t}=$ ex post real T-Bill rate, $x r_{t}=$ excess stock return, $x b_{t}=$ excess bond return, $(d-p)_{t}=$ $\log$ dividend-price ratio, $y_{t}=$ nominal T-bill yield, $s p r_{t}=$ yield spread. The bond is a 5 -year nominal bond in the quarterly dataset and a 20 -year for the annual dataset. 
TABLE 3

Mean Asset Demands ( $\psi=1$ Case)

\begin{tabular}{|c|c|c|c|c|c|c|}
\hline \multicolumn{7}{|c|}{ A: Quarterly Sample (1952.Q2 - 1999.Q4) } \\
\hline & State Variables: & Constant & $A R_{t}$ & $y_{t}$ & $(d-p)_{t}$ & $\operatorname{spr}_{t}$ \\
\hline \multicolumn{7}{|c|}{$\gamma=1, \psi=1, \rho=0.92^{1 / 4}$} \\
\hline \multirow[t]{2}{*}{ Stock } & Total Demand & 272.77 & 292.42 & 296.33 & 303.41 & 302.79 \\
\hline & Hedging Demand & 0.00 & 0.00 & 0.00 & 0.00 & 0.00 \\
\hline \multirow[t]{2}{*}{ Bond } & Total Demand & 172.93 & 162.73 & 160.07 & 160.67 & 171.01 \\
\hline & Hedging Demand & 0.00 & 0.00 & 0.00 & 0.00 & 0.00 \\
\hline \multirow[t]{2}{*}{ Cash } & Total Demand & -345.70 & -355.15 & -356.40 & -364.08 & -373.80 \\
\hline & Hedging Demand & 0.00 & 0.00 & 0.00 & 0.00 & 0.00 \\
\hline \multicolumn{7}{|c|}{$\gamma=2, \psi=1, \rho=0.92^{1 / 4}$} \\
\hline \multirow[t]{2}{*}{ Stock } & Total Demand & 135.52 & 146.02 & 149.62 & 246.07 & 246.61 \\
\hline & Hedging Demand & 0.00 & 0.20 & 1.95 & 94.91 & 95.77 \\
\hline \multirow[t]{2}{*}{ Bond } & Total Demand & 82.13 & 33.53 & -7.22 & 6.25 & -8.17 \\
\hline & Hedging Demand & 0.00 & -43.86 & -83.35 & -70.18 & -90.00 \\
\hline \multirow[t]{2}{*}{ Cash } & Total Demand & -117.65 & -79.55 & -42.39 & -152.32 & -138.44 \\
\hline & Hedging Demand & 0.00 & 43.66 & 81.41 & -24.73 & -5.77 \\
\hline \multicolumn{7}{|c|}{$\gamma=5, \psi=1, \rho=0.92^{1 / 4}$} \\
\hline \multirow[t]{2}{*}{ Stock } & Total Demand & 53.17 & 56.52 & 57.40 & 157.64 & 160.51 \\
\hline & Hedging Demand & 0.00 & -1.34 & -1.08 & 97.83 & 100.84 \\
\hline \multirow[t]{2}{*}{ Bond } & Total Demand & 27.65 & -3.94 & -15.70 & -43.70 & -94.24 \\
\hline & Hedging Demand & 0.00 & -30.13 & -41.47 & -69.59 & -122.57 \\
\hline \multirow[t]{2}{*}{ Cash } & Total Demand & 19.18 & 47.42 & 58.30 & -13.94 & 33.73 \\
\hline & Hedging Demand & 0.00 & 31.47 & 42.55 & -28.24 & 21.72 \\
\hline \multicolumn{7}{|c|}{$\gamma=20, \psi=1, \rho=0.92^{1 / 4}$} \\
\hline \multirow[t]{2}{*}{ Stock } & Total Demand & 12.00 & 12.01 & 11.47 & 59.37 & 59.54 \\
\hline & Hedging Demand & 0.00 & -1.88 & -2.41 & 45.23 & 45.46 \\
\hline \multirow[t]{2}{*}{ Bond } & Total Demand & 0.41 & -11.28 & 3.61 & -19.55 & -39.95 \\
\hline & Hedging Demand & 0.00 & -11.86 & 3.03 & -20.17 & -41.53 \\
\hline \multirow[t]{2}{*}{ Cash } & Total Demand & 87.59 & 99.27 & 84.92 & 60.18 & 80.41 \\
\hline & Hedging Demand & 0.00 & 13.74 & -0.62 & -25.06 & -3.94 \\
\hline
\end{tabular}

Note: $A R_{t}=$ real returns on T-Bills, excess return on stocks, and excess return on bonds; $y_{t}=$ nominal yield on T-Bills; $(d-p)_{t}=\log$ dividend-price ratio; $s p r_{t}=$ yield spread. The bond is a 5 -year nominal bond in the quarterly dataset and a 20 -year in the annual dataset. 
TABLE 3 (Ctd.)

Mean Asset Demands $(\psi=1$ Case $)$

\begin{tabular}{|c|c|c|c|c|c|c|}
\hline \multicolumn{7}{|c|}{ B: Annual Sample (1890 - 1998) } \\
\hline & State Variables: & Constant & $A R_{t}$ & $y_{t}$ & $(d-p)_{t}$ & $\operatorname{spr}_{t}$ \\
\hline \multicolumn{7}{|c|}{$\gamma=1, \psi=1, \rho=0.92$} \\
\hline \multirow[t]{2}{*}{ Stock } & Total Demand & 192.33 & 207.77 & 209.27 & 215.20 & 219.34 \\
\hline & Hedging Demand & 0.00 & 0.00 & 0.00 & 0.00 & 0.00 \\
\hline \multirow[t]{2}{*}{ Bond } & Total Demand & 120.29 & 152.23 & 161.31 & 162.08 & 241.55 \\
\hline & Hedging Demand & 0.00 & 0.00 & 0.00 & 0.00 & 0.00 \\
\hline \multirow[t]{2}{*}{ Cash } & Total Demand & -212.62 & -260.00 & -270.57 & -277.28 & -360.89 \\
\hline & Hedging Demand & 0.00 & 0.00 & 0.00 & 0.00 & 0.00 \\
\hline \multicolumn{7}{|c|}{$\gamma=2, \psi=1, \rho=0.92$} \\
\hline \multirow[t]{2}{*}{ Stock } & Total Demand & 98.94 & 108.84 & 108.84 & 132.21 & 133.41 \\
\hline & Hedging Demand & 0.00 & 0.96 & 0.55 & 20.83 & 20.10 \\
\hline \multirow[t]{2}{*}{ Bond } & Total Demand & 65.44 & 89.60 & 96.87 & 83.16 & 142.25 \\
\hline & Hedging Demand & 0.00 & 6.99 & 11.53 & -2.58 & 19.78 \\
\hline \multirow[t]{2}{*}{ Cash } & Total Demand & -64.38 & -98.43 & -105.71 & -115.36 & -175.67 \\
\hline & Hedging Demand & 0.00 & -7.96 & -12.08 & -18.25 & -39.88 \\
\hline \multicolumn{7}{|c|}{$\gamma=5, \psi=1, \rho=0.92$} \\
\hline \multirow[t]{2}{*}{ Stock } & Total Demand & 42.91 & 53.87 & 52.77 & 67.38 & 66.70 \\
\hline & Hedging Demand & 0.00 & 5.94 & 5.06 & 18.29 & 17.01 \\
\hline \multirow[t]{2}{*}{ Bond } & Total Demand & 32.53 & 52.31 & 63.87 & 53.76 & 90.99 \\
\hline & Hedging Demand & 0.00 & 11.48 & 24.12 & 13.84 & 39.95 \\
\hline \multirow[t]{2}{*}{ Cash } & Total Demand & 24.56 & -6.19 & -16.64 & -21.14 & -57.69 \\
\hline & Hedging Demand & 0.00 & -17.42 & -29.17 & -32.13 & -56.96 \\
\hline \multicolumn{7}{|c|}{$\gamma=20, \psi=1, \rho=0.92$} \\
\hline \multirow[t]{2}{*}{ Stock } & Total Demand & 14.89 & 27.61 & 25.82 & 29.25 & 29.32 \\
\hline & Hedging Demand & 0.00 & 9.64 & 8.40 & 11.31 & 11.44 \\
\hline \multirow[t]{2}{*}{ Bond } & Total Demand & 16.07 & 34.03 & 48.01 & 44.10 & 76.42 \\
\hline & Hedging Demand & 0.00 & 14.08 & 31.05 & 27.08 & 61.10 \\
\hline \multirow[t]{2}{*}{ Cash } & Total Demand & 69.03 & 38.36 & 26.17 & 26.65 & -5.73 \\
\hline & Hedging Demand & 0.00 & -23.73 & -39.45 & -38.39 & -72.54 \\
\hline
\end{tabular}

Note: $A R_{t}=$ real returns on T-Bills, excess return on stocks, and excess return on bonds; $y_{t}=$ nominal yield on T-Bills; $(d-p)_{t}=\log$ dividend-price ratio; $s p r_{t}=$ yield spread. The bond is a 5 -year nominal bond in the quarterly dataset and a 20-year in the annual dataset. 
TABLE 4

Variability of Asset Demands

\section{A: Quarterly Sample (1952Q2 - 1999Q4)}

\begin{tabular}{|c|c|c|c|}
\hline & $\operatorname{Var}\left(\alpha^{m}\right) / \operatorname{Var}(\alpha)$ & $\operatorname{Var}\left(\alpha^{h}\right) / \operatorname{Var}(\alpha) \quad(\%)$ & $\operatorname{Cov}\left(\alpha^{m}, \alpha^{h}\right) / \operatorname{Var}(\alpha)$ \\
\hline Stock & 52.00 & 14.31 & 16.84 \\
\hline Bond & 60.49 & 21.44 & 9.03 \\
\hline
\end{tabular}

Percentage of Total Variation Explained By:

Stocks

\begin{tabular}{rcccccc} 
& $r t b_{t}$ & \multicolumn{1}{c}{$x r_{t}$} & \multicolumn{1}{c}{$x b_{t}$} & \multicolumn{1}{c}{$y_{t}$} & $(d-p)_{t}$ & $s p r_{t}$ \\
$r t b_{t}$ & 1.22 & 0.00 & 0.00 & 0.00 & 0.00 & 0.00 \\
$x r_{t}$ & 0.58 & 1.56 & 0.00 & 0.00 & 0.00 & 0.00 \\
$x b_{t}$ & 2.94 & 1.93 & 13.88 & 0.00 & 0.00 & 0.00 \\
$y_{t}$ & -1.27 & 3.00 & 13.59 & 56.82 & 0.00 & 0.00 \\
$(d-p)_{t}$ & -0.32 & -2.09 & 1.15 & -64.93 & 83.73 & 0.00 \\
$s p r_{t}$ & -1.09 & -0.52 & -4.07 & -11.02 & 1.20 & 3.69
\end{tabular}

Bonds

$\begin{array}{rrrrrrr}r t b_{t} & 0.01 & 0.00 & 0.00 & 0.00 & 0.00 & 0.00 \\ x r_{t} & 0.19 & 14.11 & 0.00 & 0.00 & 0.00 & 0.00 \\ x b_{t} & 0.24 & 4.25 & 7.44 & 0.00 & 0.00 & 0.00 \\ y_{t} & -0.15 & 9.82 & 10.82 & 67.20 & 0.00 & 0.00 \\ (d-p)_{t} & -0.02 & -3.58 & 0.48 & -40.26 & 27.23 & 0.00 \\ s p r_{t} & -0.53 & -6.94 & -13.27 & -53.47 & 3.06 & 73.38\end{array}$

Note: $r t b_{t}=$ ex post real T-Bill rate, $x r_{t}=$ excess stock return, $x b_{t}=$ excess bond return, $(d-p)_{t}=$ $\log$ dividend-price ratio, $r b_{t}=$ relative bill rate, $s p r_{t}=$ yield spread. The bond is a 5 -year nominal bond in the monthly dataset and a 20-year in the annual dataset. 
TABLE 4 (Ctd.) Variability of Asset Demands

\section{B: Annual Sample (1890-1998)}

\begin{tabular}{|c|c|c|c|}
\hline & $\operatorname{Var}\left(\alpha^{m}\right) / \operatorname{Var}(\alpha)$ & $\operatorname{Var}\left(\alpha^{h}\right) / \operatorname{Var}(\alpha)$ & $\operatorname{Cov}\left(\alpha^{m}, \alpha^{h}\right) / \operatorname{Var}(\alpha)$ \\
\hline Stock & 103.17 & 13.95 & -8.56 \\
\hline Bond & 96.54 & 0.40 & 1.53 \\
\hline
\end{tabular}

Percentage of Total Variation Explained By:

Stocks

\begin{tabular}{rrrrlrl} 
& $r t b_{t}$ & \multicolumn{1}{c}{$x r_{t}$} & \multicolumn{1}{c}{$x b_{t}$} & $y_{t}$ & $(d-p)_{t}$ & $s p r_{t}$ \\
$r t b_{t}$ & 0.51 & 0.00 & 0.00 & 0.00 & 0.00 & 0.00 \\
$x r_{t}$ & -0.91 & 13.01 & 0.00 & 0.00 & 0.00 & 0.00 \\
$x b_{t}$ & 0.22 & -0.60 & 2.48 & 0.00 & 0.00 & 0.00 \\
$y_{t}$ & -0.68 & 1.77 & -1.78 & 2.13 & 0.00 & 0.00 \\
$(d-p)_{t}$ & -1.01 & -8.14 & 3.35 & 7.42 & 83.58 & 0.00 \\
spr $_{t}$ & -0.17 & 0.83 & -1.11 & 0.62 & -1.97 & 0.45
\end{tabular}

Bonds

$\begin{array}{rrrrrrr}r t b_{t} & 17.59 & 0.00 & 0.00 & 0.00 & 0.00 & 0.00 \\ x r_{t} & -6.76 & 20.69 & 0.00 & 0.00 & 0.00 & 0.00 \\ x b_{t} & 2.50 & -1.46 & 9.21 & 0.00 & 0.00 & 0.00 \\ y_{t} & -0.28 & 0.16 & -0.24 & 0.01 & 0.00 & 0.00 \\ (d-p)_{t} & -0.76 & -1.31 & 0.82 & 0.07 & 1.35 & 0.00 \\ s p r_{t} & -13.90 & 14.86 & -30.49 & 0.62 & -3.57 & 90.88\end{array}$

Note: $r t b_{t}=$ ex post real T-Bill rate, $x r_{t}=$ excess stock return, $x b_{t}=$ excess bond return, $(d-p)_{t}=$ $\log$ dividend-price ratio, $r b_{t}=$ relative bill rate, $s p r_{t}=$ yield spread. The bond is a 5 -year nominal bond in the monthly dataset and a 20-year in the annual dataset. 
TABLE 5

Mean Asset Demands with Hypothetical Real Bonds (Quarterly Sample: 1952.Q2 - 1999.Q4)

\begin{tabular}{|c|c|c|}
\hline \multicolumn{3}{|c|}{ A: Nominal Bills, Stocks, and Real Consol Bond } \\
\hline State Variables: & Constant & Full VAR \\
\hline \multicolumn{3}{|l|}{$\gamma=1, \psi=1, \rho=0.92$} \\
\hline Stocks & 322.40 & 361.03 \\
\hline Real Consol Bond & 741.86 & 813.66 \\
\hline Cash & -964.26 & -1074.70 \\
\hline \multicolumn{3}{|l|}{$\gamma=2, \psi=1, \rho=0.92$} \\
\hline Stocks & 160.46 & 265.55 \\
\hline Real Consol Bond & 379.69 & 262.14 \\
\hline Cash & -440.16 & -427.69 \\
\hline \multicolumn{3}{|l|}{$\gamma=5, \psi=1, \rho=0.92$} \\
\hline Stocks & 63.31 & 155.59 \\
\hline Real Consol Bond & 162.39 & 61.03 \\
\hline Cash & -125.70 & -116.66 \\
\hline \multicolumn{3}{|c|}{$\gamma=20, \psi=1, \rho=0.92$} \\
\hline Stocks & 14.73 & 55.97 \\
\hline Real Consol Bond & 53.74 & 58.12 \\
\hline Cash & 31.53 & -14.09 \\
\hline \multicolumn{3}{|c|}{$\gamma=2000, \psi=1, \rho=0.92$} \\
\hline Stocks & -1.30 & 2.53 \\
\hline Real Consol Bond & 17.88 & 97.10 \\
\hline Cash & 83.42 & 0.37 \\
\hline
\end{tabular}

Note: "Constant" column reports mean asset demands when the VAR system only has a constant in each regression, corresponding to the case in which risk premia are constant and realized returns on all assets, including the short-term real interest rate, are i.i.d. "Full VAR" column reports mean asset demands when the VAR system includes all state variables. The nominal bond is a 5-year nominal bond in the quarterly dataset and a 20-year in the annual dataset. 
TABLE 5 (ctd.)

Mean Asset Demands with Hypothetical Real Bonds

(Quarterly Sample: 1952.Q2 - 1999.Q4)

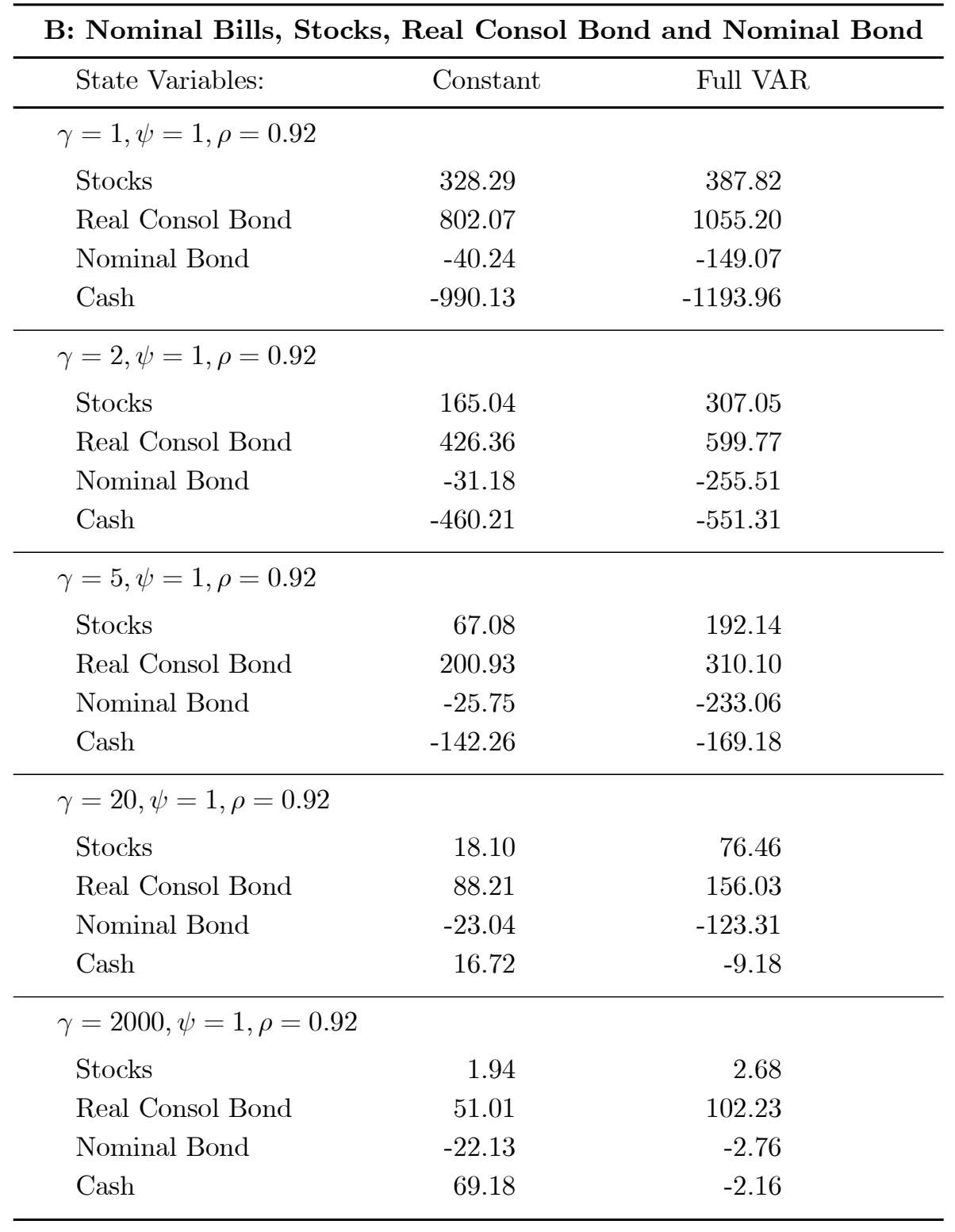

Note: "Constant" column reports mean asset demands when the VAR system only has a constant in each regression, corresponding to the case in which risk premia are constant and realized returns on all assets, including the short-term real interest rate, are i.i.d. "Full VAR" column reports mean asset demands when the VAR system includes all state variables. The nominal bond is a 5 -year nominal bond in the quarterly dataset and a 20-year in the annual dataset. 
TABLE 6

Mean Value Function ( $\psi=1$ Case)

(Quarterly Sample: 1952.Q2 - 1999.Q4)

\begin{tabular}{cc}
\hline$\gamma$ & $E\left[V_{t}\right]$ \\
\hline Nominal Bills and Stocks \\
1 & 0.803 \\
2 & 0.158 \\
5 & 0.043 \\
20 & 0.015 \\
2000 & 0.000 \\
\hline
\end{tabular}

Nominal Bills, Stocks, and Nominal Bond

\begin{tabular}{cc}
1 & 13.392 \\
2 & 0.692 \\
5 & 0.087 \\
20 & 0.020 \\
2000 & 0.001 \\
\hline Nominal Bills, Stocks, and Real Consol Bond \\
1 & 1.920 \\
2 & 0.192 \\
5 & 0.044 \\
20 & 0.016 \\
2000 & 0.009 \\
\hline Nominal Bills, Stocks, Nominal Bond, and Real Consol Bond \\
1 & 3456.715 \\
2 & 4.762 \\
5 & 0.174 \\
20 & 0.023 \\
2000 & 0.009 \\
\hline
\end{tabular}


Figure 1. Epstein-Zin Utility

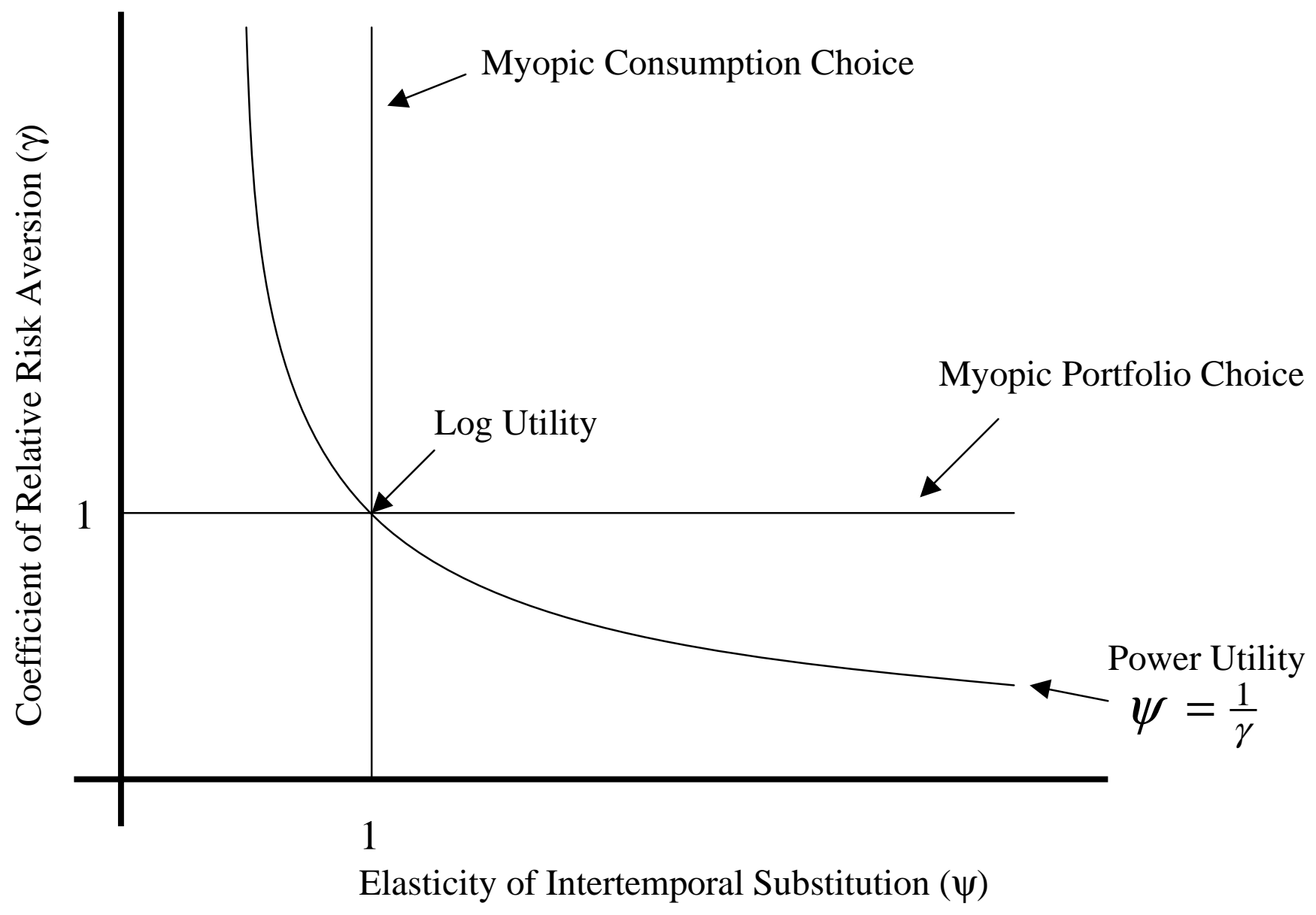


Figure 2: History of State Variables (1952.Q2 - 1999.Q4)
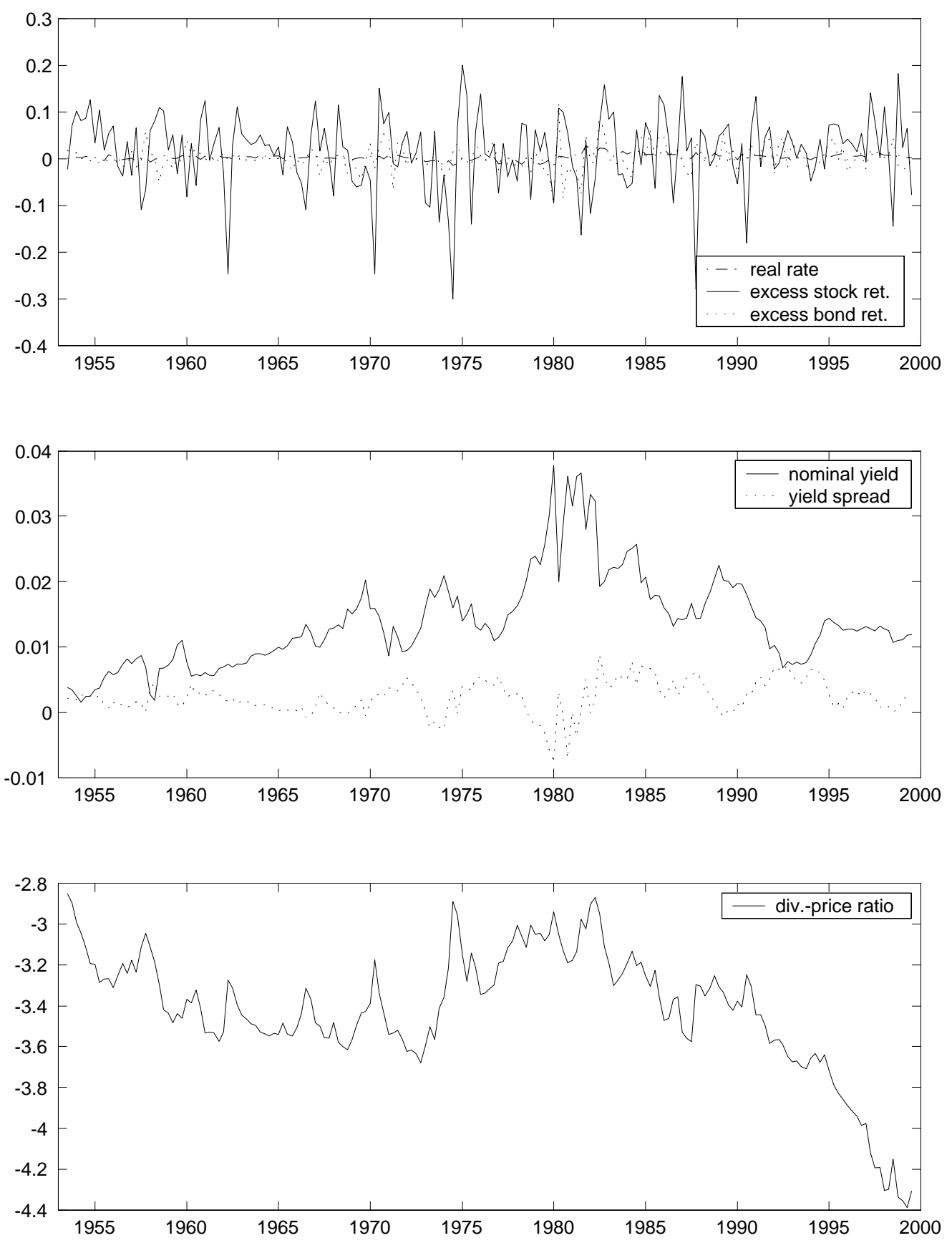
Figure 3: Optimal Asset Allocations to Stocks and Nominal Bond (Quarterly Sample)
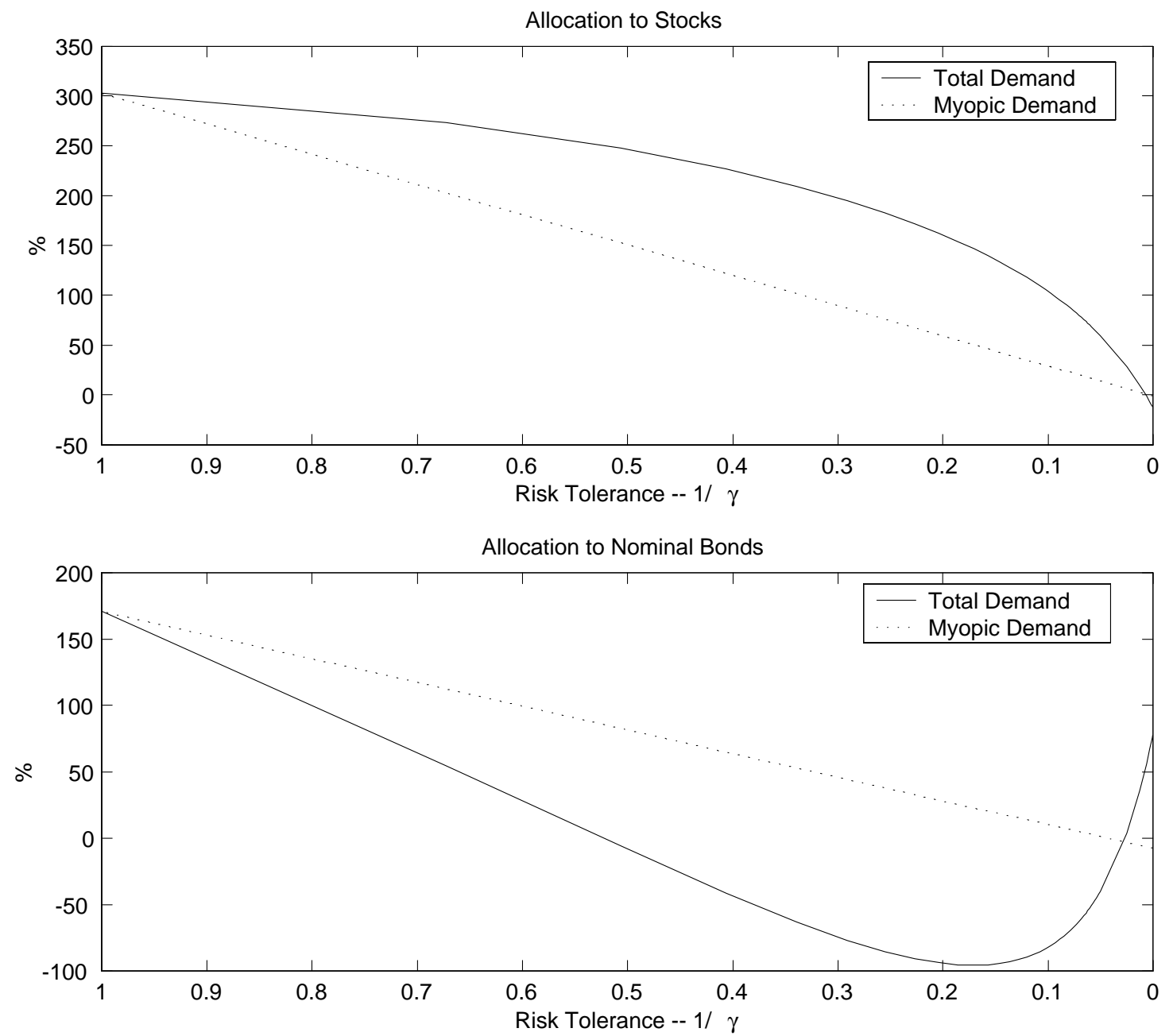
Figure 4: History of Asset Allocations (1952.Q2 - 1999.Q4)
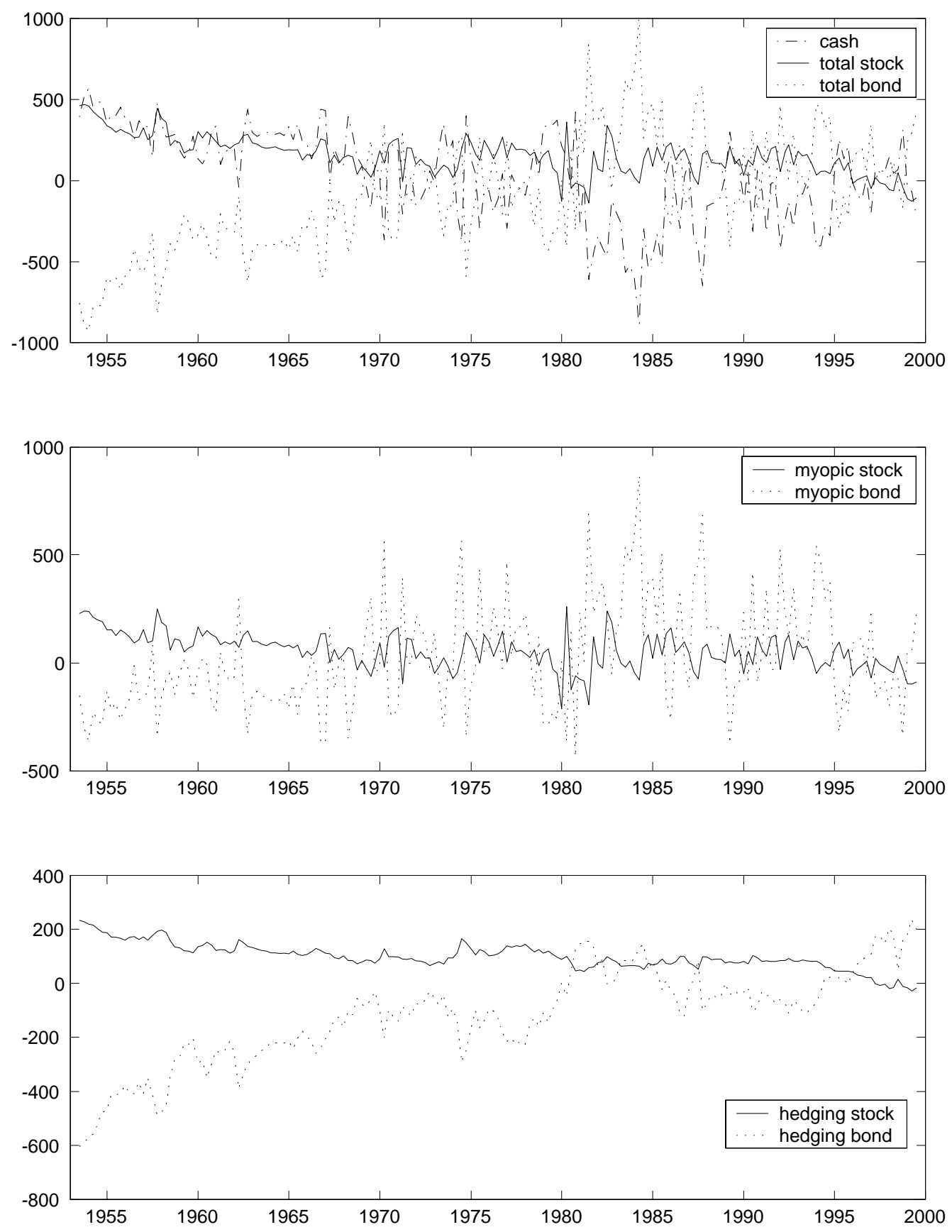
Figure 5: Optimal Allocations to Stocks and Real Consol Bond (Quarterly Sample)
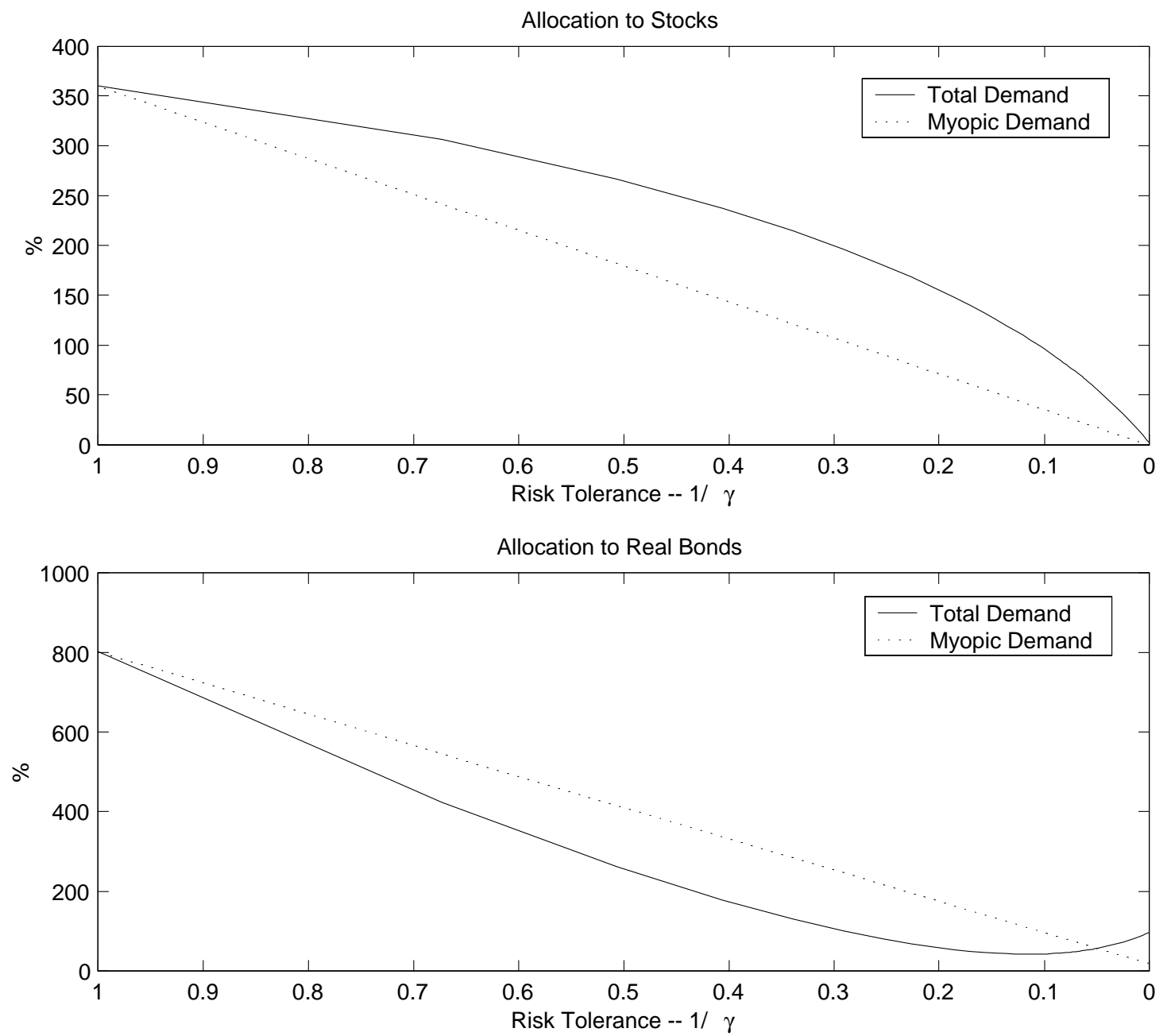
Figure 6: Optimal Allocations to Stocks, Nominal Bond and Real Consol Bond (Quarterly Sample)
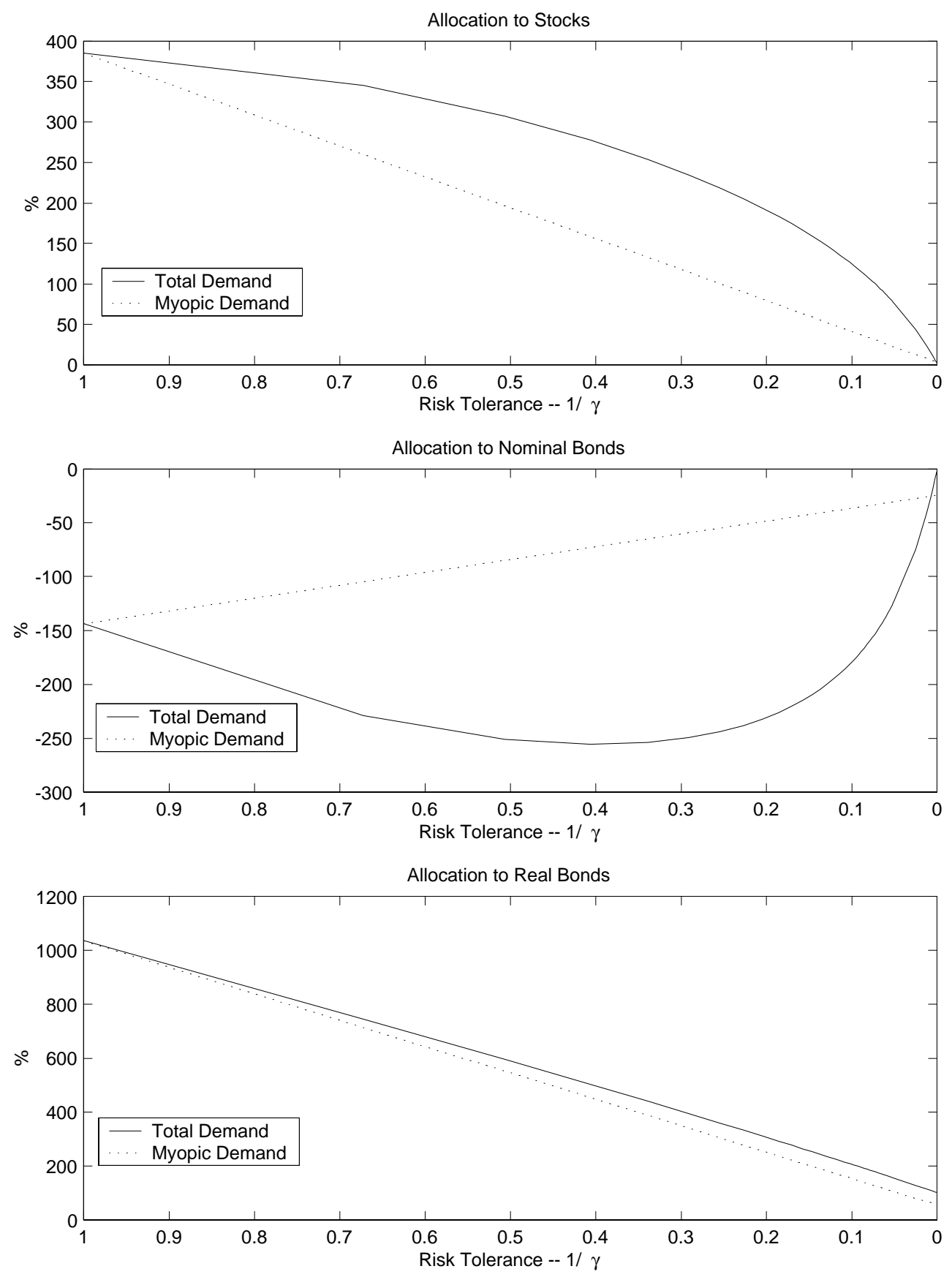


\title{
Appendix to A Multivariate Model of Strategic Asset Allocation
}

\author{
John Y. Campbell, Yeung Lewis Chan, and Luis M. Viceira ${ }^{1}$
}

First draft: September 1999

This version: October 2001

\footnotetext{
${ }^{1}$ Campbell: Department of Economics, Littauer Center 213, Harvard University, Cambridge MA 02138, USA, and NBER. Email john_campbell@harvard.edu. Chan: Department of Finance, School of Business and Management, Hong Kong University of Science and Technology, Clear Water Bay, Kowloon, Hong Kong. Email ylchan@ust.hk. Viceira: Graduate School of Business Administration, Morgan Hall 367, Harvard University, Boston MA 02163, USA, and NBER. Email lviceira@hbs.edu. Campbell acknowledges the financial support of the National Science Foundation. We are grateful to participants at the 1999 Intertemporal Asset Pricing Conference hosted by the Centre Interuniversitaire de Recherche en Analyse des Organizations (CIRANO) of Montreal for helpful comments and suggestions.
} 


\section{A Appendix A: Derivation of Main Equations in Text}

We first summarize three results on matrix algebra that will be convenient in deriving the expressions given in the text.

\section{Result 1.}

$$
\begin{aligned}
\mathbf{z}_{t+1} \mathbf{z}_{t+1}^{\prime}-\mathrm{E}_{t}\left(\mathbf{z}_{t+1} \mathbf{z}_{t+1}^{\prime}\right)= & \left(\Phi_{0}+\Phi_{1} \mathbf{z}_{t}+\mathbf{v}_{t+1}\right)\left(\Phi_{0}+\Phi_{1} z_{t}+\mathbf{v}_{t+1}\right)^{\prime}-\mathrm{E}_{t}\left(\mathbf{z}_{t+1} \mathbf{z}_{t+1}^{\prime}\right) \\
= & \Phi_{0} \Phi_{0}^{\prime}+\Phi_{1} \mathbf{z}_{t} \Phi_{0}^{\prime}+\mathbf{v}_{t+1} \Phi_{0}^{\prime}+\Phi_{0} \mathbf{z}_{t}^{\prime} \Phi_{1}^{\prime}+\Phi_{1} \mathbf{z}_{t} \mathbf{z}_{t}^{\prime} \Phi_{1}^{\prime} \\
& +\mathbf{v}_{t+1} \mathbf{z}_{t}^{\prime} \Phi_{1}^{\prime}+\Phi_{0} \mathbf{v}_{t+1}^{\prime}+\Phi_{1} \mathbf{z}_{t} \mathbf{v}_{t+1}^{\prime}+\mathbf{v}_{t+1} \mathbf{v}_{t+1}^{\prime}-\mathrm{E}_{t}\left(\mathbf{z}_{t+1} \mathbf{z}_{t+1}^{\prime}\right) \\
= & \mathbf{v}_{t+1} \Phi_{0}^{\prime}+\mathbf{v}_{t+1} \mathbf{z}_{t}^{\prime} \Phi_{1}^{\prime}+\Phi_{0} \mathbf{v}_{t+1}^{\prime}+\Phi_{1} \mathbf{z}_{t} \mathbf{v}_{t+1}^{\prime}+\mathbf{v}_{t+1} \mathbf{v}_{t+1}^{\prime}-\Sigma_{v} .
\end{aligned}
$$

Result 2.

$$
\begin{aligned}
r_{i, t+1}-\mathrm{E}_{t}\left(r_{i, t+1}\right) & =\mathbf{x}_{t+1}^{(i-1)}+r_{1, t+1}-\mathrm{E}_{t}\left(\mathbf{x}_{t+1}^{(i-1)}+r_{1, t+1}\right) \\
& =\mathbf{v}_{t+1}^{(i)}+\mathbf{v}_{t+1}^{(1)}
\end{aligned}
$$

where $\mathbf{x}_{t+1}^{(i-1)}$ denotes the $(i-1)$ th element of the excess return vector $\mathbf{x}_{t+1}$ and likewise with $\mathbf{v}_{t+1}$

Result 3. Any quadratic form $\mathbf{z}_{t+1}^{\prime} \mathbf{M} \mathbf{z}_{t+1}$ admits the following vector form representation:

$$
\mathbf{z}_{t+1}^{\prime} \mathbf{M} \mathbf{z}_{t+1}=\operatorname{vec}(\mathbf{M})^{\prime} \operatorname{vec}\left(\mathbf{z}_{t+1} \mathbf{z}_{t+1}^{\prime}\right),
$$

where $\operatorname{vec}(\cdot)$ is the vectorization operator.

Result 4. (Muirhead, 1982, pp.518)

$$
\operatorname{Var}_{t}\left(\operatorname{vec}\left(\mathbf{v}_{t+1} \mathbf{v}_{t+1}^{\prime}\right)\right)=\left(\mathbf{I}_{m^{2}}+\sum_{i, j}^{m}\left(\mathbf{Q}_{i j} \otimes \mathbf{Q}_{i j}^{\prime}\right)\right)\left(\Sigma_{v} \otimes \Sigma_{v}\right),
$$

where $\mathbf{Q}_{i j}$ is a $m \times m$ zero matrix except for the $(i, j)$ th element which is equal to 1 , and $\otimes$ is the kronecker product operator.

\section{Unconditional distribution of the state vector $\mathrm{z}_{t}$.}

The linearity of the VAR system (4) implies that the state vector $\mathbf{z}_{t}$ inherits the normality of the shocks $\mathbf{v}_{t+1}$. It has unconditional mean $\boldsymbol{\mu}_{z}$ and variance-covariance matrix $\boldsymbol{\Sigma}_{z z}$ given by

$$
\begin{aligned}
\boldsymbol{\mu}_{z} & =\left(\mathbf{I}_{m}-\boldsymbol{\Phi}_{1}\right)^{-1} \boldsymbol{\Phi}_{0} \\
\operatorname{vec}\left(\boldsymbol{\Sigma}_{z z}\right) & =\left(\mathbf{I}_{m^{2}}-\boldsymbol{\Phi}_{1} \otimes \boldsymbol{\Phi}_{1}\right)^{-1} \operatorname{vec}\left(\boldsymbol{\Sigma}_{v}\right) .
\end{aligned}
$$




\section{Derivation of Equation (10)}

The $\log$ return on the portfolio $r_{p, t+1}$ is a discrete-time approximation to its continuous-time counterpart. We begin by specifying the return processes for the short-term instrument $B_{t}$ and other risky assets $\mathbf{P}_{t}$ in continuous time:

$$
\begin{aligned}
\frac{d B_{t}}{B_{t}} & =\mu_{b, t} d t+\boldsymbol{\sigma}_{b} d \mathbf{W}_{t} \\
\frac{d \mathbf{P}_{t}}{\mathbf{P}_{t}} & =\boldsymbol{\mu}_{t} d t+\boldsymbol{\sigma} d \mathbf{W}_{t}
\end{aligned}
$$

where $\mu_{b, t}$ and $\boldsymbol{\mu}_{t}$ are the drifts, $\boldsymbol{\sigma}_{b}$ and $\boldsymbol{\sigma}$ are the diffusion, and $\mathbf{W}_{t}$ is a $m$-dimensional standard Brownian motion. ${ }^{15}$ We allow the drifts to depend on other state variables, but for notational simplicity, we suppress this dependency and simply use the time subscript. Moreover, note that the same $\mathbf{W}_{t}$ appears in the two equations.

We can obtain the log return on each asset using Ito's Lemma:

$$
\begin{aligned}
d \log B_{t} & =\left(\frac{d B_{t}}{B_{t}}\right)-\frac{1}{2}\left(\boldsymbol{\sigma}_{b} \boldsymbol{\sigma}_{b}^{\prime}\right) d t, \\
d \log P_{i, t} & =\left(\frac{d P_{i, t}}{P_{i, t}}\right)-\frac{1}{2}\left(\boldsymbol{\sigma}_{i} \boldsymbol{\sigma}_{i}^{\prime}\right) d t,
\end{aligned}
$$

where $\boldsymbol{\sigma}_{i}$ is the $i$ th row of the diffusion matrix $\boldsymbol{\sigma}$, and $i=1, . ., n-1$.

Let $V_{t}$ be the value of the portfolio at time $t$. We will use $d \log V_{t}$ to approximate $r_{p, t+1}$. By Ito's Lemma,

$$
d \log V_{t}=\left(\frac{d V_{t}}{V_{t}}\right)-\frac{1}{2}\left(\frac{d V_{t}}{V_{t}}\right)^{2} .
$$

We will now derive these two terms in order:

$$
\begin{aligned}
\frac{d V_{t}}{V_{t}}= & \boldsymbol{\alpha}_{t}^{\prime}\left(\frac{d \mathbf{P}_{t}}{\mathbf{P}_{t}}\right)+\left(1-\boldsymbol{\alpha}_{t}^{\prime} \boldsymbol{\iota}\right) \frac{d B_{t}}{B_{t}} \\
= & \boldsymbol{\alpha}_{t}^{\prime}\left(d \log \mathbf{P}_{t}+\frac{1}{2}\left[\boldsymbol{\sigma}_{i} \boldsymbol{\sigma}_{i}^{\prime}\right] d t\right)+\left(1-\boldsymbol{\alpha}_{t}^{\prime} \boldsymbol{\iota}\right)\left(d \log B_{t}+\frac{1}{2}\left(\boldsymbol{\sigma}_{b} \boldsymbol{\sigma}_{b}^{\prime}\right) d t\right) \\
= & \boldsymbol{\alpha}_{t}^{\prime}\left(d \log \mathbf{P}_{t}-d \log B_{t} \cdot \boldsymbol{\iota}\right)+d \log B_{t} \\
& +\frac{1}{2} \boldsymbol{\alpha}_{t}^{\prime}\left(\left[\boldsymbol{\sigma}_{i} \boldsymbol{\sigma}_{i}^{\prime}\right]-\boldsymbol{\sigma}_{b} \boldsymbol{\sigma}_{b}^{\prime} \cdot \boldsymbol{\iota}\right) d t+\frac{1}{2} \boldsymbol{\sigma}_{b} \boldsymbol{\sigma}_{b}^{\prime} d t,
\end{aligned}
$$

where $\iota$ is a $n \times 1$ vector of ones and the bracket [.] denotes a vector with $\boldsymbol{\sigma}_{i} \boldsymbol{\sigma}_{i}^{\prime}$ the $i$ th entry. Next,

$$
\begin{aligned}
\left(\frac{d V_{t}}{V_{t}}\right)^{2}= & \boldsymbol{\alpha}_{t}^{\prime}\left(d \log \mathbf{P}_{t}-d \log B_{t} \cdot \boldsymbol{\iota}\right)\left(d \log \mathbf{P}_{t}-d \log B_{t} \cdot \boldsymbol{\iota}\right)^{\prime} \boldsymbol{\alpha}_{t}+\left(d \log B_{t}\right)^{2} \\
& +2 \boldsymbol{\alpha}_{t}^{\prime}\left(d \log \mathbf{P}_{t}-d \log B_{t} \cdot \boldsymbol{\iota}\right)\left(d \log B_{t}\right)+o(d t)
\end{aligned}
$$

\footnotetext{
${ }^{15}$ The dimensions of $\mu_{b}, \boldsymbol{\mu}, \boldsymbol{\sigma}_{b}, \boldsymbol{\sigma}$ are $1 \times 1,(n-1) \times 1,1 \times m,(n-1) \times m$, respectively.
} 
where the $o(d t)$ terms vanish because they involve either $(d t)^{2}$ or $(d t)\left(d \mathbf{W}_{t}\right)$.

Now, from equation (31)-(33) and ignoring $d t$ terms,

$$
d \log \mathbf{P}_{t}-d \log B_{t} \cdot \boldsymbol{\iota}=\left(\boldsymbol{\sigma}-\boldsymbol{\iota} \cdot \boldsymbol{\sigma}_{b}\right) d \mathbf{W}_{t} .
$$

Thus,

$$
\begin{aligned}
\left(d \log \mathbf{P}_{t}-d \log B_{t} \cdot \boldsymbol{\iota}\right)\left(d \log \mathbf{P}_{t}-d \log B_{t} \cdot \boldsymbol{\iota}\right)^{\prime} & =\left(\boldsymbol{\sigma}-\boldsymbol{\iota} \cdot \boldsymbol{\sigma}_{b}\right)\left(\boldsymbol{\sigma}-\boldsymbol{\iota} \cdot \boldsymbol{\sigma}_{b}\right)^{\prime} \\
\left(d \log \mathbf{P}_{t}-d \log B_{t} \cdot \boldsymbol{\iota}\right)\left(d \log B_{t}\right) & =\left(\boldsymbol{\sigma}-\boldsymbol{\iota} \cdot \boldsymbol{\sigma}_{1}\right) \cdot \boldsymbol{\sigma}_{b}^{\prime} .
\end{aligned}
$$

Collecting these results and using our notation for excess returns: $\mathbf{x}_{t+1}=d \log \mathbf{P}_{t}-d \log B_{t} \cdot \boldsymbol{\iota}$, $r_{1, t+1}=d \log \left(B_{t}\right)$ and $d t=1$,

$$
\begin{aligned}
r_{p, t+1}= & d \log V_{t} \\
= & \boldsymbol{\alpha}_{t}^{\prime} \mathbf{x}_{t+1}+r_{1, t+1}+\frac{1}{2} \boldsymbol{\alpha}_{t}^{\prime}\left(\left[\boldsymbol{\sigma}_{i} \boldsymbol{\sigma}_{i}^{\prime}\right]-\boldsymbol{\sigma}_{b} \boldsymbol{\sigma}_{b}^{\prime} \cdot \boldsymbol{\iota}\right) \\
& -\frac{1}{2}\left[\boldsymbol{\alpha}_{t}^{\prime}\left(\boldsymbol{\sigma}-\boldsymbol{\iota} \cdot \boldsymbol{\sigma}_{b}\right)\left(\boldsymbol{\sigma}-\boldsymbol{\iota} \cdot \boldsymbol{\sigma}_{b}\right)^{\prime} \boldsymbol{\alpha}_{t}+2 \boldsymbol{\alpha}_{t}^{\prime}\left(\boldsymbol{\sigma}-\boldsymbol{\iota} \cdot \boldsymbol{\sigma}_{b}\right) \boldsymbol{\sigma}_{b}^{\prime}\right]
\end{aligned}
$$

Using the notation in the VAR system with the Cholesky decomposition for $\Sigma_{v}=\mathbf{G G}^{\prime}, \boldsymbol{\sigma}_{i}-\boldsymbol{\sigma}_{b}$ is equal to the $i$ th row of $\mathbf{G}, \mathbf{G}_{i}$. Hence,

$$
\begin{aligned}
\left(\boldsymbol{\sigma}-\boldsymbol{\iota} \cdot \boldsymbol{\sigma}_{b}\right)\left(\boldsymbol{\sigma}-\boldsymbol{\iota} \cdot \boldsymbol{\sigma}_{b}\right)^{\prime} & =\mathbf{G}_{2: n} \mathbf{G}_{2: n}^{\prime}=\boldsymbol{\Sigma}_{x x}, \\
\boldsymbol{\sigma}_{b} \boldsymbol{\sigma}_{b}^{\prime} & =\mathbf{G}_{1} \mathbf{G}_{1}^{\prime}=\sigma_{1}^{2}, \\
\boldsymbol{\sigma}_{i} \boldsymbol{\sigma}_{i}^{\prime} & =\mathbf{G}_{i} \mathbf{G}_{i}^{\prime}+\boldsymbol{\sigma}_{b} \mathbf{G}_{i}^{\prime}+\mathbf{G}_{i} \boldsymbol{\sigma}_{b}^{\prime}+\boldsymbol{\sigma}_{b} \boldsymbol{\sigma}_{b}^{\prime}, \\
{\left[\boldsymbol{\sigma}_{i} \boldsymbol{\sigma}_{i}^{\prime}\right] } & =\sigma_{x}^{2}+2 \boldsymbol{\sigma}_{1 x}+\sigma_{1}^{2} \boldsymbol{\iota}, \\
\left(\boldsymbol{\sigma}-\boldsymbol{\iota} \cdot \boldsymbol{\sigma}_{b}\right) \boldsymbol{\sigma}_{b}^{\prime} & =\mathbf{G}_{2: n} \mathbf{G}_{1}^{\prime}=\boldsymbol{\sigma}_{1 x},
\end{aligned}
$$

where $\mathbf{G}_{2: n}$ denotes the submatrix formed by taking the 2 nd to $n$th rows of $\mathbf{G}$.

With these terms, the return on the portfolio is

$$
\begin{aligned}
r_{p, t+1} & =\boldsymbol{\alpha}_{t}^{\prime} \mathbf{x}_{t+1}+r_{1, t+1}+\frac{1}{2} \boldsymbol{\alpha}_{t}^{\prime}\left(\sigma_{x}^{2}+2 \boldsymbol{\sigma}_{1 x}\right)-\frac{1}{2} \boldsymbol{\alpha}_{t}^{\prime} \boldsymbol{\Sigma}_{x x} \boldsymbol{\alpha}_{t}-\boldsymbol{\alpha}_{t}^{\prime} \boldsymbol{\sigma}_{1 x} \\
& =\boldsymbol{\alpha}_{t}^{\prime} \mathbf{x}_{t+1}+r_{1, t+1}+\frac{1}{2} \boldsymbol{\alpha}_{t}^{\prime}\left(\sigma_{x}^{2}-\boldsymbol{\Sigma}_{x x} \boldsymbol{\alpha}_{t}\right) .
\end{aligned}
$$

\section{Solving for the Optimal Portfolio Rule.}

Subtracting the $\log$ Euler equation (12) with $i=1$ from (12), we obtain

$$
\begin{aligned}
\mathrm{E}_{t}\left(r_{i, t+1}-r_{1, t+1}\right)+\frac{1}{2} \operatorname{Var}_{t}\left(r_{i, t+1}-r_{1, t+1}\right)= & \operatorname{Cov}_{t}\left(\frac{\theta}{\psi} \Delta c_{t+1}+(1-\theta) r_{p, t+1}, r_{i, t+1}\right) \\
& -\operatorname{Cov}_{t}\left(\frac{\theta}{\psi} \Delta c_{t+1}+(1-\theta) r_{p, t+1}, r_{1, t+1}\right) \\
& -\frac{1}{2}\left(\operatorname{Var}_{t}\left(r_{i, t+1}\right)-\operatorname{Var}_{t}\left(r_{1, t+1}\right)-\operatorname{Var}_{t}\left(r_{i, t+1}-r_{1, t+1}\right)\right) .
\end{aligned}
$$


Using the budget constraint (11) and the trivial identity $\Delta c_{t+1}=\left(c_{t+1}-w_{t+1}\right)-\left(c_{t}-w_{t}\right)+\Delta w_{t+1}$,

$$
\frac{\theta}{\psi} \Delta c_{t+1}+(1-\theta) r_{p, t+1}=\frac{\theta}{\psi}\left(c_{t+1}-w_{t+1}\right)+\gamma r_{p, t+1}+\text { time } t \text { terms and constants. }
$$

Thus, equation (36) can be written as

$\mathrm{E}_{t}\left(r_{i, t+1}-r_{1, t+1}\right)+\frac{1}{2} \operatorname{Var}_{t}\left(r_{i, t+1}-r_{1, t+1}\right)=\frac{\theta}{\psi}\left[\sigma_{i, c-w, t}-\sigma_{1, c-w, t}\right]+\gamma\left[\sigma_{i, p, t}-\sigma_{1, p, t}\right]$

$$
-\frac{1}{2}\left(\operatorname{Var}_{t}\left(r_{i, t+1}\right)-\operatorname{Var}_{t}\left(r_{1, t+1}\right)-\operatorname{Var}_{t}\left(r_{i, t+1}-r_{1, t+1}\right)\right) \text {. }
$$

We will derive these terms now.

Using the equation for log return on the portfolio and ignoring time $t$ terms and constants,

$$
\begin{aligned}
\sigma_{i, p, t}= & \operatorname{Cov}_{t}\left(\boldsymbol{\alpha}_{t}^{\prime} \mathbf{x}_{t+1}+r_{1, t+1}, r_{i, t+1}\right) \\
= & \boldsymbol{\alpha}_{t}^{\prime}\left(\Sigma_{x x}^{(i-1)}+\boldsymbol{\sigma}_{1 x}\right)+\boldsymbol{\sigma}_{1 x}^{(i-1)}+\sigma_{1}^{2}, \\
\sigma_{1, p, t} & =\operatorname{Cov}_{t}\left(\boldsymbol{\alpha}_{t}^{\prime} \mathbf{x}_{t+1}+r_{1, t+1}, r_{1, t+1}\right) \\
& =\boldsymbol{\alpha}_{t}^{\prime} \boldsymbol{\sigma}_{1 x}+\sigma_{1}^{2} .
\end{aligned}
$$

To evaluate the conditional covariances $\sigma_{i, c-w, t}$ and $\sigma_{1, c-w, t}$, we use the conjectured policy rule for the consumption-wealth ratio.

$$
\begin{aligned}
& \sigma_{i, c-w, t} \\
= & \operatorname{Cov}_{t}\left(c_{t+1}-w_{t+1}-\mathrm{E}_{t}\left(c_{t+1}-w_{t+1}\right), r_{i, t+1}-\mathrm{E}_{t}\left(r_{i, t+1}\right)\right) \\
= & \operatorname{Cov}_{t}\left(\mathbf{B}_{1}^{\prime} \mathbf{v}_{t+1}+\left(\boldsymbol{\Phi}_{0}+\boldsymbol{\Phi}_{1} \mathbf{z}_{t}+\mathbf{v}_{t+1}\right)^{\prime} \mathbf{B}_{2}\left(\boldsymbol{\Phi}_{0}+\boldsymbol{\Phi}_{1} \mathbf{z}_{t}+\mathbf{v}_{t+1}\right), \mathbf{v}_{t+1}^{(i)}+\mathbf{v}_{t+1}^{(1)}\right) \\
= & \operatorname{Cov}_{t}\left(\mathbf{B}_{1}^{\prime} \mathbf{v}_{t+1}+\boldsymbol{\Phi}_{0}^{\prime} \mathbf{B}_{2} \mathbf{v}_{t+1}+\mathbf{z}_{t}^{\prime} \boldsymbol{\Phi}_{1}^{\prime} \mathbf{B}_{2} \mathbf{v}_{t+1}+\mathbf{v}_{t+1}^{\prime} \mathbf{B}_{2} \boldsymbol{\Phi}_{0}+\mathbf{v}_{t+1}^{\prime} \mathbf{B}_{2} \boldsymbol{\Phi}_{1} \mathbf{z}_{t}, \mathbf{v}_{t+1}^{(i)}+\mathbf{v}_{t+1}^{(1)}\right) \\
= & \mathbf{B}_{1}^{\prime}\left(\Sigma_{v}^{(i)}+\Sigma_{v}^{(1)}\right)+\boldsymbol{\Phi}_{0}^{\prime} \mathbf{B}_{2}\left(\Sigma_{v}^{(i)}+\Sigma_{v}^{(1)}\right)+\left(\Sigma_{v}^{(i)}+\Sigma_{v}^{(1)}\right)^{\prime} \mathbf{B}_{2} \boldsymbol{\Phi}_{0} \\
& +\mathbf{z}_{t}^{\prime} \boldsymbol{\Phi}_{1}^{\prime} \mathbf{B}_{2}\left(\Sigma_{v}^{(i)}+\Sigma_{v}^{(1)}\right)+\left(\Sigma_{v}^{(i)}+\Sigma_{v}^{(1)}\right)^{\prime} \mathbf{B}_{2} \mathbf{\Phi}_{1} \mathbf{z}_{t},
\end{aligned}
$$

where the second equality follows from using Result 1 and 2 , and $\Sigma_{v}^{(i)}$ denotes the $i$ th column of $\Sigma_{v}$. Note that $\mathbf{B}_{2}$ is not necessarily symmetric, so that we cannot combine any of the terms in the expression above. Similarly, for the return on the short-term bond we have

$$
\sigma_{1, c-w, t}=\mathbf{B}_{1}^{\prime} \Sigma_{v}^{(1)}+\boldsymbol{\Phi}_{0}^{\prime} \mathbf{B}_{2} \Sigma_{v}^{(1)}+\left(\Sigma_{v}^{(1)}\right)^{\prime} \mathbf{B}_{2} \boldsymbol{\Phi}_{0}+\mathbf{z}_{t}^{\prime} \boldsymbol{\Phi}_{1}^{\prime} \mathbf{B}_{2} \Sigma_{v}^{(1)}+\left(\Sigma_{v}^{(1)}\right)^{\prime} \mathbf{B}_{2} \boldsymbol{\Phi}_{1} \mathbf{z}_{t} .
$$

Therefore

$$
\begin{aligned}
\sigma_{i, c-w, t}-\sigma_{1, c-w, t} & =\mathbf{B}_{1}^{\prime} \Sigma_{v}^{(i)}+\left(\boldsymbol{\Phi}_{0}^{\prime} \mathbf{B}_{2}+\mathbf{z}_{t}^{\prime} \boldsymbol{\Phi}_{1}^{\prime} \mathbf{B}_{2}\right) \Sigma_{v}^{(i)}+\left(\Sigma_{v}^{(i)}\right)^{\prime}\left(\mathbf{B}_{2} \boldsymbol{\Phi}_{0}+\mathbf{B}_{2} \boldsymbol{\Phi}_{1} \mathbf{z}_{t}\right) \\
& =\mathbf{B}_{1}^{\prime} \Sigma_{v}^{(i)}+\left(\boldsymbol{\Phi}_{0}^{\prime}+\mathbf{z}_{t}^{\prime} \boldsymbol{\Phi}_{1}^{\prime}\right)\left(\mathbf{B}_{2}+\mathbf{B}_{2}^{\prime}\right) \Sigma_{v}^{(i)} \\
& =\left(\Sigma_{v}^{(i)}\right)^{\prime} \mathbf{B}_{1}+\left(\Sigma_{v}^{(i)}\right)^{\prime}\left(\mathbf{B}_{2}+\mathbf{B}_{2}^{\prime}\right)\left(\boldsymbol{\Phi}_{0}+\boldsymbol{\Phi}_{1} \mathbf{z}_{t}\right)
\end{aligned}
$$


Stacked, this equations give

$$
\begin{aligned}
& \boldsymbol{\sigma}_{c-w, t}-\sigma_{1, c-w, t} \iota \\
= & \left(\left[\begin{array}{c}
\Sigma_{v}^{(2) \prime} \\
\vdots \\
\Sigma_{v}^{(n) \prime}
\end{array}\right] \mathbf{B}_{1}+2\left[\begin{array}{c}
\Sigma_{v}^{(2) \prime} \\
\vdots \\
\Sigma_{v}^{(n) \prime}
\end{array}\right]\left(\mathbf{B}_{2}+\mathbf{B}_{2}^{\prime}\right) \mathbf{\Phi}_{0}\right)+\left(\left[\begin{array}{c}
\Sigma_{v}^{(2) \prime} \\
\vdots \\
\Sigma_{v}^{(n) \prime}
\end{array}\right]\left(\mathbf{B}_{2}+\mathbf{B}_{2}^{\prime}\right) \boldsymbol{\Phi}_{1}\right) \mathbf{z}_{t} \\
= & {\left[\left(\Sigma_{v} \mathbf{H}_{x}^{\prime}\right)^{\prime} \mathbf{B}_{1}+\left(\Sigma_{v} \mathbf{H}_{x}^{\prime}\right)\left(\mathbf{B}_{2}+\mathbf{B}_{2}^{\prime}\right) \boldsymbol{\Phi}_{0}\right]+\left[\left(\Sigma_{v} \mathbf{H}_{x}^{\prime}\right)^{\prime}\left(\mathbf{B}_{2}+\mathbf{B}_{2}^{\prime}\right) \boldsymbol{\Phi}_{1}\right] \mathbf{z}_{t} } \\
= & \Lambda_{0}+\Lambda_{1} \mathbf{z}_{t},
\end{aligned}
$$

as claimed in equation (17)

\section{Solving for the Optimal Consumption Rule.}

We derive first equation (26). To derive this equation, note that log consumption growth verifies the following trivial identity: $\Delta c_{t+1}=\left(c_{t+1}-w_{t+1}\right)-\left(c_{t}-w_{t}\right)+\Delta w_{t+1}$. Substituting the loglinearized budget constraint (11) into this equation and taking expectations we obtain

$$
\begin{aligned}
\mathrm{E}_{t}\left(\Delta c_{t+1}\right) & =\mathrm{E}_{t}\left(c_{t+1}-w_{t+1}\right)-\left(c_{t}-w_{t}\right)+\mathrm{E}_{t}\left(\Delta w_{t+1}\right) \\
& =\mathrm{E}_{t}\left(c_{t+1}-w_{t+1}\right)-\left(c_{t}-w_{t}\right)+\mathrm{E}_{t}\left(r_{p, t+1}\right)+\left(1-\frac{1}{\rho}\right)\left(c_{t}-w_{t}\right)+k .
\end{aligned}
$$

Combining the two equations (24) and (38), we obtain a difference equation in $c_{t}-w_{t}$, given in (26).

Next we show that both the expected $\log$ return on the wealth portfolio $\mathrm{E}_{t} r_{p, t+1}$ and the variance term $\chi_{p, t}$ in equation (24) for expected log consumption growth are quadratic functions of the vector of state variables.

Taking conditional expectations of equation (10) and substituting the portfolio policy rule $\boldsymbol{\alpha}_{t}=$ $\mathbf{A}_{0}+\mathbf{A}_{1} \mathbf{z}_{t}$

$$
\begin{aligned}
\mathrm{E}_{t}\left(r_{p, t+1}\right)= & \boldsymbol{\alpha}_{t}^{\prime} \mathrm{E}_{t}\left(\mathbf{x}_{t+1}\right)+\mathrm{E}_{t}\left(r_{1, t+1}\right)+\frac{1}{2} \boldsymbol{\alpha}_{t}^{\prime}\left(\sigma_{x}^{2}-\Sigma_{x x} \boldsymbol{\alpha}_{t}\right) \\
= & \left(\mathbf{A}_{0}^{\prime}+\mathbf{z}_{t}^{\prime} \mathbf{A}_{1}^{\prime}\right) \mathbf{H}_{x}\left(\Phi_{0}+\Phi_{1} \mathbf{z}_{t}\right)+\mathbf{H}_{1}\left(\Phi_{0}+\Phi_{1} \mathbf{z}_{t}\right) \\
& +\frac{1}{2}\left(\mathbf{A}_{0}^{\prime}+\mathbf{z}_{t}^{\prime} \mathbf{A}_{1}^{\prime}\right) \sigma_{x}^{2}-\frac{1}{2}\left(\mathbf{A}_{0}^{\prime}+\mathbf{z}_{t}^{\prime} \mathbf{A}_{1}^{\prime}\right) \Sigma_{x x}\left(\mathbf{A}_{0}+\mathbf{A}_{1} \mathbf{z}_{t}\right) \\
= & \Gamma_{0}+\Gamma_{1} \mathbf{z}_{t}+\Gamma_{2} \operatorname{vec}\left(\mathbf{z}_{t} \mathbf{z}_{t}^{\prime}\right)
\end{aligned}
$$

where

$$
\begin{aligned}
\Gamma_{0} & \equiv \mathbf{A}_{0}^{\prime} \mathbf{H}_{x} \Phi_{0}+\mathbf{H}_{1} \Phi_{0}+\frac{1}{2} \mathbf{A}_{0}^{\prime} \sigma_{x}^{2}-\frac{1}{2} \mathbf{A}_{0}^{\prime} \Sigma_{x x} \mathbf{A}_{0}, \\
\Gamma_{1} & \equiv \Phi_{0}^{\prime} \mathbf{H}_{x}^{\prime} \mathbf{A}_{1}+\mathbf{A}_{0}^{\prime} \mathbf{H}_{x} \Phi_{1}+\mathbf{H}_{1} \Phi_{1}+\frac{1}{2} \sigma_{x}^{2} \mathbf{A}_{1}-\mathbf{A}_{0}^{\prime} \Sigma_{x x} \mathbf{A}_{1}, \\
\Gamma_{2} & \equiv \operatorname{vec}\left(\mathbf{A}_{1}^{\prime} \mathbf{H}_{x} \Phi_{1}\right)^{\prime}-\frac{1}{2} \operatorname{vec}\left(\mathbf{A}_{1}^{\prime} \Sigma_{x x} \mathbf{A}_{1}\right)^{\prime},
\end{aligned}
$$


and $\mathbf{H}_{1}$ and $\mathbf{H}_{x}$ are selection matrices that select the short-term real interest rate and the vector of excess returns from the full state vector.

We now evaluate the variance term

$$
\chi_{p, t}=\frac{1}{2}\left(\frac{\theta}{\psi}\right) \operatorname{Var}_{t}\left(\Delta c_{t+1}-\psi r_{p, t+1}\right)
$$

Using the trivial identity for $\Delta c_{t+1}$ and the budget constraint (11), substituting the conjecture for the consumption rule

$$
\begin{aligned}
c_{t}-w_{t} & =b_{0}+\mathbf{B}_{1}^{\prime} \mathbf{z}_{t}+\mathbf{z}_{t}^{\prime} \mathbf{B}_{2} \mathbf{z}_{t} \\
& =b_{0}+\mathbf{B}_{1}^{\prime} \mathbf{z}_{t}+\operatorname{vec}\left(\mathbf{B}_{2}\right)^{\prime} \operatorname{vec}\left(\mathbf{z}_{t} \mathbf{z}_{t}^{\prime}\right)
\end{aligned}
$$

and $\boldsymbol{\alpha}_{t}=\mathbf{A}_{0}+\mathbf{A}_{1} \mathbf{z}_{t}$, and ignoring time $t$ terms and constants, we can write the argument of the variance as:

$$
\begin{aligned}
& \Delta c_{t+1}-\psi r_{p, t+1} \\
= & {\left[\mathbf{B}_{1}^{\prime}+\mathbf{\Phi}_{0}^{\prime}\left(\mathbf{B}_{2}+\mathbf{B}_{2}^{\prime}\right)+(1-\psi) \mathbf{A}_{0}^{\prime} \mathbf{H}_{x}+(1-\psi) \mathbf{H}_{1}\right] \mathbf{v}_{t+1} } \\
& +\mathbf{z}_{t}^{\prime}\left[\boldsymbol{\Phi}_{1}^{\prime}\left(\mathbf{B}_{2}+\mathbf{B}_{2}^{\prime}\right)+(1-\psi) \mathbf{A}_{1}^{\prime} \mathbf{H}_{x}\right] \mathbf{v}_{t+1} \\
& +\operatorname{vec}\left(\mathbf{B}_{2}\right)^{\prime} \operatorname{vec}\left(\mathbf{v}_{t+1} \mathbf{v}_{t+1}^{\prime}\right) \\
= & {\left[\Pi_{1}+\mathbf{z}_{t}^{\prime} \Pi_{2}\right] \mathbf{v}_{t+1}+\operatorname{vec}\left(\mathbf{B}_{2}\right)^{\prime} \operatorname{vec}\left(\mathbf{v}_{t+1} \mathbf{v}_{t+1}^{\prime}\right), }
\end{aligned}
$$

where

$$
\begin{aligned}
\Pi_{1} & \equiv \mathbf{B}_{1}^{\prime}+\boldsymbol{\Phi}_{0}^{\prime}\left(\mathbf{B}_{2}+\mathbf{B}_{2}^{\prime}\right)+(1-\psi) \mathbf{A}_{0}^{\prime} \mathbf{H}_{x}+(1-\psi) \mathbf{H}_{1} \\
\Pi_{2} & \equiv \mathbf{\Phi}_{1}^{\prime}\left(\mathbf{B}_{2}+\mathbf{B}_{2}^{\prime}\right)+(1-\psi) \mathbf{A}_{1}^{\prime} \mathbf{H}_{x} .
\end{aligned}
$$

Since $\mathbf{v}_{t+1}$ is conditionally normally distributed, all third moments are zero. Thus,

$$
\begin{aligned}
& \operatorname{Var}_{t}\left(\Delta c_{t+1}-\psi r_{p, t+1}\right) \\
= & \Pi_{1} \Sigma_{v} \Pi_{1}^{\prime}+\left[2 \Pi_{1} \Sigma_{v} \Pi_{2}^{\prime}\right] \mathbf{z}_{t}+\operatorname{vec}\left(\Pi_{2} \Sigma_{v} \Pi_{2}^{\prime}\right)^{\prime} \operatorname{vec}\left(\mathbf{z}_{t} \mathbf{z}_{t}^{\prime}\right) \\
& +\operatorname{vec}\left(\mathbf{B}_{2}\right)^{\prime} \operatorname{Var}_{t}\left(\operatorname{vec}\left(\mathbf{v}_{t+1} \mathbf{v}_{t+1}^{\prime}\right)\right) \operatorname{vec}\left(\mathbf{B}_{2}\right),
\end{aligned}
$$

and $\operatorname{Var}_{t}\left(\operatorname{vec}\left(\mathbf{v}_{t+1} \mathbf{v}_{t+1}^{\prime}\right)\right)$ is given by the expression in Result 4 above. Putting these pieces together, we have

$$
\chi_{p, t}=V_{0}+\mathbf{V}_{1} \mathbf{z}_{t}+\mathbf{V}_{2} \operatorname{vec}\left(\mathbf{z}_{t} \mathbf{z}_{t}^{\prime}\right)
$$

where

$$
\begin{aligned}
V_{0} & \equiv \frac{\theta}{2 \psi}\left[\Pi_{1} \Sigma_{v} \Pi_{1}^{\prime}+\operatorname{vec}\left(\mathbf{B}_{2}\right)^{\prime} \operatorname{Var}_{t}\left(\operatorname{vec}\left(\mathbf{v}_{t+1} \mathbf{v}_{t+1}^{\prime}\right)\right) \operatorname{vec}\left(\mathbf{B}_{2}\right)\right] \\
\mathbf{V}_{1} & \equiv \frac{\theta}{2 \psi}\left[2 \Pi_{1} \Sigma_{v} \Pi_{2}^{\prime}\right] \\
\mathbf{V}_{2} & \equiv \frac{\theta}{2 \psi}\left[\operatorname{vec}\left(\Pi_{2} \Sigma_{v} \Pi_{2}^{\prime}\right)^{\prime}\right]
\end{aligned}
$$


We can now solve for the coefficients of the optimal consumption rule. Simple substitution of the expressions for $\mathrm{E}_{t} r_{p, t+1}$ and $\chi_{p, t}$, and the expression for the conditional expectation of $\left(c_{t+1}-w_{t+1}\right)$ into the RHS of $(26)$ yields

$$
c_{t}-w_{t}=\Xi_{0}+\Xi_{1} \mathbf{z}_{t}+\Xi_{2} \operatorname{vec}\left(\mathbf{z}_{t} \mathbf{z}_{t}^{\prime}\right)
$$

where

$$
\begin{aligned}
\Xi_{0} \equiv & \rho\left[-\psi \log \delta+k-V_{0}+(1-\psi) \Gamma_{0}+b_{0}+\mathbf{B}_{1}^{\prime} \Phi_{0}\right. \\
& \left.+\operatorname{vec}\left(\mathbf{B}_{2}\right)^{\prime} \operatorname{vec}\left(\boldsymbol{\Phi}_{0} \boldsymbol{\Phi}_{0}^{\prime}\right)+\operatorname{vec}\left(\mathbf{B}_{2}\right)^{\prime} \operatorname{vec}\left(\Sigma_{v}\right)\right] \\
\Xi_{1} \equiv & \rho\left[-\mathbf{V}_{1}+(1-\psi) \Gamma_{1}+\mathbf{B}_{1}^{\prime} \boldsymbol{\Phi}_{1}+2 \boldsymbol{\Phi}_{0}^{\prime}\left(\mathbf{B}_{2}^{\prime}+\mathbf{B}_{2}\right) \boldsymbol{\Phi}_{1}\right], \\
\Xi_{2} \equiv & \rho\left[-\mathbf{V}_{2}+(1-\psi) \Gamma_{2}+\operatorname{vec}\left(\boldsymbol{\Phi}_{1}^{\prime} \mathbf{B}_{2} \boldsymbol{\Phi}_{1}\right)^{\prime}\right]
\end{aligned}
$$

Equation (39) confirms our initial conjecture on the form of the consumption-wealth ratio. Notice that $\Xi_{0}, \Xi_{1}, \Xi_{2}$ depend on $b_{0}, \mathbf{B}_{1}$ and $\mathbf{B}_{2}$. Therefore, for the solution to be consistent, $\left\{b_{0}, \mathbf{B}_{1}, \mathbf{B}_{2}\right\}$ must solve the following set of equations:

$$
\begin{aligned}
b_{0} & =\Xi_{0}, \\
\mathbf{B}_{1} & =\Xi_{1}^{\prime}, \\
\operatorname{vec}\left(\mathbf{B}_{2}\right) & =\Xi_{2}^{\prime} .
\end{aligned}
$$

The resulting set of values for $b_{0}, \mathbf{B}_{1}$ and $\operatorname{vec}\left(\mathbf{B}_{2}\right)$ determines the optimal consumption rule.

\section{Verification that the optimal portfolio rule is independent of $\psi$ given $\rho$.}

$>$ From equations (22) and (23) in text, and equation (37) in the Appendix, we can write $\mathbf{A}_{0}$ and $\mathbf{A}_{1}$ as:

$$
\begin{aligned}
\mathbf{A}_{0} & =\left(\frac{1}{\gamma}\right) \boldsymbol{\Sigma}_{x x}^{-1}\left(\mathbf{H}_{x} \Phi_{0}+\frac{1}{2} \boldsymbol{\sigma}_{x}^{2}+(1-\gamma) \boldsymbol{\sigma}_{1 x}\right)+\left(1-\frac{1}{\gamma}\right) \boldsymbol{\Sigma}_{x x}^{-1} \frac{-\boldsymbol{\Lambda}_{0}}{1-\psi} \\
& =\left(\frac{1}{\gamma}\right) \Sigma_{x x}^{-1}\left(\mathbf{H}_{x} \Phi_{0}+\frac{1}{2} \boldsymbol{\sigma}_{x}^{2}+(1-\gamma) \Sigma \boldsymbol{\sigma}_{1 x}\right)-\left(1-\frac{1}{\gamma}\right) \Sigma_{x x}^{-1}\left[\left(\Sigma_{v} \mathbf{H}_{x}^{\prime}\right)^{\prime} \frac{\mathbf{B}_{1}}{1-\psi}+\left(\Sigma_{v} \mathbf{H}_{x}^{\prime}\right)\left(\frac{\mathbf{B}_{2}+\mathbf{B}_{2}^{\prime}}{1-\psi}\right) \boldsymbol{\Phi}_{0}\right] \\
\mathbf{A}_{1} & =\left(\frac{1}{\gamma}\right) \boldsymbol{\Sigma}_{x x}^{-1} \mathbf{H}_{x} \Phi_{1}+\left(1-\frac{1}{\gamma}\right) \boldsymbol{\Sigma}_{x x}^{-1} \frac{-\boldsymbol{\Lambda}_{1}}{1-\psi} \\
& =\frac{1}{\gamma} \Sigma_{x x}^{-1}\left(\mathbf{H}_{x} \Phi_{1}\right)-\left(1-\frac{1}{\gamma}\right) \Sigma_{x x}^{-1}\left[\left(\Sigma_{v} \mathbf{H}_{x}^{\prime}\right)^{\prime}\left(\frac{\mathbf{B}_{2}+\mathbf{B}_{2}^{\prime}}{1-\psi}\right) \mathbf{\Phi}_{1}\right] .
\end{aligned}
$$

Thus, showing that the optimal portfolio rule is independent of $\psi$ given $\rho$ is equivalent to showing that $\mathcal{B}_{1} \equiv \mathbf{B}_{1} /(1-\psi)$ and $\mathcal{B}_{2} \equiv \mathbf{B}_{2} /(1-\psi)$ are independent of $\psi$ given $\rho$.

First, consider $\mathcal{B}_{2}$. From (40), we have

$$
(1-\psi) \operatorname{vec}\left(\mathcal{B}_{2}\right)=\rho\left[-\mathbf{V}_{2}^{\prime}+(1-\psi) \Gamma_{2}^{\prime}+(1-\psi) \operatorname{vec}\left(\boldsymbol{\Phi}_{1}^{\prime} \mathcal{B}_{2} \boldsymbol{\Phi}_{1}\right)\right]
$$


Using the definition of $\mathbf{V}_{2}$, we have

$$
\begin{aligned}
-\mathbf{V}_{2}^{\prime} & =\frac{1-\gamma}{2(1-\psi)} \operatorname{vec}\left[\left(\boldsymbol{\Phi}_{1}^{\prime}\left(\mathbf{B}_{2}+\mathbf{B}_{2}^{\prime}\right)+(1-\psi) \mathbf{A}_{1}^{\prime} \mathbf{H}_{x}\right) \Sigma_{v}\left(\boldsymbol{\Phi}_{1}^{\prime}\left(\mathbf{B}_{2}+\mathbf{B}_{2}^{\prime}\right)+(1-\psi) \mathbf{A}_{1}^{\prime} \mathbf{H}_{x}\right)^{\prime}\right] \\
& =\frac{1-\gamma}{2(1-\psi)} \operatorname{vec}\left[(1-\psi)^{2}\left(\boldsymbol{\Phi}_{1}^{\prime}\left(\mathcal{B}_{2}+\mathcal{B}_{2}^{\prime}\right)+\mathbf{A}_{1}^{\prime} \mathbf{H}_{x}\right) \Sigma_{v}\left(\boldsymbol{\Phi}_{1}^{\prime}\left(\mathcal{B}_{2}+\mathcal{B}_{2}^{\prime}\right)+\mathbf{A}_{1}^{\prime} \mathbf{H}_{x}\right)^{\prime}\right] \\
& =\frac{1-\gamma}{2}(1-\psi) \operatorname{vec}\left[\left(\boldsymbol{\Phi}_{1}^{\prime}\left(\mathcal{B}_{2}+\mathcal{B}_{2}^{\prime}\right)+\mathbf{A}_{1}^{\prime} \mathbf{H}_{x}\right) \Sigma_{v}\left(\boldsymbol{\Phi}_{1}^{\prime}\left(\mathcal{B}_{2}+\mathcal{B}_{2}^{\prime}\right)+\mathbf{A}_{1}^{\prime} \mathbf{H}_{x}\right)^{\prime}\right] \\
& \equiv(1-\psi) \overline{\mathbf{V}}_{2}^{\prime},
\end{aligned}
$$

which is independent of $\psi$, since $\mathbf{A}_{1}$ does not depend on $\psi$, given $\mathcal{B}_{2}$.

Similarly, using the definition of $\Gamma_{2}$, we have:

$$
(1-\psi) \Gamma_{2}^{\prime}=(1-\psi)\left[\operatorname{vec}\left(\mathbf{A}_{1}^{\prime} \mathbf{H}_{x} \Phi_{1}\right)-\frac{1}{2} \operatorname{vec}\left(\mathbf{A}_{1}^{\prime} \Sigma_{x x} \mathbf{A}_{1}\right)\right],
$$

which is also independent of $\psi$, since $\mathbf{A}_{1}$ does not depend on $\psi$, given $\mathcal{B}_{2}$.

Thus, (41) reduces to

$$
\operatorname{vec}\left(\mathcal{B}_{2}\right)=\rho\left[\overline{\mathbf{V}}_{2}^{\prime}+\Gamma_{2}^{\prime}+\operatorname{vec}\left(\boldsymbol{\Phi}_{1}^{\prime} \mathcal{B}_{2} \boldsymbol{\Phi}_{1}\right)\right] .
$$

This is a quadratic equation in $\mathcal{B}_{2}$, whose coefficients do not depend on $\psi$, except for $\rho$. The loglinearization coefficient $\rho \equiv 1-\exp \left(\mathrm{E}_{t}\left[c_{t}-w_{t}\right]\right)$ does depend on $\psi$ indirectly, through the dependence of $\mathrm{E}_{t}\left[c_{t}-w_{t}\right]$ on $b_{0}, \mathbf{B}_{1}$ and $\mathbf{B}_{2}$, which are functions of $\psi$. Consequently, the solution for $\mathcal{B}_{2}$ will also be independent of $\psi$ given $\rho$.

Using the same logic, we can show that $\mathcal{B}_{1}$ is independent of $\psi$. From (40) we have

$$
(1-\psi) \mathcal{B}_{1}=\rho\left[-\mathbf{V}_{1}^{\prime}+(1-\psi) \Gamma_{1}^{\prime}+(1-\psi) \boldsymbol{\Phi}_{1}^{\prime} \mathcal{B}_{1}+(1-\psi) \boldsymbol{\Phi}_{1}^{\prime}\left(\mathcal{B}_{2}+\mathcal{B}_{2}^{\prime}\right) \boldsymbol{\Phi}_{0}\right]
$$

Now,

$$
\begin{aligned}
-\mathbf{V}_{1}^{\prime} & =\frac{1-\gamma}{(1-\psi)}\left[\left((1-\psi) \bar{\Pi}_{1}\right) \Sigma_{v}^{\prime}\left(\boldsymbol{\Phi}_{1}^{\prime}\left(\mathcal{B}_{2}+\mathcal{B}_{2}^{\prime}\right)+\mathbf{A}_{1}^{\prime} \mathbf{H}_{x}\right)\right]^{\prime} \\
& =(1-\gamma)(1-\psi)\left[\bar{\Pi}_{1} \Sigma_{v}^{\prime}\left(\boldsymbol{\Phi}_{1}^{\prime}\left(\mathcal{B}_{2}+\mathcal{B}_{2}^{\prime}\right)+\mathbf{A}_{1}^{\prime} \mathbf{H}_{x}\right)\right]^{\prime} \\
& \equiv(1-\psi) \bar{V}_{1}^{\prime}
\end{aligned}
$$

where

$$
\bar{\Pi}_{1} \equiv \mathcal{B}_{1}^{\prime}+\boldsymbol{\Phi}_{0}^{\prime}\left(\mathcal{B}_{2}+\mathcal{B}_{2}^{\prime}\right)+\mathbf{A}_{0}^{\prime} \mathbf{H}_{x}+\mathbf{H}_{1} .
$$

Both $\bar{V}_{1}$ and $\bar{\Pi}_{1}$ are also independent of $\psi$, since $\mathbf{A}_{0}$ and $\mathbf{A}_{1}$ do not depend on $\psi$, given $\mathcal{B}_{1}$ and $\mathcal{B}_{2}$.

Also, $\Gamma_{1}$ is only a function of $\mathcal{B}_{1}$ and $\mathcal{B}_{2}$ via its dependence on $\mathbf{A}_{0}$ and $\mathbf{A}_{1}$, not of $\psi$. Therefore, (42) becomes

$$
\mathcal{B}_{1}=\rho\left[\overline{\mathbf{V}}_{1}^{\prime}+\Gamma_{1}^{\prime}+\boldsymbol{\Phi}_{1}^{\prime} \mathcal{B}_{1}+\boldsymbol{\Phi}_{1}^{\prime}\left(\mathcal{B}_{2}+\mathcal{B}_{2}^{\prime}\right) \boldsymbol{\Phi}_{0}\right]
$$


which again implies that the solution for $\mathcal{B}_{1}$ does not depend on $\psi$ given $\rho$ This completes our proof.

Value function when $\psi=1$.

First, note that we have just proved that $\mathcal{B}_{1}$ and $\mathcal{B}_{2}$ do not depend on $\psi$ given $\rho$. We now derive an expression for the value function when $\psi=1$. The value function is given by

$$
\begin{aligned}
V_{t} & =(1-\delta)^{-\frac{\psi}{1-\psi}}\left(\frac{C_{t}}{W_{t}}\right)^{\frac{1}{1-\psi}} \\
& =\exp \left\{-\frac{\psi}{1-\psi} \log (1-\delta)+\frac{b_{0}}{1-\psi}+\frac{\mathbf{B}_{1}^{\prime}}{1-\psi} \mathbf{z}_{t}+\frac{\operatorname{vec}\left(\mathbf{B}_{2}\right)^{\prime}}{1-\psi} \operatorname{vec}\left(\mathbf{z}_{t} \mathbf{z}_{t}^{\prime}\right)\right\} \\
& =\exp \left\{\mathcal{B}_{0}+\mathcal{B}_{1}^{\prime} \mathbf{z}_{t}+\operatorname{vec}\left(\mathcal{B}_{2}\right)^{\prime} \operatorname{vec}\left(\mathbf{z}_{t} \mathbf{z}_{t}^{\prime}\right)\right\},
\end{aligned}
$$

where $\mathcal{B}_{1}^{\prime}$, and vec $\mathcal{B}_{2}$ are independent of $\psi$ given $\rho$, but $\mathcal{B}_{0}$ does depend on $\psi$.

We now find the limiting expression for $\mathcal{B}_{0}$ when $\psi=1$ :

$$
\begin{aligned}
\mathcal{B}_{0}= & -\frac{\psi}{1-\psi} \log (1-\delta)+\frac{b_{0}}{1-\psi} \\
= & -\frac{\psi}{1-\psi} \log (1-\delta) \\
& +\frac{\rho}{1-\rho}\left[-\frac{\psi}{1-\psi} \log \delta+\frac{k}{1-\psi}-\frac{V_{0}}{1-\psi}+\Gamma_{0}+\frac{\mathbf{B}_{1}^{\prime}}{1-\psi} \Phi_{0}+\frac{\operatorname{vec}\left(\mathbf{B}_{2}\right)^{\prime}}{1-\psi} \operatorname{vec}\left(\Phi_{0} \Phi_{0}^{\prime}\right)+\frac{\operatorname{vec}\left(\mathbf{B}_{2}\right)^{\prime}}{1-\psi} \operatorname{vec}\left(\Sigma_{v}\right)\right] \\
= & \frac{1}{1-\psi} \frac{\rho}{1-\rho}\left[-\frac{1-\rho}{\rho} \psi \log (1-\delta)-\psi \log \delta+k\right] \\
& +\frac{\rho}{1-\rho}\left[-\frac{V_{0}}{1-\psi}+\Gamma_{0}+\frac{\mathbf{B}_{1}^{\prime}}{1-\psi} \Phi_{0}+\frac{\operatorname{vec}\left(\mathbf{B}_{2}\right)^{\prime}}{1-\psi} \operatorname{vec}\left(\Phi_{0} \Phi_{0}^{\prime}\right)+\frac{\operatorname{vec}\left(\mathbf{B}_{2}\right)^{\prime}}{1-\psi} \operatorname{vec}\left(\Sigma_{v}\right)\right] .
\end{aligned}
$$

Substituting $k=\log \rho+((1-\rho) / \rho) \log (1-\rho)$ into the first term of the last equality, and noting that $\rho=\delta$ when $\psi=1$, we have

$$
\begin{aligned}
& \frac{1}{1-\psi} \frac{\rho}{1-\rho}\left[-\frac{1-\rho}{\rho} \psi \log (1-\delta)-\psi \log \delta+k\right] \\
= & \frac{1}{1-\psi} \frac{\rho}{1-\rho}\left[-\frac{1-\rho}{\rho} \psi \log (1-\delta)-\psi \log \delta+\log \rho+\frac{1-\rho}{\rho} \log (1-\rho)\right] \\
= & \frac{1}{1-\psi} \frac{\rho}{1-\rho}\left[\frac{1-\rho}{\rho}(1-\psi) \log (1-\delta)+(1-\psi) \log \delta\right] \\
= & \log (1-\delta)+\frac{\delta}{1-\delta} \log \delta,
\end{aligned}
$$

which is independent of $\psi$. 
$>$ From previous results, we know that all the terms in the second term of the last equality are independent of $\psi$ given $\rho$, except for $V_{0} /(1-\psi)$. We now verify that this term is also independent of $\psi$ given $\rho$ :

$$
\begin{aligned}
\mathcal{V}_{0} & \equiv \frac{V_{0}}{1-\psi} \\
& =-\frac{1-\gamma}{2}\left[\frac{\Pi_{1} \Sigma_{v} \Pi_{1}^{\prime}}{(1-\psi)^{2}}+\frac{\operatorname{vec}\left(\mathbf{B}_{2}\right)^{\prime}}{1-\psi} \operatorname{Var}_{t}(.) \frac{\operatorname{vec}\left(\mathbf{B}_{2}\right)^{\prime}}{1-\psi}\right] \\
& =-\frac{1-\gamma}{2}\left[\frac{\Pi_{1} \Sigma_{v} \Pi_{1}^{\prime}}{(1-\psi)^{2}}+\operatorname{vec}\left(\mathcal{B}_{2}\right)^{\prime} \operatorname{Var}_{t}(.) \operatorname{vec}\left(\mathcal{B}_{2}\right)\right]
\end{aligned}
$$

where the second term is independent of $\psi$ given $\rho$, and the first one is also verifiably independent of $\psi$ :

$$
\begin{aligned}
\frac{\Pi_{1} \Sigma_{v} \Pi_{1}^{\prime}}{(1-\psi)^{2}} & =\left(\frac{\mathbf{B}_{1}^{\prime}}{(1-\psi)}+\mathbf{A}_{0}^{\prime} \mathbf{H}_{x}+\mathbf{H}_{1}+\Phi_{0}^{\prime} \frac{\mathbf{B}_{2}+\mathbf{B}_{2}^{\prime}}{1-\psi}\right) \Sigma_{v}\left(\frac{\mathbf{B}_{1}}{(1-\psi)}+\mathbf{H}_{x}^{\prime} \mathbf{A}_{0}+\mathbf{H}_{1}^{\prime}+\frac{\mathbf{B}_{2}+\mathbf{B}_{2}^{\prime}}{(1-\psi)} \Phi_{0}\right) \\
& =\left(\mathcal{B}_{1}^{\prime}+\mathbf{A}_{0}^{\prime} \mathbf{H}_{x}+\mathbf{H}_{1}+\Phi_{0}^{\prime}\left(\mathcal{B}_{2}+\mathcal{B}_{2}^{\prime}\right)\right) \Sigma_{v}\left(\mathcal{B}_{1}+\mathbf{H}_{x}^{\prime} \mathbf{A}_{0}+\mathbf{H}_{1}^{\prime}+\left(\mathcal{B}_{2}+\mathcal{B}_{2}^{\prime}\right) \Phi_{0}\right)
\end{aligned}
$$

which does not depend on $\psi$ given $\rho$.

Thus when $\psi=1$ we have:

$$
\begin{aligned}
\mathcal{B}_{0}= & \log (1-\delta)+\frac{\delta}{1-\delta} \log \delta \\
& +\frac{\delta}{1-\delta}\left[-\mathcal{V}_{0}+\Gamma_{0}+\mathcal{B}_{1}^{\prime} \Phi_{0}+\operatorname{vec}\left(\mathcal{B}_{2}\right)^{\prime} \operatorname{vec}\left(\Phi_{0} \Phi_{0}^{\prime}\right)+\operatorname{vec}\left(\mathcal{B}_{2}\right)^{\prime} \operatorname{vec}\left(\Sigma_{v}\right)\right]
\end{aligned}
$$

Now, since $\rho$ is independent of $\psi$ in the special case $\psi=1$ - because $\rho=\delta$-, we conclude that $\mathcal{B}_{0}, \mathcal{B}_{1}$ and $\mathcal{B}_{2}$ are independent of $\psi$ when $\psi=1$.

\section{Derivation of $\mathrm{E}\left[V_{t}\right]$.}

$>$ From the previous section, we learn how to obtain the coefficient matrices $\mathcal{B}_{0}, \mathcal{B}_{1}$ and $\mathcal{B}_{2}$. Now we want to evaluate explicitly

$$
\mathrm{E}\left(V_{t}\right)=\mathrm{E}\left[\exp \left(\mathcal{B}_{0}+\mathcal{B}_{1}^{\prime} \mathbf{z}_{t}+\mathbf{z}_{t}^{\prime} \mathcal{B}_{2} \mathbf{z}_{t}\right)\right]
$$

where $\mathbf{z}_{t}$ has a multivariate normal distribution

$$
\mathbf{z}_{t} \sim \mathcal{N}\left(\boldsymbol{\mu}_{z}, \boldsymbol{\Sigma}_{z z}\right)
$$

with

$$
\begin{aligned}
\boldsymbol{\mu}_{z} & =\left(\mathbf{I}_{m}-\boldsymbol{\Phi}_{1}\right)^{-1} \boldsymbol{\Phi}_{0} \\
\operatorname{vec}\left(\boldsymbol{\Sigma}_{z z}\right) & =\left(\mathbf{I}_{m^{2}}-\boldsymbol{\Phi}_{1} \otimes \mathbf{\Phi}_{1}\right)^{-1} \operatorname{vec}\left(\boldsymbol{\Sigma}_{v}\right) .
\end{aligned}
$$


First, consider a change of variable. Define

$$
\mathbf{h}_{t}=\mathbf{z}_{t}-\boldsymbol{\mu}_{z}
$$

Then,

$$
\mathcal{B}_{0}+\mathcal{B}_{1}^{\prime} \mathbf{z}_{t}+\mathbf{z}_{t}^{\prime} \mathcal{B}_{2} \mathbf{z}_{t}=\mathcal{C}_{0}+\mathcal{C}_{1} \mathbf{h}_{t}+\mathbf{h}_{t}^{\prime} \mathcal{C}_{2} \mathbf{h}_{t}
$$

where

$$
\begin{aligned}
& \mathcal{C}_{0} \equiv \mathcal{B}_{0}+\mathcal{B}_{1}^{\prime} \boldsymbol{\mu}_{z}+\boldsymbol{\mu}_{z}^{\prime} \mathcal{B}_{2} \boldsymbol{\mu}_{z} \\
& \mathcal{C}_{1} \equiv \mathcal{B}_{1}^{\prime}+2 \boldsymbol{\mu}_{z}^{\prime} \mathcal{B}_{2} \\
& \mathcal{C}_{2} \equiv \mathcal{B}_{2}
\end{aligned}
$$

To calculate $\mathrm{E}\left(V_{t}\right)$,

$$
\begin{aligned}
& \mathrm{E}\left(V_{t}\right) \\
= & \int_{-\infty}^{\infty} \cdots \int_{-\infty}^{\infty} \exp \left(\mathcal{B}_{0}+\mathcal{B}_{1}^{\prime} \mathbf{z}_{t}+\mathbf{z}_{t}^{\prime} \mathcal{B}_{2} \mathbf{z}_{t}\right) \\
& \times\left(\frac{1}{\sqrt{2 \pi}}\left|\boldsymbol{\Sigma}_{z z}\right|^{-\frac{1}{2}} \exp \left(-\frac{1}{2}\left(\mathbf{z}_{t}-\boldsymbol{\mu}_{z}\right)^{\prime} \boldsymbol{\Sigma}_{z z}^{-1}\left(\mathbf{z}_{t}-\boldsymbol{\mu}_{z}\right)\right)\right) d z_{1 t} \ldots d z_{m t} \\
= & \int_{-\infty}^{\infty} \cdots \int_{-\infty}^{\infty} \exp \left(\mathcal{C}_{0}+\mathcal{C}_{1} \mathbf{h}_{t}+\mathbf{h}_{t}^{\prime} \mathcal{C}_{2} \mathbf{h}_{t}\right) \cdot\left(\frac{1}{\sqrt{2 \pi}}\left|\boldsymbol{\Sigma}_{z z}\right|^{-\frac{1}{2}} \exp \left(-\frac{1}{2} \mathbf{h}_{t}^{\prime} \boldsymbol{\Sigma}_{z z}^{-1} \mathbf{h}_{t}\right)\right) d h_{1 t} \ldots d h_{m t} \\
= & \frac{1}{\sqrt{2 \pi}}\left|\boldsymbol{\Sigma}_{z z}\right|^{-\frac{1}{2}} \cdot \int_{-\infty}^{\infty} \cdots \int_{-\infty}^{\infty} \exp \left(\mathcal{C}_{0}+\mathcal{C}_{1} \mathbf{h}_{t}-\frac{1}{2} \mathbf{h}_{t}^{\prime}\left(\boldsymbol{\Sigma}_{z z}^{-1}-2 \mathcal{C}_{2}\right) \mathbf{h}_{t}\right) d h_{1 t} \ldots d h_{m t} \\
= & \frac{\left|\boldsymbol{\Sigma}_{z z}\right|^{-\frac{1}{2}}}{\sqrt{2 \pi}} \frac{\left|\left(\boldsymbol{\Sigma}_{z z}^{-1}-2 \mathcal{C}_{2}\right)^{-1}\right|^{-\frac{1}{2}}}{\left|\left(\boldsymbol{\Sigma}_{z z}^{-1}-2 \mathcal{C}_{2}\right)^{-1}\right|^{-\frac{1}{2}}} \cdot \int_{-\infty}^{\infty} \cdots \int_{-\infty}^{\infty} \exp \left(\mathcal{C}_{0}+\mathcal{C}_{1} \mathbf{h}_{t}-\frac{1}{2} \mathbf{h}_{t}^{\prime}\left(\boldsymbol{\Sigma}_{z z}^{-1}-2 \mathcal{C}_{2}\right) \mathbf{h}_{t}\right) d h_{1 t} \ldots d h_{m t} \\
= & \frac{\left|\boldsymbol{\Sigma}_{z z}\right|^{-\frac{1}{2}}}{\left|\left(\boldsymbol{\Sigma}_{z z}^{-1}-2 \mathcal{C}_{2}\right)\right|^{\frac{1}{2}}} \\
& \times \frac{1}{\sqrt{2 \pi}}\left|\left(\boldsymbol{\Sigma}_{z z}^{-1}-2 \mathcal{C}_{2}\right)^{-1}\right|^{-\frac{1}{2}} \int_{-\infty}^{\infty} \ldots \int_{-\infty}^{\infty} \exp \left(\mathcal{C}_{0}+\mathcal{C}_{1} \mathbf{h}_{t}-\frac{1}{2} \mathbf{h}_{t}^{\prime}\left(\boldsymbol{\Sigma}_{z z}^{-1}-2 \mathcal{C}_{2}\right) \mathbf{h}_{t}\right) d h_{1 t} \ldots d h_{m t} \\
= & \frac{\left|\boldsymbol{\Sigma}_{z z}\right|^{-\frac{1}{2}}}{\left|\left(\boldsymbol{\Sigma}_{z z}^{-1}-2 \mathcal{C}_{2}\right)\right|^{\frac{1}{2}}} \cdot \widetilde{\mathrm{E}}\left(\exp \left(\mathcal{C}_{0}+\mathcal{C}_{1} \mathbf{h}_{t}\right)\right),
\end{aligned}
$$

where the expectation $\widetilde{\mathrm{E}}$ is taken as if $\mathbf{h}_{t}$ is normally distributed with mean zero and covariance matrix $\left(\boldsymbol{\Sigma}_{z z}^{-1}-2 \mathcal{C}_{2}\right)^{-1}$. Thus, we immediately have

$$
\mathrm{E}\left(V_{t}\right)=\frac{\left|\boldsymbol{\Sigma}_{z z}\right|^{-\frac{1}{2}}}{\left|\left(\boldsymbol{\Sigma}_{z z}^{-1}-2 \mathcal{C}_{2}\right)\right|^{\frac{1}{2}}} \cdot \exp \left(\mathcal{C}_{0}+\frac{1}{2} \mathcal{C}_{1}\left(\boldsymbol{\Sigma}_{z z}^{-1}-2 \mathcal{C}_{2}\right)^{-1} \mathcal{C}_{1}^{\prime}\right) .
$$




\section{B Appendix B: Numerical Procedure}

Equations (21) and (40) show that the coefficients $\left\{\mathbf{A}_{0}, \mathbf{A}_{1}\right\},\left\{b_{0}, \mathbf{B}_{1}, \operatorname{vec}\left(\mathbf{B}_{2}\right)\right\}$ in the optimal policy rules are functions of the underlying parameters. When there is one state variable as in Campbell and Viceira (1999), solving explicitly for these coefficients is manageable. However, with multiple state variables, such an exercise is practically impossible. Therefore, we employ a simple numerical procedure to find these coefficients instead.

To find the coefficients of the optimal portfolio rule for each value of $\gamma$, we use the fact that they are independent of $\psi$ given $\rho$. Thus, for each $\gamma$, we fix a value for $\rho$, choose an arbitrary value for $\psi$, and start with some initial values for $\left\{\mathbf{B}_{1}, \operatorname{vec}\left(\mathbf{B}_{2}\right)\right\}$-denote these by $\left\{\mathbf{B}_{1}^{(1)}\right.$, vec $\left.\left(\mathbf{B}_{2}\right)^{(1)}\right\}$. Through equation (21), this implies a set of values for $\left\{\mathbf{A}_{0}, \mathbf{A}_{1}\right\}$-denote these by $\left\{\mathbf{A}_{0}^{(1)}, \mathbf{A}_{1}^{(1)}\right\}$.

With $\rho,\left\{\mathbf{A}_{0}^{(1)}, \mathbf{A}_{1}^{(1)}\right\},\left\{\mathbf{B}_{1}^{(1)}, \operatorname{vec}\left(\mathbf{B}_{2}\right)^{(1)}\right\}$, we can compute the coefficients $\left\{\Xi_{1}, \Xi_{2}\right\}$ in the $c-w$ difference equation (39). By equating these coefficients with the $\left\{\mathbf{B}_{1}, \operatorname{vec}\left(\mathbf{B}_{2}\right)\right\}$ in the conjectured policy function, we have a new set of values for $\left\{\mathbf{B}_{1}, \operatorname{vec}\left(\mathbf{B}_{2}\right)\right\}$ - call them $\left\{\mathbf{B}_{1}^{(2)}, \operatorname{vec}\left(\mathbf{B}_{2}\right)^{(2)}\right\}$. Since the initial values are arbitrary, $\left\{\mathbf{B}_{1}^{(2)}, \operatorname{vec}\left(\mathbf{B}_{2}\right)^{(2)}\right\}$ will be different from $\left\{\mathbf{B}_{1}^{(1)}, \operatorname{vec}\left(\mathbf{B}_{2}\right)^{(1)}\right\}$ in general. Thus, we recompute $\left\{\mathbf{A}_{0}, \mathbf{A}_{1}\right\}$ using $\rho$, and $\left\{\mathbf{B}_{1}^{(2)}, \operatorname{vec}\left(\mathbf{B}_{2}\right)^{(2)}\right\}$ to get $\left\{\mathbf{A}_{0}^{(2)}, \mathbf{A}_{1}^{(2)}\right\}$. We obtain then a new set of values for $\left\{\Xi_{1}, \Xi_{2}\right\}$. We continue until values of $\left\{\mathbf{B}_{1}, \operatorname{vec}\left(\mathbf{B}_{2}\right)\right\}$, and hence $\left\{\mathbf{A}_{0}, \mathbf{A}_{1}\right\}$, converge.

The convergence criterion for $\left\{\mathbf{B}_{1}, \operatorname{vec}\left(\mathbf{B}_{2}\right)\right\}$ is rather stringent. We first calculate the maximum of the squared deviations of all elements from 2 consecutive iterations. We then require for parameter convergence that the sum of 20 such consecutive maxima be less than 0.00001 .

Note once again that coefficients $\left\{\mathbf{A}_{0}, \mathbf{A}_{1}\right\}$ are the same for all values of $\psi$ given the loglinearization parameter $\rho$. In the special case $\psi=1$, we also have that $\rho=\delta$, so that the solution is exact, and choosing a value for $\rho$ is equivalent to choosing a value for $\delta$. When $\psi$ is not equal to one, we implement a recursive procedure similar to the one described in Campbell and Viceira (1999, 2001). Given an initial value of $\rho$, we compute coefficients $\left\{\mathbf{A}_{0}, \mathbf{A}_{1}\right\},\left\{b_{0}, \mathbf{B}_{1}, \operatorname{vec}\left(\mathbf{B}_{2}\right)\right\}$ using the procedure described above. From $\left\{b_{0}, \mathbf{B}_{1}, \operatorname{vec}\left(\mathbf{B}_{2}\right)\right\}$, we can compute $\mathbf{E}_{t}\left[c_{t}-w_{t}\right]$, and a new value of $\rho$. We iterate until convergence. 


\section{Appendix C: Construction of Hypothetical Real Bonds}

Recall that the first element of our VAR system is the ex post real bill return. Therefore, the ex ante $\log$ real bill return at time $t+1$ is the first element of $\mathrm{E}_{t}\left(\mathbf{z}_{t+1}\right)=\Phi_{0}+\Phi_{1} \mathbf{z}_{t}$. In other words, the log real yield at time $t$ is given by

$$
\widehat{y}_{1 t}=\mathbf{H}_{1} \cdot \mathrm{E}_{t}\left(\mathbf{z}_{t+1}\right) \equiv \mathbf{H}_{1} \cdot \widehat{\mathbf{z}}_{t, t+1},
$$

where $\mathbf{H}_{1} \equiv(1,0, \ldots, 0)$ and $\widehat{\mathbf{z}}_{t, t+1} \equiv \mathrm{E}_{t}\left(\mathbf{z}_{t+1}\right)$.

The next step is to assume that the log expectations hypothesis holds for the real term structure; that is,

$$
y_{n, t}=\frac{1}{n} \sum_{i=0}^{n-1} \mathrm{E}_{t}\left(y_{1, t+i}\right),
$$

where $y_{n, t}$ is the $\log$ yield on a real bond with maturity $n$. Note that we have implicitly assume that inflation risk premium is zero. An estimate of $y_{n, t}$ can be easily constructed as follows:

$$
\widehat{y}_{n, t}=\frac{1}{n} \sum_{i=0}^{n-1} \widehat{y}_{1, t+i}=\frac{1}{n} \sum_{i=0}^{n-1} \mathbf{H}_{1} \cdot \widehat{\mathbf{z}}_{t, t+i+1} .
$$

To compute $\widehat{\mathbf{z}}_{t, t+i+1}$, we can iterate the VAR(1) system forward to get

$$
\widehat{\mathbf{z}}_{t, t+k}=\left(\sum_{j=0}^{k-1} \Phi_{1}^{j}\right) \Phi_{0}+\Phi_{1}^{k} \mathbf{z}_{t} .
$$

Using this result, log yield can be expressed as a function of current state variables:

$$
\begin{aligned}
\widehat{y}_{n, t} & =\frac{1}{n} \mathbf{H}_{1} \sum_{i=1}^{n} \widehat{\mathbf{z}}_{t, t+i} \\
& =\frac{1}{n} \mathbf{H}_{1} \sum_{i=1}^{n}\left[\left(\sum_{j=0}^{i-1} \Phi_{1}^{j}\right) \Phi_{0}+\Phi_{1}^{i} \mathbf{z}_{t}\right] \\
& \equiv \frac{1}{n} \mathbf{H}_{1}\left(\mathbf{Q}_{c}+\mathbf{Q}_{n} \mathbf{z}_{t}\right)
\end{aligned}
$$

where

$$
\begin{aligned}
& \mathbf{Q}_{n} \equiv \sum_{i=1}^{n} \Phi_{1}^{i}=\Phi_{1}\left(\mathbf{I}_{m}-\Phi_{1}\right)^{-1}\left(\mathbf{I}_{m}-\Phi_{1}^{n}\right), \\
& \mathbf{Q}_{c} \equiv\left(\mathbf{I}_{m}-\Phi_{1}\right)^{-1}\left(\mathbf{I}_{m}-\mathbf{Q}_{n}\right) \Phi_{0},
\end{aligned}
$$


and $\mathbf{I}_{m}$ is the identity matrix, $m=\operatorname{dim}\left(\mathbf{z}_{t}\right)$.

Finally, the 1-period return on a hypothetical real $n$-period bond is calculated as

$$
\begin{aligned}
r_{n, t+1} & =n \widehat{y}_{n, t}-(n-1) \widehat{y}_{n-1, t+1} \\
& \approx n \widehat{y}_{n, t}-(n-1) \widehat{y}_{n, t+1}
\end{aligned}
$$

And the excess return on the hypothetical real $n$-period bond is

$$
\begin{aligned}
& r_{n, t+1}-r_{1, t+1} \\
= & \left(n \widehat{y}_{n, t}-(n-1) \widehat{y}_{n, t+1}\right)-\widehat{y}_{1 t} \\
= & \left\{\mathbf{H}_{1}\left(\mathbf{Q}_{c}+\mathbf{Q}_{n} \mathbf{z}_{t}\right)-\frac{n-1}{n} \mathbf{H}_{1}\left(\mathbf{Q}_{c}+\mathbf{Q}_{n} \mathbf{z}_{t+1}\right)\right\}-\mathbf{H}_{1}\left(\Phi_{0}+\Phi_{1} \mathbf{z}_{t}\right) .
\end{aligned}
$$

The next step is to construct a real perpetuity from these zero-coupon bonds. Campbell, Lo and MacKinlay (1997) show how to use a loglinearization framework to construct real perpetuity returns. Specifically,their equations (10.1.16) and (10.1.17) show that the log yield on a real perpetuity or "consol" $y_{c, \infty, t}$ is given by

$$
y_{c, \infty, t}=\left(1-\rho_{c}\right) \sum_{i=0}^{\infty} \rho_{c}^{i} r_{c, \infty, t+1+i}
$$

where $r_{c, \infty, t+i}$ is the one-period log return on a perpetuity at time $t+i$ and $\rho_{c}=1-\exp \left(\mathrm{E}\left[-p_{c, t}\right]\right)$, where $p_{c, t}$ is the log "cum-dividend" price of the perpetuity including its current coupon payout.

Taking conditional expectations at time $t$ and imposing the expectations hypothesis,

$$
\begin{aligned}
y_{c, \infty, t} & =\left(1-\rho_{c}\right) \sum_{i=0}^{\infty} \rho_{c}^{i} \mathbf{H}_{1} \widehat{\mathbf{z}}_{t, t+i+1} \\
& =\mathbf{H}_{1}\left(1-\rho_{c}\right)\left(\sum_{i=0}^{\infty} \rho_{c}^{i} \sum_{j=0}^{i} \Phi_{1}^{j}\right) \Phi_{0}+\mathbf{H}_{1}\left(1-\rho_{c}\right)\left(\sum_{i=0}^{\infty} \rho_{c}^{i} \Phi_{1}^{i+1}\right) \mathbf{z}_{t} .
\end{aligned}
$$

It is straightforward to show that

$$
\begin{aligned}
\sum_{i=0}^{\infty} \rho_{c}^{i} \sum_{j=0}^{i} \Phi_{1}^{j} & =\frac{1}{1-\rho_{c}}\left(\mathbf{I}_{m}-\rho_{c} \Phi_{1}\right)^{-1} \\
\sum_{i=0}^{\infty} \rho_{c}^{i} \Phi_{1}^{i+1} & =\left(\mathbf{I}_{m}-\rho_{c} \Phi_{1}\right)^{-1} \Phi_{1}
\end{aligned}
$$

Thus, the log yield can be expressed as function of the VAR parameters, current state variables and the loglinearization constant $\rho_{c}$ :

$$
y_{c, \infty, t}=\mathbf{H}_{1}\left(\mathbf{I}_{m}-\rho_{c} \Phi_{1}\right)^{-1} \Phi_{0}+\mathbf{H}_{1}\left(1-\rho_{c}\right)\left(\mathbf{I}_{m}-\rho_{c} \Phi_{1}\right)^{-1} \Phi_{1} \mathbf{z}_{t} .
$$


D Appendix D: Tables 
TABLE A

VAR Estimation Results

Nominal Bills, Stocks and Real Consol Bond

\begin{tabular}{|c|c|c|c|c|c|c|c|}
\hline \multicolumn{8}{|c|}{ A: Quarterly Sample (1952.Q2 - 1999.Q4) } \\
\hline $\begin{array}{c}\text { Dependent } \\
\text { Variable }\end{array}$ & $\begin{array}{c}r t b_{t} \\
(t)\end{array}$ & $\begin{array}{l}x r_{t} \\
(t)\end{array}$ & $\begin{array}{c}x r c b_{t} \\
(t)\end{array}$ & $\begin{array}{l}y_{t} \\
(t)\end{array}$ & $\begin{array}{c}(d-p)_{t} \\
(t)\end{array}$ & $\begin{array}{l}s p r_{t} \\
(t)\end{array}$ & $\begin{array}{l}R^{2} \\
(p)\end{array}$ \\
\hline \multicolumn{8}{|c|}{ VAR Estimation Results } \\
\hline$r t b_{t+1}$ & $\begin{array}{c}0.435 \\
(6.154)\end{array}$ & $\begin{array}{c}0.005 \\
(0.775)\end{array}$ & $\begin{array}{c}0.015 \\
(0.359)\end{array}$ & $\begin{array}{c}0.270 \\
(3.478)\end{array}$ & $\begin{array}{l}-0.001 \\
(-1.173)\end{array}$ & $\begin{array}{c}0.428 \\
(2.261)\end{array}$ & $\begin{array}{c}0.338 \\
(0.000)\end{array}$ \\
\hline & $(6.154)$ & $(0.775)$ & $(0.359)$ & $(3.478)$ & $(-1.173)$ & $(2.261)$ & $(0.000)$ \\
\hline$x r_{t+1}$ & $\begin{array}{c}1.866 \\
(1.559)\end{array}$ & $\begin{array}{c}0.079 \\
(0.953)\end{array}$ & $\begin{array}{c}0.919 \\
(1.580)\end{array}$ & $\begin{array}{c}-2.341 \\
(-2.627)\end{array}$ & $\begin{array}{c}0.050 \\
(2.404)\end{array}$ & $\begin{array}{c}0.201 \\
(0.077)\end{array}$ & $\begin{array}{c}0.084 \\
(0.008)\end{array}$ \\
\hline$x r c b_{t+1}$ & $\begin{array}{c}0.000 \\
(0.000)\end{array}$ & $\begin{array}{c}0.000 \\
(0.000)\end{array}$ & $\begin{array}{c}0.000 \\
(0.000)\end{array}$ & $\begin{array}{c}0.000 \\
(0.000)\end{array}$ & $\begin{array}{c}0.000 \\
(0.000)\end{array}$ & $\begin{array}{c}0.000 \\
(0.000)\end{array}$ & $\begin{array}{c}0.000 \\
(1.000)\end{array}$ \\
\hline$y_{t+1}$ & $\begin{array}{c}-0.001 \\
(-0.024)\end{array}$ & $\begin{array}{c}0.004 \\
(1.505)\end{array}$ & $\begin{array}{c}-0.000 \\
(-0.009)\end{array}$ & $\begin{array}{c}0.948 \\
(18.671)\end{array}$ & $\begin{array}{c}0.000 \\
(0.002)\end{array}$ & $\begin{array}{c}0.120 \\
(1.151)\end{array}$ & $\begin{array}{c}0.868 \\
(0.000)\end{array}$ \\
\hline$(d-p)_{t+1}$ & $\begin{array}{l}-1.972 \\
(-1.615)\end{array}$ & $\begin{array}{c}-0.072 \\
(-0.803)\end{array}$ & $\begin{array}{c}-0.819 \\
(-1.333)\end{array}$ & $\begin{array}{c}1.640 \\
(1.765)\end{array}$ & $\begin{array}{c}0.959 \\
(44.168)\end{array}$ & $\begin{array}{c}-0.955 \\
(-0.355)\end{array}$ & $\begin{array}{c}0.932 \\
(0.000)\end{array}$ \\
\hline$s p r_{t+1}$ & $\begin{array}{c}0.009 \\
(0.304)\end{array}$ & $\begin{array}{c}-0.000 \\
(-0.045)\end{array}$ & $\begin{array}{c}0.009 \\
(0.586)\end{array}$ & $\begin{array}{c}0.026 \\
(0.815)\end{array}$ & $\begin{array}{c}-0.000 \\
(-0.232)\end{array}$ & $\begin{array}{c}0.743 \\
(10.996)\end{array}$ & $\begin{array}{c}0.540 \\
(0.000)\end{array}$ \\
\hline
\end{tabular}

Cross-Correlation of Residuals

$\begin{array}{llllccc} & r t b & x r & x r c b & y & (d-p) & s p r \\ r t b & 0.551 & 0.228 & -0.465 & -0.390 & -0.228 & 0.183 \\ x r & - & 7.764 & -0.351 & -0.164 & -0.981 & 0.023 \\ x r c b & - & - & 1.236 & -0.408 & 0.333 & 0.111 \\ y & - & - & - & 0.256 & 0.196 & -0.776 \\ (d-p) & - & - & - & - & 7.946 & -0.056 \\ s p r & - & - & - & - & - & 0.172\end{array}$

Note: $r t b_{t}=$ ex post real T-Bill rate, $x r_{t}=$ excess stock return, $x r c b_{t}=$ excess real consol bond return, $(d-p)_{t}=\log$ dividend-price ratio, $y_{t}=$ nominal T-bill yield, $s p r_{t}=$ yield spread. The bond is a 5 -year nominal bond in the quarterly dataset and a 20 -year for the annual dataset. 
TABLE A (Ctd.)

VAR Estimation Results

Nominal Bills, Stocks and Real Consol Bond

\begin{tabular}{cccccccc}
\hline \multicolumn{7}{c}{ B: Annual Sample } & $(\mathbf{1 8 9 0}-\mathbf{1 9 9 8})$ \\
\hline Dependent & $r t b_{t}$ & $x r_{t}$ & $x r c b_{t}$ & $y_{t}$ & $(d-p)_{t}$ & $s p r_{t}$ & $R^{2}$ \\
Variable & $(t)$ & $(t)$ & $(t)$ & $(t)$ & $(t)$ & $(t)$ & $(p)$ \\
\hline VAR Estimation Results & & & & & & \\
$r t b_{t+1}$ & 0.309 & -0.056 & 0.000 & 0.604 & -0.009 & -0.548 & 0.235 \\
& $(2.299)$ & $(-1.467)$ & $(0.004)$ & $(2.546)$ & $(-0.320)$ & $(-1.081)$ & $(0.000)$ \\
$x r_{t+1}$ & -0.096 & 0.078 & -0.211 & 0.052 & 0.136 & 1.682 & 0.058 \\
& $(-0.270)$ & $(0.650)$ & $(-1.100)$ & $(0.080)$ & $(2.385)$ & $(1.217)$ & $(0.314)$ \\
$x r c b_{t+1}$ & 0.000 & 0.000 & 0.000 & 0.000 & 0.000 & 0.000 & 0.000 \\
& $(0.000)$ & $(0.000)$ & $(0.000)$ & $(0.000)$ & $(0.000)$ & $(0.000)$ & $(1.000)$ \\
$y_{t+1}$ & -0.058 & -0.013 & -0.017 & 0.897 & -0.006 & 0.098 & 0.774 \\
& $(-2.142)$ & $(-1.928)$ & $(-1.035)$ & $(11.157)$ & $(-1.343)$ & $(0.956)$ & $(0.000)$ \\
$(d-p)_{t+1}$ & -0.362 & -0.136 & 0.192 & -0.928 & 0.826 & -1.505 & 0.719 \\
& $(-1.202)$ & $(-1.310)$ & $(1.047)$ & $(-1.498)$ & $(12.505)$ & $(-1.113)$ & $(0.000)$ \\
$s p r_{t+1}$ & 0.030 & 0.003 & 0.011 & 0.093 & 0.004 & 0.767 & 0.541 \\
& $(1.565)$ & $(0.500)$ & $(0.962)$ & $(1.672)$ & $(1.245)$ & $(9.785)$ & $(0.000)$ \\
& & & & & & &
\end{tabular}

Cross-Correlation of Residuals

\begin{tabular}{lllrrrr} 
& $r t b$ & $x r$ & $x r c b$ & $y$ & $(d-p)$ & \multicolumn{1}{c}{$s p r$} \\
$r t b$ & 7.619 & -0.169 & -0.839 & 0.126 & 0.109 & -0.160 \\
$x r$ & - & 17.429 & 0.166 & -0.149 & -0.721 & 0.196 \\
$x r c b$ & - & - & 12.416 & -0.579 & -0.026 & 0.617 \\
$y$ & - & - & - & 1.235 & 0.205 & -0.892 \\
$(d-p)$ & - & - & - & - & 16.104 & -0.185 \\
$s p r$ & - & - & - & - & - & 0.977
\end{tabular}

Note: $r t b_{t}=$ ex post real T-Bill rate, $x r_{t}=$ excess stock return, $x r c b_{t}=$ excess real consol bond return, $(d-p)_{t}=\log$ dividend-price ratio, $y_{t}=$ nominal T-bill yield, $s p r_{t}=$ yield spread. The bond is a 5 -year nominal bond in the quarterly dataset and a 20-year for the annual dataset. 
TABLE B

VAR Estimation Results

Nominal Bills, Stocks, Real Consol Bond, and Nominal Bond

\begin{tabular}{ccccccccc}
\hline \multicolumn{7}{c}{ A: Quarterly Sample (1952.Q2 - 1999.Q4) } \\
\hline $\begin{array}{c}\text { Dependent } \\
\text { Variable }\end{array}$ & $r t b_{t}$ & $x r_{t}$ & $x n b_{t}$ & $x r c b_{t}$ & $y_{t}$ & $(d-p)_{t}$ & $s p r_{t}$ & $R^{2}$ \\
\hline VAR Estimation Results & $(t)$ & $(t)$ & $(t)$ & $(t)$ & $(t)$ & $(t)$ & $(p)$ \\
$r t b_{t+1}$ & 0.593 & 0.012 & -0.058 & 0.128 & 0.236 & -0.001 & 0.409 & 0.352 \\
& $(5.344)$ & $(1.984)$ & $(-1.929)$ & $(1.967)$ & $(3.129)$ & $(-0.721)$ & $(2.178)$ & $(0.000)$ \\
$x r_{t+1}$ & 0.962 & 0.038 & 0.329 & 0.276 & -2.148 & 0.047 & 0.310 & 0.087 \\
& $(0.558)$ & $(0.394)$ & $(0.729)$ & $(0.261)$ & $(-2.286)$ & $(2.277)$ & $(0.119)$ & $(0.006)$ \\
$x n b_{t+1}$ & 0.375 & -0.038 & -0.189 & 0.280 & 0.314 & 0.003 & 2.968 & 0.099 \\
& $(0.727)$ & $(-1.473)$ & $(-1.128)$ & $(0.866)$ & $(0.731)$ & $(0.441)$ & $(2.700)$ & $(0.002)$ \\
$x r c b_{t+1}$ & 0.000 & 0.000 & 0.000 & 0.000 & 0.000 & 0.000 & 0.000 & 0.000 \\
& $(0.000)$ & $(0.000)$ & $(0.000)$ & $(0.000)$ & $(0.000)$ & $(0.000)$ & $(0.000)$ & $(1.000)$ \\
$y_{t+1}$ & -0.042 & 0.002 & 0.015 & -0.029 & 0.957 & -0.000 & 0.125 & 0.869 \\
& $(-0.769)$ & $(0.816)$ & $(0.778)$ & $(-0.935)$ & $(19.692)$ & $(-0.260)$ & $(1.204)$ & $(0.000)$ \\
$(d-p)_{t+1}$ & -0.980 & -0.027 & -0.362 & -0.112 & 1.428 & 0.962 & -1.074 & 0.932 \\
& $(-0.539)$ & $(-0.262)$ & $(-0.757)$ & $(-0.102)$ & $(1.457)$ & $(44.524)$ & $(-0.401)$ & $(0.000)$ \\
$s p r_{t+1}$ & 0.019 & 0.000 & -0.004 & 0.017 & 0.024 & -0.000 & 0.741 & 0.540 \\
& $(0.506)$ & $(0.175)$ & $(-0.298)$ & $(0.802)$ & $(0.779)$ & $(-0.138)$ & $(10.975)$ & $(0.000)$
\end{tabular}

Cross-Correlation of Residuals

$\begin{array}{llllllll} & r t b & x r & x n b & x r c b & y & (d-p) & s p r \\ r t b & 0.545 & 0.239 & 0.389 & -0.462 & -0.384 & -0.240 & 0.181 \\ x r & - & 7.751 & 0.228 & -0.355 & -0.170 & -0.981 & 0.025 \\ x n b & - & - & 2.670 & 0.543 & -0.764 & -0.245 & 0.195 \\ x r c b & - & - & - & 1.236 & -0.414 & 0.337 & 0.112 \\ y & - & - & - & - & 0.255 & 0.202 & -0.776 \\ (d-p) & - & - & - & - & - & 7.932 & -0.058 \\ s p r & - & - & - & - & - & - & 0.172\end{array}$

Note: $r t b_{t}=$ ex post real T-Bill rate, $x r_{t}=$ excess stock return, $x r c b_{t}=$ excess real consol bond return, $(d-p)_{t}=\log$ dividend-price ratio, $y_{t}=$ nominal T-bill yield, $x n b_{t}=$ excess nominal long bond return, spr $r_{t}$ $=$ yield spread. The bond is a 5 -year nominal bond in the quarterly dataset and a 20 -year for the annual dataset. 
TABLE B (Ctd.)

VAR Estimation Results

Nominal Bills, Stocks, Real Consol Bond, and Nominal Bond

\begin{tabular}{ccccccccc}
\hline \multicolumn{7}{c}{ B: Annual Sample (1890 - 1998) } \\
\hline $\begin{array}{c}\text { Dependent } \\
\text { Variable }\end{array}$ & $r t b_{t}$ & $x r_{t}$ & $x n b_{t}$ & $x r c b_{t}$ & $y_{t}$ & $(d-p)_{t}$ & $s p r_{t}$ & $R^{2}$ \\
\hline VAR Estimation Results & $(t)$ & $(t)$ & $(t)$ & $(t)$ & $(t)$ & $(t)$ & $(p)$ \\
$r t b_{t+1}$ & 0.305 & -0.052 & 0.122 & 0.002 & 0.700 & -0.004 & -0.781 & 0.240 \\
& $(2.258)$ & $(-1.314)$ & $(0.902)$ & $(0.026)$ & $(2.380)$ & $(-0.147)$ & $(-1.177)$ & $(0.000)$ \\
$x r_{t+1}$ & -0.093 & 0.074 & -0.098 & -0.212 & -0.025 & 0.132 & 1.869 & 0.059 \\
& $(-0.262)$ & $(0.616)$ & $(-0.332)$ & $(-1.114)$ & $(-0.036)$ & $(2.371)$ & $(1.251)$ & $(0.305)$ \\
$x n b_{t+1}$ & 0.223 & 0.106 & -0.196 & 0.023 & -0.117 & 0.012 & 2.566 & 0.393 \\
& $(1.890)$ & $(2.954)$ & $(-1.485)$ & $(0.274)$ & $(-0.333)$ & $(0.612)$ & $(5.118)$ & $(0.000)$ \\
$x r c b_{t+1}$ & 0.000 & 0.000 & 0.000 & 0.000 & 0.000 & 0.000 & 0.000 & 0.000 \\
& $(0.000)$ & $(0.000)$ & $(0.000)$ & $(0.000)$ & $(0.000)$ & $(0.000)$ & $(0.000)$ & $(1.000)$ \\
$y_{t+1}$ & -0.059 & -0.012 & 0.036 & -0.017 & 0.925 & -0.005 & 0.029 & 0.779 \\
& $(-2.239)$ & $(-1.746)$ & $(1.280)$ & $(-1.037)$ & $(12.568)$ & $(-1.115)$ & $(0.249)$ & $(0.000)$ \\
$(d-p)_{t+1}$ & -0.373 & -0.124 & 0.363 & 0.197 & -0.642 & 0.840 & -2.198 & 0.723 \\
& $(-1.260)$ & $(-1.174)$ & $(1.163)$ & $(1.103)$ & $(-0.992)$ & $(13.412)$ & $(-1.459)$ & $(0.000)$ \\
$s p r_{t+1}$ & 0.030 & 0.002 & -0.013 & 0.011 & 0.083 & 0.004 & 0.791 & 0.543 \\
& $(1.593)$ & $(0.415)$ & $(-0.649)$ & $(0.953)$ & $(1.557)$ & $(1.142)$ & $(8.432)$ & $(0.000)$
\end{tabular}

Cross-Correlation of Residuals

\begin{tabular}{llllllrr} 
& $r t b$ & $x r$ & $x n b$ & $x r c b$ & $y$ & $(d-p)$ & \multicolumn{1}{c}{$s p r$} \\
$r t b$ & 7.592 & -0.168 & -0.020 & -0.842 & 0.115 & 0.101 & -0.155 \\
$x r$ & - & 17.422 & -0.017 & 0.166 & -0.146 & -0.723 & 0.195 \\
$x n b$ & - & - & 5.099 & 0.257 & -0.651 & -0.059 & 0.262 \\
$x r c b$ & - & - & - & 12.416 & -0.585 & -0.026 & 0.618 \\
$y$ & - & - & - & - & 1.221 & 0.191 & -0.894 \\
$(d-p)$ & - & - & - & - & - & 15.996 & -0.179 \\
$s p r$ & - & - & - & - & - & - & 0.975
\end{tabular}

Note: $r t b_{t}=$ ex post real T-Bill rate, $x r_{t}=$ excess stock return, $x r c b_{t}=$ excess real consol bond return, $(d-p)_{t}=\log$ dividend-price ratio, $y_{t}=$ nominal T-bill yield, $x n b_{t}=$ excess nominal long bond return, $s p r_{t}$ $=$ yield spread. The bond is a 5 -year nominal bond in the quarterly dataset and a 20 -year for the annual dataset. 
TABLE C

Mean Asset Demands with Hypothetical Real Bonds

(Annual Sample: 1890 - 1998)

\begin{tabular}{|c|c|c|}
\hline \multicolumn{3}{|c|}{ A: Nominal Bills, Stocks, and Real Consol Bond } \\
\hline State Variables: & Constant & Full VAR \\
\hline \multicolumn{3}{|l|}{$\gamma=1, \psi=1, \rho=0.92$} \\
\hline Stocks & 200.45 & 226.91 \\
\hline Real Consol Bond & -54.43 & -64.46 \\
\hline Cash & -46.02 & -62.45 \\
\hline \multicolumn{3}{|l|}{$\gamma=2, \psi=1, \rho=0.92$} \\
\hline Stocks & 100.58 & 140.21 \\
\hline Real Consol Bond & -1.02 & -10.05 \\
\hline Cash & 0.43 & -30.16 \\
\hline \multicolumn{3}{|l|}{$\gamma=5, \psi=1, \rho=0.92$} \\
\hline Stocks & 40.67 & 65.69 \\
\hline Real Consol Bond & 31.03 & 44.67 \\
\hline Cash & 28.30 & -10.36 \\
\hline \multicolumn{3}{|c|}{$\gamma=20, \psi=1, \rho=0.92$} \\
\hline Stocks & 10.71 & 17.40 \\
\hline Real Consol Bond & 47.06 & 82.94 \\
\hline Cash & 42.24 & -0.34 \\
\hline \multicolumn{3}{|c|}{$\gamma=2000, \psi=1, \rho=0.92$} \\
\hline Stocks & 0.82 & -0.84 \\
\hline Real Consol Bond & 52.34 & 97.86 \\
\hline Cash & 46.84 & 2.98 \\
\hline
\end{tabular}

Note: "Constant" column reports mean asset demands when the VAR system only has a constant in each regression, corresponding to the case in which risk premia are constant and realized returns on all assets, including the short-term real interest rate, are i.i.d. "Full VAR" column reports mean asset demands when the VAR system includes all state variables. The nominal bond is a 5 -year nominal bond in the quarterly dataset and a 20 -year in the annual dataset. 
TABLE C (ctd.)

Mean Asset Demands with Hypothetical Real Bonds

(Annual Sample: 1890 - 1998)

\begin{tabular}{|c|c|c|}
\hline \multicolumn{3}{|c|}{ B: Nominal Bills, Stocks, Real Consol Bond and Nominal Bond } \\
\hline State Variables: & Constant & Full VAR \\
\hline \multicolumn{3}{|l|}{$\gamma=1, \psi=1, \rho=0.92$} \\
\hline Stocks & 198.39 & 232.42 \\
\hline Real Consol Bond & -68.22 & -97.56 \\
\hline Nominal Bond & 143.96 & 301.23 \\
\hline Cash & -174.13 & -336.09 \\
\hline \multicolumn{3}{|l|}{$\gamma=2, \psi=1, \rho=0.92$} \\
\hline Stocks & 99.61 & 137.51 \\
\hline Real Consol Bond & -7.54 & -30.05 \\
\hline Nominal Bond & 68.06 & 163.36 \\
\hline Cash & -60.13 & -170.81 \\
\hline \multicolumn{3}{|l|}{$\gamma=5, \psi=1, \rho=0.92$} \\
\hline Stocks & 40.34 & 60.01 \\
\hline Real Consol Bond & 28.87 & 39.15 \\
\hline Nominal Bond & 22.51 & 64.02 \\
\hline Cash & 8.27 & -63.18 \\
\hline \multicolumn{3}{|c|}{$\gamma=20, \psi=1, \rho=0.92$} \\
\hline Stocks & 10.71 & 15.95 \\
\hline Real Consol Bond & 47.08 & 81.05 \\
\hline Nominal Bond & -0.26 & 19.78 \\
\hline Cash & 42.47 & -16.79 \\
\hline \multicolumn{3}{|c|}{$\gamma=2000, \psi=1, \rho=0.92$} \\
\hline Stocks & 0.93 & 0.61 \\
\hline Real Consol Bond & 53.09 & 95.75 \\
\hline Nominal Bond & -7.77 & 7.58 \\
\hline Cash & 53.75 & -3.94 \\
\hline
\end{tabular}

Note: "Constant" column reports mean asset demands when the VAR system only has a constant in each regression, corresponding to the case in which risk premia are constant and realized returns on all assets, including the short-term real interest rate, are i.i.d. "Full VAR" column reports mean asset demands when the VAR system includes all state variables. The nominal bond is a 5 -year nominal bond in the quarterly dataset and a 20-year in the annual dataset. 
TABLE D

Mean Value Function ( $\psi=1$ Case)

(Annual Sample: 1890 - 1998)

\begin{tabular}{rc}
\hline$\gamma$ & $E\left[V_{t}\right]$ \\
\hline Nominal Bills and Stocks \\
1 & 0.164 \\
2 & 0.088 \\
5 & 0.050 \\
20 & 0.015 \\
2000 & 0.000 \\
\hline Nominal Bills, Stocks, and Nominal Bond \\
1 & 14.911 \\
2 & 0.446 \\
5 & 0.086 \\
20 & 0.018 \\
2000 & 0.000 \\
\hline Nominal Bills, Stocks, and Real Consol Bond \\
1 & 0.175 \\
2 & 0.090 \\
5 & 0.053 \\
20 & 0.038 \\
2000 & 0.014 \\
\hline Nominal Bills, Stocks, Nominal Bond, and Real Consol Bond \\
1 & 37.37 \\
2 & 0.526 \\
5 & 0.095 \\
2000 & 0.023 \\
\hline
\end{tabular}

